CoMDD: uma abordagem colaborativa para auxiliar o desenvolvimento orientado a modelos 



\title{
CoMDD: uma abordagem colaborativa para auxiliar o desenvolvimento orientado a modelos
}

\author{
David Fernandes Neto
}

Orientadora: Profa. Dra. Renata Pontin de Mattos Fortes

Dissertação apresentada ao Instituto de Ciências Matemáticas e de Computação - ICMC-USP, como parte dos requisitos para obtenção do título de Mestre em Ciências - Ciências de Computação e Matemática Computacional. VERSÃO REVISADA 
Ficha catalográfica elaborada pela Biblioteca Prof. Achille Bassi e Seção Técnica de Informática, ICMC/USP, com os dados fornecidos pelo(a) autor(a)

\begin{tabular}{|c|c|}
\hline \multirow[t]{3}{*}{ F345c } & $\begin{array}{l}\text { Fernandes Neto, David } \\
\text { ComDD: uma abordagem colaborativa para auxiliar o } \\
\text { desenvolvimento orientado a modelos / David } \\
\text { Fernandes Neto; orientadora Renata Pontin de Mattos } \\
\text { Fortes. -- São Carlos, } 2012 \text {. } \\
\quad 87 \text { p. }\end{array}$ \\
\hline & $\begin{array}{l}\text { Dissertação (Mestrado - Programa de Pós-Graduação en } \\
\text { Ciências de Computação e Matemática Computacional) -- } \\
\text { Instituto de Ciências Matemáticas e de Computação, } \\
\text { Universidade de São Paulo, } 2012 \text {. }\end{array}$ \\
\hline & $\begin{array}{l}\text { 1. Model Driven Development. 2. Domain Specific } \\
\text { Languages. } 3 \text {. Wiki. } 4 \text {. Colaboração. } 5 \text {. Versionamento. } \\
\text { I. Pontin de Mattos Fortes, Renata, orient. II. } \\
\text { Título. }\end{array}$ \\
\hline
\end{tabular}




\section{Agradecimentos}

Inicialmente gostaria de agradecer à Baylat, CNPq, FUSP e ICMC, pelo fomento e incentivo à pesquisa. À todos que participaram no estudo de caso pelo tempo e disposição em me ajudar; à todos do instituto de pesquisa alemão Fortiss e principalmente ao professor Bernhard Schätz e Daniel Ratiu pela orientação.

Agradeço aos professores Rodrigo Mello, Rosana Braga, José Maldonado, Elisa Nakagawa e Simone Senger, com quem tive a oportunidade de trabalhar e aprender.

À professora Renata Pontin pela orientação, incentivo, paciência, carinho e principalmente pela amizade. Sem ela a minha vida teria sido bem diferente.

Aos amigos Paulo Nardi, Rodrigo Fraxino, André Endo, Daniel Feitosa, Rafael Messias, Murilo Furquim, Maria Adelina, Marcelo Eler, Katia Felizardo, Rafael Durelli, Harry Trinta, Draylson Micael, Bruno Cafeo, Jorge Cutigi, Fabiano Ferraz, Flavio Dusse, Rodrigo Gondim, Arineiza Pinheiro, Eduardo Steiner, Joice Machado e todos os demais amigos do LABES, por serem muito mais do que amigos de laboratório.

Aos amigos do Intermídia e do grupo de pesquisa, Eduardo Pezutti, Adriano Rivolli, Kleberson Serique, Roberto Rigolin, João Paulo, Americo Talarico, Silvana Affonso, Adalberto Gonzaga, Ana Luiza, Ricardo Ramos, Thiago Jabur, Matheus Uihara, Claudia Roberta, Graça Pimentel e demais, pela boa convivência, lições e parcerias em trabalhos e risadas.

Aos amigos que fiz na Alemanha, Gabriela Pittari, Kellen Goncalves, Suely Guglielmi, Cello Pietro, Ana Paula, Dany Macedo, Marianela Della, Manu Rueda, Thomas Bohm, Andrei Mituca, Mario Alani, Helmi Memmi, Mohamed Gmar, Jordi Puig, Luis Jimen, Franziska Koehler, Lukas Ziegler, Liwei Luo, Max Stricker, Wadim Kehl, Jonas Henkel, Felix Funck, Markus Klann, Thomas Leitner, Eva Bartok, Valeria, Thomas Runte e à todo 8th Floor, por me acolherem tão bem a ponto de me sentir em casa.

Aos amigos da UFPa, Allan Michel, Raul Borges, Andson Balieiro, Peterson Yoshioka, José Borges e todos os outros, onde me formei e fiz grandes amizades.

Aos amigos Fernando Santos, Fernando Stabnow, Shirley Carmona, Otavio Chase, Érika Paiva, Larissa Medeiros, Pedro Henrique, Monika Miccione, Jacklene Carréra, Vanessa Chaves, Ana Cristina, Joana Rosa, Rodrigo Reis, Luciane Silva, Dayana Nascimento, por serem pessoas muito queridas e por terem me ajudado de diversas maneiras.

Aos amigos Murilo Coutinho, Isaac Serique, Felipe Serique, Rodrigo Barbalho, Diogo Reis, Rafael Martins e Fabrício Araújo, que mesmo na distância, estão comigo há longa data e com quem compartilhei grandes momentos da vida. 
À querida Cibelle Leão que sempre me apoiou enquanto esteve comigo, e à Cintia Leão, Daniel e Marcio Fuchshuber, Higo Lacerda, Henrique Bordalo e todos demais membros da família Pantoja Leão, que estiveram comigo por muito tempo e por quem guardo um eterno carinho.

Aos amigos Alexandre Nishiwaki, Luciana Caretti, Cláudia Foganholi, Vivian Parreira, Sara Oliveira, Deca Tahan, Vinícius Dantas, Lígia Nunes, Juliana Freitas, Natalia Rosatti, Tiago Moraes, Priscilla Loiola, Felipe Noronha, Diego Talarico, Maíra Ladeira, Mariana Ladeira, Pedro Scotton, Aécio Junior, Eder, Elias Rodrigues, Guilherme Oliveira, Cleber Rocco, Mariana Miccione, Helder Batista, Pablo Jaskowiak, Mauricio Dias, Francisco de Souza, Renato Resina, Maycon Leone, Cyntia Montenegro, Jorge Garou, Didier Oliveros, Lilian Berton, Glenda Botelho, Alberto Hata, Lívia Faim, Renato Rodrigues, Fernando Cavalcanti, Guilherme Freire, Felipe Duarte, Daniel Bonetti, Priscila Freitas, Juliana Morais, Chiara Silva, Paulo Franco, Lívia Santos, Bruna Gonçalves, Bruno Drugowick, Cleber Santos, Artur Sampaio, Herick Marques, Rogerio Miguel, Mariana Bachiega, Glauce Mendes, Davi Santos e Marcelo Manzato, por tornarem São Carlos uma cidade tão especial e minha segunda terra natal.

Agradeço especialmente os amigos Diogo Pedrosa, Uaiana Prates, Vanessa Mantovani, Eurípedes Júnior, Diego Duarte, Jessica Vieira, Fanny Gaukeley, Florian Reeb, Peter Dishes, Bruno Mesquita, Rodrigo Chinaglia, Marta Casado, Jia Huang e sua esposa, Anthony Mark, Aline Siqueira, Willian Watanabe, Daniel Lucrédio, Roberto Sadao, Lucas Bueno, Rafael Oliveira, Adriano Bezerra, Vinicius Durelli, Marco Aurélio, Gabriel Gadelha, Danilo Coimbra e sua família, Tácito Neves, José Augusto e sua família, Heline Hellen, Gustavo Pessin e Marcilyanne Gois. Sou muito grato a vocês que me apoiaram de diversas formas. Vocês são fantásticos!

Ao meu grande irmão Leonardo Fadul, ao meu pai David Júnior, aos meus avós e familiares paternos, a minha segunda mãe e avó, e a toda minha grande e amada família, inclusive aos que se tornaram parte dela, Marcos Baia, Samuel Baia e Domingas da Conceição. Obrigado pelo carinho e amor.

Por fim, agradeço à minha mãe, que cada dia que passa menos tenho como agradecer. Para ela não há palavras que possam expressar minha gratidão.

Este é meu singelo agradecimento a estas pessoas que me ajudaram simplesmente pelo fato de serem tão especiais. Obrigado. 
O valor das coisas não está no tempo em que elas duram, mas na intensidade com que acontecem. Por isso existem momentos inesquecíveis, coisas inexplicáveis e pessoas incomparáveis. Fernando Pessoa 

na indústria e na academia, trazendo grandes benefícios, como o aumento de produtividade. Uma forma de se trabalhar usando MDD em equipe é usando uma IDE (Integrated Development Environment) associada a um sistema de versionamento. Entretanto, trabalhar colaborativamente usando uma IDE associada a um sistema de versionamento pode trazer algumas complicações para o desenvolvimento como: conflitos de modelos, documentação descontinuada, dificuldades por parte dos interessados em usar sistemas de versionamento, etc. Nesse contexto, este trabalho propõe uma abordagem de uso de wiki para desenvolvimento de MDD, de modo que o desenvolvedor seja capaz de criar modelos, gerar código fonte, compartilhar e versionar os modelos e ainda documentar colaborativamente, de maneira mais simples e fácil do que abordagens tradicionais. Isso possibilita que mais usuários não desenvolvedores possam participar mais no processo de desenvolvimento e ainda permite o aumento de produtividade. Para tentar evidenciar de que é possível uma wiki ser usada para desenvolver software, foi criada uma Domain Specific Language - DSL em uma wiki e foram realizados três estudos de caso: um com estudantes do ensino médio e que representam os não desenvolvedores, um com quatro alunos de pós-graduação com experiência de desenvolvimento na indústria e o último estudo de caso foi realizado com 48 participantes entre desenvolvedores e alunos de pósgraduação em Ciências da Computação. Os estudos de caso mostraram que é viável usar uma wiki para desenvolvimento, que não desenvolvedores se adaptam bem à abordagem e que $86 \%$ dos desenvolvedores usariam a abordagem proposta se tivessem que trabalhar com MDD. Os estudos de caso também levantaram as principais barreiras para aumentar a aceitação da abordagem. Com isso, este trabalho apresenta além de uma abordagem relativamente inédita na literatura, resultados sobre uso de sistemas de versionamento, de IDEs e de desenvolvimento colaborativo. 
he Model Driven Development (MDD) is an approach that has gained more space in industry and academia, bringing great benefits such as increased productivity. One way of working in teams with MDD is using an IDE (Integrated Development Environment) with a versioning system. However, to collaboratively work with an IDE and a versioning system may have implications and problems for the development as: conflicts of models, documentation discontinued, difficulties for stakeholders to use versioning systems, etc. In this context, this work proposes an approach to use a wiki to develop MDD, so that the developer is able to create models, generate source code, sharing and versioning models and also to collaboratively document, in a more simple and easy way than the traditional approaches. This enables non developers can participate more in the development process and also allows increasing productivity. To try to show that a wiki can be used to develop software, we created a Domain Specific Language (DSL) in a wiki and were performed three case studies: one with high school students and represent the non developers, another one with four graduate students with experience in software development in the industry, and the last case study was conducted with 48 participants among developers and graduate students in Computer Science. The case studies showed the feasibility of using a wiki for development, that non developers adapted well to the approach and $86 \%$ of the developers would use a wiki to develop MDD. The study also raised the main barriers to increase the acceptance of the approach. Therefore, this work presents also a relatively new approach in the literature and results on the use of versioning systems, IDEs and collaboratively development. 

$\begin{array}{lll}\text { Resumo } & \mathbf{v}\end{array}$

$\begin{array}{lll}\text { Abstract } & \text { vii }\end{array}$

1 Introdução $\quad 1$

1.1 Contextualização do Trabalho . . . . . . . . . . . . . . . . . 1

1.2 Hipótese e Objetivo . . . . . . . . . . . . . . . . . . . . . 4

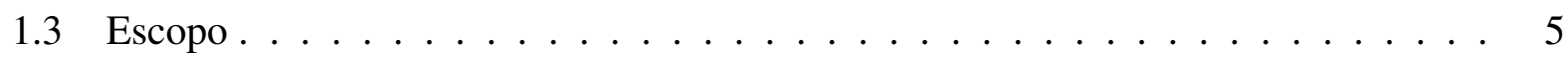

1.4 Resultados Esperados . . . . . . . . . . . . . . . . . . . . . . . . . . . . . .

1.5 Estrutura do Trabalho . . . . . . . . . . . . . . . . . . . 5

2 Revisão Bibliográfica $\quad 7$

2.1 Desenvolvimento Orientado a Modelos . . . . . . . . . . . . . . . . . . . . 7

2.2 Definição de DSL e de Templates . . . . . . . . . . . . . . . . . . . . . . . 10

2.3 Colaboração . . . . . . . . . . . . . . . . . . . 11

2.4 Sistemas de Versionamento . . . . . . . . . . . . . . . . . . . . 12

2.5 Wiki . . . . . . . . . . . . . . . . . . . . 14

2.6 Considerações Finais . . . . . . . . . . . . . . . . . 16

3 A Abordagem CoMDD 17

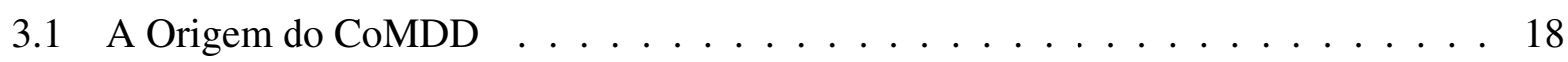

3.2 CoMDD - Collaborative Model Driven Development . . . . . . . . . . . . . . . . 19

3.3 Arquitetura do CoMDD . . . . . . . . . . . . . . . . . . . . 24

3.4 A Implementação do CoMDD . . . . . . . . . . . . . . . . . . . . . 24

3.5 Trabalhos Relacionados . . . . . . . . . . . . . . . . . . . . 28

3.6 Considerações Finais . . . . . . . . . . . . . . . . . . . . . 32

4 Método $\quad 33$

4.1 Estudo de Caso I - EC-ND . . . . . . . . . . . . . . . . . . . . . . . . 34

4.1.1 Descrição dos participantes . . . . . . . . . . . . . . 34 
4.1.2 Instruções e Problema Apresentado . . . . . . . . . . . . . . . . . . 34

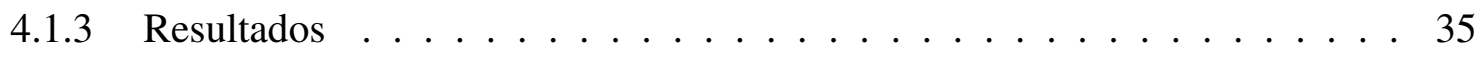

4.1 .4 Opiniões dos participantes . . . . . . . . . . . . . . . 38

4.1 .5 Observações do EC-ND . . . . . . . . . . . . . . . 38

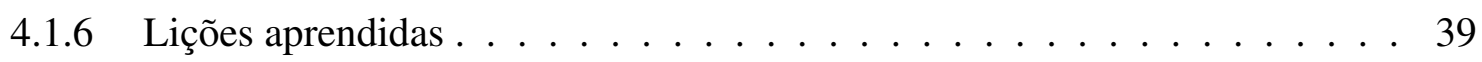

4.2 Estudo de Caso II - EC-PG . . . . . . . . . . . . . . . . . . . . . . . . 39

4.2.1 Descrição dos participantes . . . . . . . . . . . . . . . . . . 39

4.2.2 Instruções e Problema Apresentado . . . . . . . . . . . . . . . . . 40

4.2 .3 Equipe A: CoMDD . . . . . . . . . . . . . . . . . . 41

4.2 .4 Equipe B: Eclipse+SVN . . . . . . . . . . . . . . . . . 42

4.2 .5 Resultados . . . . . . . . . . . . . . . . . . 42

4.2.6 Opiniões dos Participantes e Observações do Pesquisador . . . . . . . . . 46

4.2 .7 Observações do EC-PG . . . . . . . . . . . . . . . . . . . . . . . 47

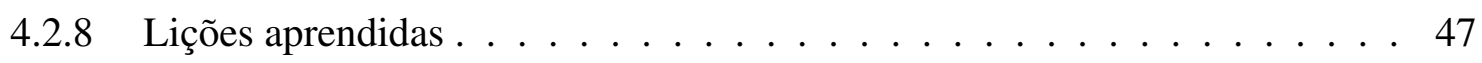

4.3 Estudo de caso III - EC-IN . . . . . . . . . . . . . . . . . . . . . . . 48

4.3.1 Descrição dos participantes . . . . . . . . . . . . . . . . . . 48

4.3.2 Instruções e Problema Apresentado . . . . . . . . . . . . . . . . . . 49

4.3.3 Resultados do EC-IN . . . . . . . . . . . . . . . . . . . . . . . . . 49

4.3.4 Opiniões dos Participantes . . . . . . . . . . . . . . . . . 52

4.4 Conclusões dos Estudos de Caso . . . . . . . . . . . . . . . . . . . . 53

4.5 A Evolução dos Estudos de Caso . . . . . . . . . . . . . . . . . . . . . 55

4.6 Considerações Finais . . . . . . . . . . . . . . . . . . 55

5 Conclusão $\quad 57$

5.1 Contribuições . . . . . . . . . . . . . . . . . . 57

5.2 Limitações do Trabalho . . . . . . . . . . . . . . . . . . . . 58

5.3 Lições aprendidas . . . . . . . . . . . . . . . . . . . . . . . 59

5.4 Trabalhos Futuros . . . . . . . . . . . . . . . . . . 60 60

5.5 Considerações Finais . . . . . . . . . . . . . . . . . 61

5.6 Publicações e Atividades Realizadas . . . . . . . . . . . . . . . . . . . 63

$\begin{array}{ll}\text { Referências } & 65\end{array}$

$\begin{array}{llr}\text { A Gramática do CoMDD } & 69\end{array}$

B Textos Apresentados no EC-PG $\quad \mathbf{7 5}$

B.1 Texto I: O que é o CoMDD? . . . . . . . . . . . . . . . . . 75

B.2 Texto II: Como programar para o CoMDD . . . . . . . . . . . . . . 76

B.3 Texto III: Instalação do Eclipse+SVN e importação da DSL . . . . . . . . . . . . . 78

$\begin{array}{lll}\text { C Discussão realizada pela equipe B no EC-PG } & 79\end{array}$

C.1 Conversa da Equipe B do Estudo de Caso 2 realizada no final do exercício . . . . . 79 
D Questionários Respondidos pelas Equipes A e B do EC - PG 81

D.1 Questionário Respondido pela Equipe A . . . . . . . . . . . . . . . . 81

D.2 Questionário Respondido pela Equipe B . . . . . . . . . . . . . . . 82

E Documentos do EC - IN $\quad \mathbf{8 5}$

E.1 Email solicitando a participação dos desenvolvedores . . . . . . . . . . . . 85

E.2 Questionário Apresentado aos Participantes . . . . . . . . . . . . . . . . 86 
2.1 Processo convencional de desenvolvimento de software (Lucrédio, 2009) . . . . . 8

2.2 Processo de desenvolvimento de software orientado a modelos (Lucrédio, 2009) . . 9

2.3 Geração de código usando templates (Lucrédio, 2009). . . . . . . . . . . . . . . . 11

2.4 Quadrantes da colaboração (Rama e Bishop, 2006). . . . . . . . . . . . . . . . 12

2.5 Versionamento de um arquivo . . . . . . . . . . . . . . . . . 13

3.1 Duas pessoas editando o mesmo modelo. . . . . . . . . . . . . . . . . . 19

3.2 Três pessoas editando diferentes modelos que dependem entre si. . . . . . . . . . . 20

3.3 Edição e armazenamento de modelos. . . . . . . . . . . . . . . . . 21

3.4 Geração de código fonte. . . . . . . . . . . . . . . . . . . . 21

3.5 Edição de diferentes modelos dependentes entre si. . . . . . . . . . . . . . 22

3.6 Comentários feitos na página de edição . . . . . . . . . . . . . . 23

3.7 Comentários feitos para cada versão da página . . . . . . . . . . . . . . . 23

3.8 Processo de edição de modelos e geração de código fonte realizado na wiki. . . . . 24

3.9 Arquitetura do CoMDD. . . . . . . . . . . . . . . . . 25

3.10 Arquitetura implementada para o CoMDD. . . . . . . . . . . . . 25

3.11 Gramática do CoMDD. . . . . . . . . . . . . . . . 26

3.12 Gramática do CoMDD. . . . . . . . . . . . . . . . . . 26

3.13 Transformações do CoMDD. . . . . . . . . . . . . . . . . . 27

3.14 Transformações do CoMDD. . . . . . . . . . . . . . . . . . . 28

4.1 Log da conversa entre o desenvolvedor 1 e o desenvolvedor $2 \ldots$. . . . . . . . 44

4.2 Log da conversa entre o desenvolvedor 1 e o desenvolvedor $2 \ldots$. . . . . . . . . 46

4.3 Experiência em programação dos participantes em anos por quantidade de partici-

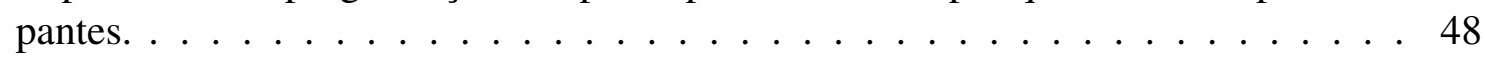

4.4 Formas de colaboração citadas. . . . . . . . . . . . . . . . . . 50 50

4.5 Principais e mais usadas funcionalidades de um sistema de versionamento citadas. . 51

4.6 Principais barreiras para o uso do CoMDD citadas. . . . . . . . . . . . . . 52 


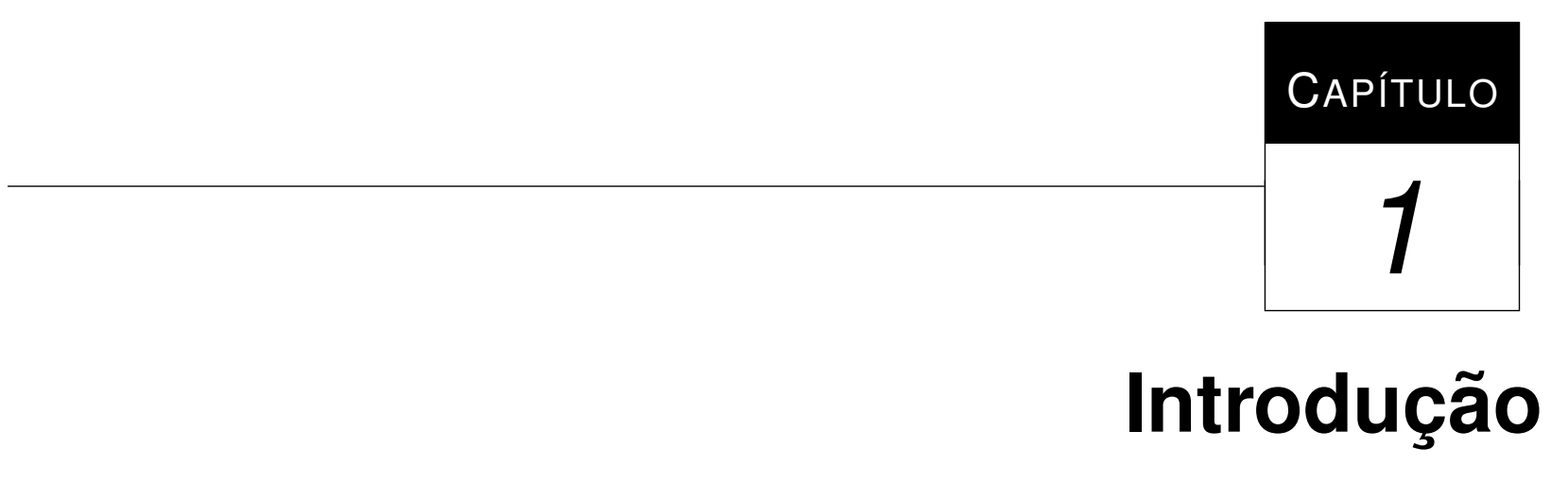

$\mathrm{E}$ Ste capítulo descreve o contexto de desenvolvimento colaborativo orientado a modelos, no qual este trabalho está inserido, apresenta o problema de pesquisa e sua justificativa, define a hipótese e o objetivo do trabalho. Também são apresentados os resultados esperados e o escopo do trabalho.

\subsection{Contextualização do Trabalho}

O desenvolvimento orientado a modelos (Model Driven Development - MDD) é uma abordagem de desenvolvimento de software que foca nos modelos como os principais artefatos do processo de desenvolvimento, e nas transformações desses modelos para gerar outros modelos em diferentes níveis de abstração, como código fonte, por exemplo. O objetivo do MDD é reduzir a distância semântica existente entre o domínio do problema e o domínio da implementação/solução, utilizando modelos mais abstratos que protegem os desenvolvedores de software das complexidades inerentes às plataformas de implementação (Teppola et al., 2009; France e Rumpe, 2007).

A principal vantagem do MDD é poder expressar modelos usando conceitos menos vinculados a detalhes de implementação, além do fato de modelos serem mais próximos do domínio do problema, o que os torna mais fáceis de se especificar, entender e manter. Em alguns casos, ainda é possível os especialistas do domínio produzirem os sistemas ao invés dos especialistas da tecnologia de implementação (Selic, 2003; Sriplakich et al., 2006)

O MDD traz benefícios como (Kleppe et al., 2003; Lucrédio, 2009; Bendix e Emanuelsson, 2009): produtividade, portabilidade, manutenção, dentre outros. Há diversos trabalhos (Aho et al., 2009; France e Rumpe, 2007; Kleppe et al., 2003; Lucrédio, 2009; Mellor et al., 2003; Sánchez et 
al., 2009; Stahl et al., 2006; Liggesmeyer e Trapp, 2009) que propõem e que usam o MDD como abordagem para desenvolvimento de software. Entre as áreas da indústria que usam MDD, a área de sistemas embarcados já se beneficia dessa abordagem antes mesmo do surgimento da UML ou da Model Driven Architecture - MDA ${ }^{1}$ (Liggesmeyer e Trapp, 2009).

Entretanto, em relação a modelos textuais ${ }^{2}$, como equipes de desenvolvimento de software trabalham? Segundo Bendix e Emanuelsson (2009), as soluções existentes ainda são incipientes em termos de ferramentas e processos necessários para auxiliar os desenvolvedores de MDD em seus trabalhos. Entretanto, uma possibilidade para se trabalhar com MDD em uma equipe de desenvolvimento é usar uma IDE, para o desenvolvimento de modelos e geração de código fonte, e um sistema de versionamento ${ }^{3}$, para compartilhar modelos entre os membros da equipe. Contudo, um típico problema dos sistemas de versionamento são os conflitos que podem ser causados quando dois ou mais desenvolvedores modificam o mesmo documento e submetem ao servidor ${ }^{4}$.

Nesse momento, desenvolvedores têm que dedicar certo tempo para resolver os conflitos e às vezes, esses conflitos só podem ser resolvidos manualmente. Além disso, para os desenvolvedores saberem como resolver o conflito corretamente eles precisam estar em contato entre si, e para decidirem como realizar o merge, os desenvolvedores precisam estar disponíveis no mesmo momento (Prudencio et al., 2012).

Observa-se ainda que quase todas as ferramentas de desenvolvimento são projetadas para os desenvolvedores principais e poucas delas servem para desenvolvedores periféricos participarem. Como resultado, há várias barreiras para desenvolvedores periféricos ${ }^{5}$ quando eles desejam contribuir para um projeto (Xiao et al., 2007). Os demais interessados e que não possuem conhecimento de programação, ficam limitados em sua participação no desenvolvimento, uma vez que pouco ou não compreendem o código fonte. Um exemplo dessa limitação para o não desenvolvedor ${ }^{6}$ é a necessidade de instalação de softwares locais.

Ao se usar IDEs e sistemas de versionamento, é preciso que cada desenvolvedor tenha instalado esses softwares em seus computadores. O que significa dizer que se um interessado quiser acompanhar o desenvolvimento de um software, ele também precisa instalar essas ferramentas ${ }^{7}$. Embora isso seja comum para desenvolvedores, esta tarefa se torna difícil e trabalhosa para não desenvolvedores.

\footnotetext{
${ }^{1}$ A MDA (Model Driven Architecture) é um padrão da OMG como abordagem do MDA, com uso da UML para a modelagem

${ }^{2}$ Lembrando que modelos podem ser textuais ou gráficos.

${ }^{3}$ Este trabalho usará os termos sistema de controle de versão ou sistema de versionamento como sinônimos.

${ }^{4}$ Isso no caso de uma política de versionamento otimistic, a qual permite o desenvolvimento concorrente (Sarma et al., 2003).

${ }^{5}$ Xiao et. al (2007) se referem ao desenvolvedor periférico no caso do desenvolvimento de software livre colaborativo por pessoas espalhadas ao redor do mundo, em que tem-se os desenvolvedores principais do núcleo do software e os desenvolvedores que contribuem com a correção de bugs, por exemplo.

${ }^{6}$ Neste trabalho é usado o termo "não desenvolvedor"para se referir aos interessados no projeto e que não possuem conhecimento de programação. Por exemplo, um especialista de domínio pode ser um não desenvolvedor.

${ }^{7} \mathrm{Em}$ um dos estudos de caso deste trabalho, descrito no Seção 4.2, dois desenvolvedores experientes levaram cerca de 40 minutos para baixar, instalar e configurar o Eclipse e o plugin do SVN
} 
Além da instalação e configuração de uma IDE e de um sistema de versionamento, o interessado deve saber como funcionam essas ferramentas. Se ele ainda quiser participar da edição dos modelos ${ }^{8}$ deverá conhecer como funciona a geração de códigos da IDE, como realizar check-in ${ }^{9}$, check-out ${ }^{10}$, entre outros termos e suas variações de nome ${ }^{11}$. Assim, trabalhar com modelos pode ser mais fácil do que trabalhar com código fonte (Selic, 2003) para um não desenvolvedor, entretanto essa vantagem acaba sendo minimizada quando há a necessidade do uso dessas ferramentas.

Além disso, todo esse processo de instalação, de check-in/check-out, etc, é relativamente demorado, passando a configurar como mais uma desvantagem somada à necessidade de conhecimento desses conceitos. Jones e Scaffidi (2011) apoiam essa ideia quando afirmam que cientistas raramente usam controle de versão devido ao alto custo inicial para configuração desses sistemas.

Ainda que o usuário receba um treinamento, as abordagens são diferentes entre si. Por exemplo, a abordagem do $\mathrm{SVN}^{12}$ é diferente da abordagem do $\mathrm{Git}^{13}$, que é diferente da abordagem usada no Team Foundation Service da Microsoft ${ }^{14}$, de modo que além da necessidade do conhecimento da instalação, configuração, conceitos e uso, é também necessário o conhecimento da lógica de funcionamento dessas abordagens e de suas ferramentas. Todas essas informações necessárias tornam o processo de versionamento um processo com alta curva de aprendizado inicial.

Dessa forma, permitindo que um não desenvolvedor possa desenvolver seus próprios programas ou acompanhar o desenvolvimentos deles, faz com que o especialista do domínio se aproxime do especialista da solução, tornando o software final o mais próximo do desejado pelo cliente (France e Rumpe, 2007). É o caso, por exemplo, de físicos, químicos ou matemáticos que tem que fazer seus próprios softwares para validar suas teorias e para isso devem aprender uma linguagem de programação ou contratar um desenvolvedor. Em ambos casos a aproximação do cliente com o desenvolvedor é proveitosa. No trabalho de Jones e Scaffidi (2011), eles apresentam algumas das dificuldades dos cientistas no desenvolvimento de software.

Um outro problema encontrado no desenvolvimento de software está relacionado a manter a documentação atualizada. Geralmente, o que ocorre é que a documentação usada para desenvolver o software fica desatualizada em relação ao código fonte (Lucrédio, 2009; Xiao et al., 2007). É um desafio para equipes de desenvolvimento manterem o código fonte e documentação sincronizados ao longo de todo o ciclo de vida do desenvolvimento, mas é algo que compensa (Xiao et al., 2007).

Uma documentação bem elaborada beneficia a todos os desenvolvedores do projeto, mas manter uma boa documentação pode ser uma tarefa difícil, custosa e maçante. Todos os artefatos

\footnotetext{
${ }^{8}$ Este trabalho parte do uso de MDD como abordagem de desenvolvimento e, por isso, está-se referindo à edição de modelos.

${ }^{9}$ Também chamado de commit, segundo Ben Collins-Sussman e Pilato (2011), é a operação de enviar mudanças da cópia local para a cópia no repositório.

${ }^{10}$ Segundo Ben Collins-Sussman e Pilato (2011), é a operação de fazer uma cópia local da cópia do repositório.

${ }^{11}$ Por exemplo, no plugin do SVN para o Eclipse, o check-out é quando se faz uma cópia completa de todos os arquivos do servidor e update quando apenas atualiza as modificações.

${ }^{12} \mathrm{http}: / /$ subversion.tigris.org/

${ }^{13} \mathrm{http}: / /$ git-scm.com/

${ }^{14} \mathrm{http}: / /$ tfspreview.com/
} 
envolvidos na documentação requerem uma contínua e constante revisão e modificação, ao longo do ciclo de vida do software, com o intuito de preservar seu valor e consistência (Aguiar e David, 2005).

Por outro lado, as wikis são ferramentas conhecidas por serem simples de usar e ágeis para colaborar (Abeti et al., 2009; Tetard et al., 2009). Dependendo do problema, o uso de uma wiki ao invés de uma IDE associada a um SVN pode contornar todos os problemas descritos anteriormente, pois as wikis funcionam em um navegador, possuem um controle de versões com histórico simplificado, possibilitam inserção de comentários e permitem travar a edição concorrente, o que evita conflitos e merge. Assim, implementar na wiki um suporte a modelagem e geração de código fonte, para que as wikis possam servir de plataforma de MDD colaborativo, mostra-se um objetivo promissor.

Ainda, analisando o histórico de aplicações como músicas, vídeos, jogos, o armazenamento de arquivos, entre outros, observa-se uma tendência das aplicações migrarem para Web. Como exemplo disso, tem-se o Grooveshark ${ }^{\circledR}{ }^{15}$ (reprodutor de músicas on-line), o Youtube ${ }^{16}{ }^{16}$ (reprodutor de vídeos on-line), o Dropbox ${ }^{\circledR 17}$ (armazenador de arquivos on-line) e até mesmo IDEs estão convergindo para a web, como é o caso do Cloud $9^{18}$. Assim, ter uma ferramenta possível de editar, compartilhar e versionar modelos, gerar código fonte e ainda permitir a entrada de comentários, pode beneficiar desenvolvedores e interessados.

Contudo, seria possível uma wiki ser usada como uma ferramenta de desenvolvimento e compartilhamento de modelos, de forma que seja capaz de atender às necessidades dos usuários de IDEs e de sistemas de versionamento? A partir deste questionamento, este trabalho definiu uma abordagem colaborativa orientada a modelos (Collaborative Model Driven Development - CoMDD), a qual usa uma wiki para apoiar o MDD de uma equipe de desenvolvimento nas tarefas de modelagem, geração de código, versionamento e comunicação.

\subsection{Hipótese e Objetivo}

A partir do cenário das dificuldades de desenvolvimento colaborativo de software usando MDD, definiu-se a seguinte hipótese que norteia este trabalho:

É possível usar uma wiki, ao invés do processo tradicional de desenvolvimento ${ }^{19}$, para desenvolver um sistema colaborativamente usando $\mathrm{MDD}^{20}$ ?

\footnotetext{
${ }^{15} \mathrm{http}: / /$ grooveshark.com

${ }^{16} \mathrm{http}: / /$ youtube.com

${ }^{17} \mathrm{http}: / /$ dropbox.com

${ }^{18}$ http://c9.io/

${ }^{19}$ Definimos processo tradicional de desenvolvimento como sendo o uso de uma IDE e de um sistema de controle de versão otimistic

${ }^{20}$ No caso estamos nos referindo a DSLs como abordagem de MDD, conceitos a serem descritos no Capítulo 2.
} 
O objetivo deste trabalho é evidenciar que a hipótese de pesquisa é verdadeira para um caso específico (a ser tratado nos estudos de caso) e, com isso, incentivar o uso do CoMDD por desenvolvedores e não desenvolvedores.

\subsection{Escopo}

Está fora do escopo deste trabalho comparar o desenvolvimento tradicional (que usa linguagens de amplo propósito, como Java, por exemplo) com o MDD, uma vez que a literatura já discute sobre isso e sobre os benefícios em termos de produtividade que o MDD agrega para o desenvolvimento de software (Aho et al., 2009; France e Rumpe, 2007; Kleppe et al., 2003; Lucrédio, 2009; Mellor et al., 2003; Sánchez et al., 2009; Stahl et al., 2006; Liggesmeyer e Trapp, 2009).

Este trabalho entende que é importante promover e incentivar a comunicação entre os integrantes de uma equipe, desenvolvedores ou não; contudo, não faz parte do escopo deste trabalho desenvolver ferramentas ou um processo de comunicação entre os integrantes e nem um estudo a fundo, mas apenas incentivar a comunicação a partir da forma que o CoMDD é concebido e incentivar o uso de mensageiros instantâneos ou ferramentas de vídeo conferência para promover a comunicação.

\subsection{Resultados Esperados}

Espera-se com este trabalho que o uso do MDD seja cada vez mais empregado no desenvolvimento de sistemas e de que as wikis evoluam a ponto de terem mais recursos de uma IDE, até que um dia, a computação tenha o suporte em termos de ferramentas e processos para desenvolver softwares de grande porte e complexos usando wikis e MDD.

\subsection{Estrutura do Trabalho}

No Capítulo 2 é feito uma revisão bibliográfica dos conceitos necessários para entender a abordagem proposta. No Capítulo 3, tem-se a apresentação do CoMDD e a apresentação de trabalhos relacionados comparando com o CoMDD. No Capítulo 4 são apresentados três estudos de caso realizados buscando evidenciar a veracidade da hipótese e, por fim, o Capítulo 5 apresenta as conclusões, as limitações da abordagem e trabalhos futuros. 



\section{Revisão Bibliográfica}

Este capítulo apresenta os principais conceitos necessários para o entendimento da abordagem apresentada ao longo do trabalho, o CoMDD. Serão apresentados: a definição e vantagens de MDD, o conceito de metamodelagem (um dos principais conceitos de MDD), a definição de DSL (abordagem de MDD usada no CoMDD), a definição de templates (abordagem para geração de código fonte usada no CoMDD), a definição de colaboração e dos quadrantes de colaboração com foco nas wikis, e por fim, é apresentado o princípio de funcionamento dos sistemas de versionamento.

\subsection{Desenvolvimento Orientado a Modelos}

O MDD é uma abordagem da Engenharia de Software que consiste na utilização de modelos para elevar o nível de abstração na qual os desenvolvedores criam e evoluem o software. Sua intenção é tanto simplificar (tornar mais fácil) quanto formalizar (padronizando, de forma que a automação seja possível) atividades e tarefas que formam o ciclo de vida do software (Hailpern e Tarr, 2006); ou numa definição mais singela: o MDD é a simples noção de construir um modelo de um sistema e depois transformá-lo em algo real (Mellor et al., 2003).

Uma outra definição semelhante é a de que o MDD é uma abordagem de desenvolvimento, integração e interoperabilidade de sistemas de tecnologia da informação. Ela se refere ao uso sistemático de modelos e de transformações de modelos durante todo o ciclo de vida do software. O MDD eleva o nível de abstração em que os desenvolvedores produzem softwares, simplificando e formalizando as diversas atividades e tarefas que compõem o processo de desenvolvimento de software (Sánchez et al., 2009; Meijler, 2005). 
O que caracteriza o MDD são os modelos como foco primário do desenvolvimento de software, ao invés das linguagens de programação. Os modelos são usados para descrever vários aspectos do software e para automatizar a geração de código. A principal vantagem disso é poder expressar modelos usando conceitos menos vinculados a detalhes de implementação, além do fato de modelos serem mais próximos do domínio do problema. Isso torna os modelos mais fáceis de se especificar, entender e manter, do que abordagens que não usam modelos. E em alguns casos, ainda é possível os especialistas do domínio produzirem os sistemas ao invés dos especialistas da tecnologia de implementação (Selic, 2003; Sriplakich et al., 2006).

As Figuras 2.1 e 2.2 mostram a diferença fundamental que distingue o desenvolvimento tradicional do MDD. Na Figura 2.1, um engenheiro de software está elicitando os requisitos, modelando com base nesses requisitos e, por fim, implementando com base nos modelos. Na Figura 2.2, o engenheiro de software está elicitando os requisitos, modelando com base nesses requisitos e os modelos servindo de base para geração de código automática.

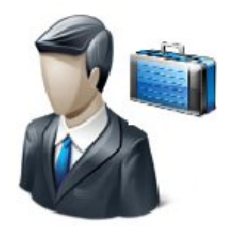

Requisitos

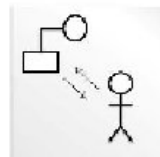

Modelos
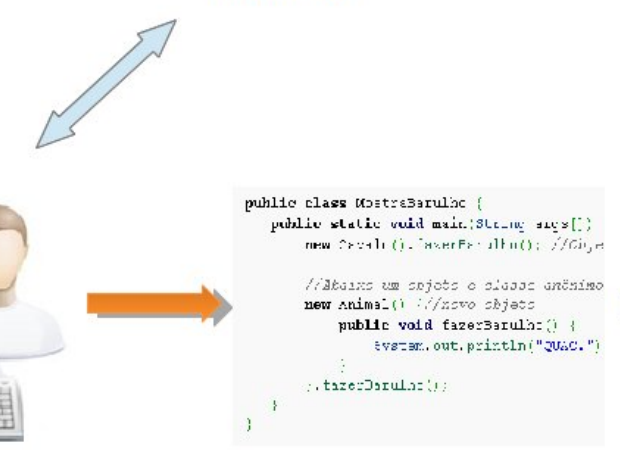

Código fonte

\section{(1)}

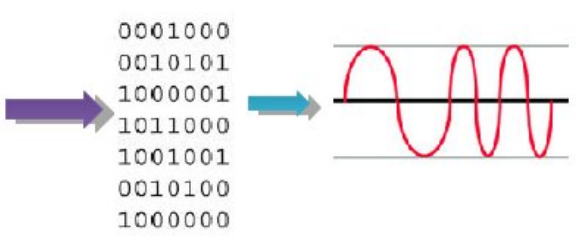

Engenheiro de Software

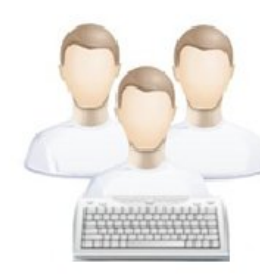

Figura 2.1: Processo conv

Segundo Kleppe et al. (2003) e Lucrédio (2009), o MDD apresenta benefícios como:

- Produtividade: fatores como redução de atividades repetitivas e manuais e o aumento da possibilidade de reúso podem contribuir para o aumento da produtividade no processo de desenvolvimento;

- Portabilidade e Interoperabilidade: como o modelo é independente de plataforma, um mesmo modelo pode ser transformado em código para diferentes plataformas; 


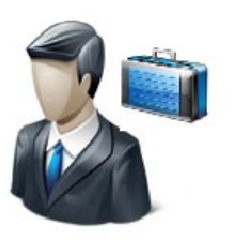

Requisitos

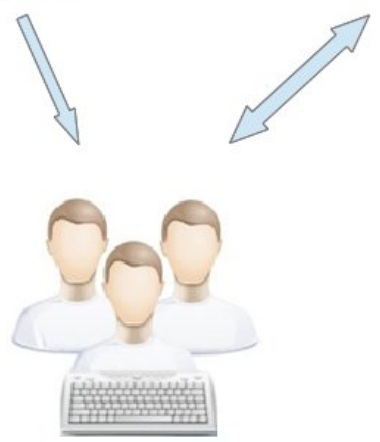

Engenheiro de Software

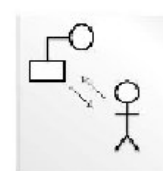

Modelos

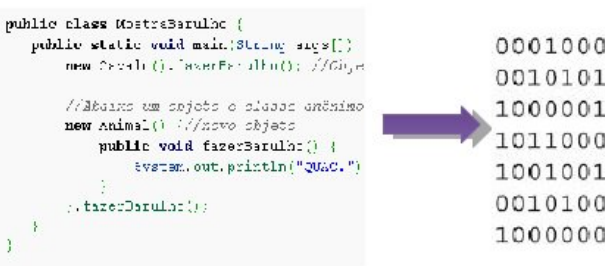

Código fonte

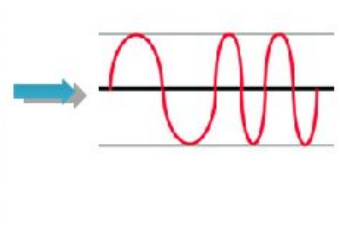

Figura 2.2: Processo de desenvolvimento de software orientado a modelos (Lucrédio, 2009)

- Corretude: o MDD evita atividades repetitivas e manuais de codificação, assim, erros de digitação são evitados, por exemplo;

- Manutenção: alterações no código relativas à manutenção podem exigir o mesmo esforço produzido durante o desenvolvimento;

- Documentação: modelos são o artefato principal do processo de desenvolvimento e, por isso, não se desatualizam. O código é gerado a partir deles e, com isso, a documentação se mantém também sempre atualizada;

- Comunicação: modelos são mais fáceis de entender do que código fonte. Isso facilita a comunicação entre os desenvolvedores, os stakeholders e demais envolvidos.

Entretanto, o MDD possui desvantagens como:

- Aumento da rigidez, pois o código fonte gerado nem sempre é acessível pelo desenvolvedor;

- Aumento da complexidade, dado que é necessário o estudo de modelagem, metamodelagem, geradores de código, etc e construir transformadores e metamodelos não é uma tarefa trivial;

- Perda de desempenho, pois nas transformações eventualmente irão códigos desnecessários para uma determinada aplicação e que são necessários para outra, por exemplo.

Analisando tais definições de MDD e suas vantagens apresentadas, pode-se concluir que MDD é um conceito bem definido, pois diferentes autores apresentam as mesmas ideias, de que MDD é uma elevação no nível de abstração do desenvolvimento de software, no qual o modelo passa de um artefato auxiliar para desempenhar um papel fundamental no processo 
de desenvolvimento. Em virtude dessa elevação na abstração muitos problemas relativos a portabilidade, interoperabilidade, corretude, manutenção e documentação são reduzidos nessa abordagem.

A seguir, é descrito o conceito de metamodelagem, o qual é um conceito chave para o MDD e sintetiza o potencial da tarefa de modelagem.

\section{Metamodelagem}

A metamodelagem é um dos principais aspectos do MDD. Para o MDD, é necessário criar um metamodelo do conhecimento a fim de lidar com alguns desafios, como: construir uma DSL; validar modelos; realizar transformações de modelo; gerar código e integrar ferramentas de modelagem a um domínio (Stahl et al., 2006).

Um metamodelo descreve a estrutura de um modelo. De maneira abstrata, o metamodelo define os construtores de uma linguagem de modelagem e seus relacionamentos, bem como as constantes e regras de modelagem; contudo, ele não descreve a sintaxe concreta da linguagem. Metamodelos e modelos têm um relacionamento de classe e instância, ou seja, cada modelo é uma instância de um metamodelo (Stahl et al., 2006).

\subsection{Definição de DSL e de Templates}

Uma DSL (Domain-Specific Language) é uma linguagem de programação ou uma linguagem de especificação, que oferece, através de notações e abstrações, poder expressivo focado em um problema de um domínio particular e, geralmente, restrito a esse domínio. Embora seja uma linguagem específica e não forneça uma solução geral para muitas áreas, ela provê uma solução muito melhor para um domínio particular (van Deursen et al., 2000) quando comparada com uma linguagem de propósito geral, como a UML.

A DSL é uma abordagem de MDD, havendo outras como a da OMG (Object Management Group), a MDA. É importante ressaltar que as DSLs podem ser textuais ou gráficas, como por exemplo, a SQL (Structured Query Language) é uma DSL textual para banco de dados e o Labview ${ }^{1}$ é uma DSL gráfica, usada por engenheiros para medições, aquisição de dados, automação, entre outros fins.

Os templates servem para auxilar nas transformações. Um template possui uma estrutura pré-definida, mas com partes em aberto, dado que esses pontos serão preenchidos de acordo com as variáveis especificadas pelo desenvolvedor (Lucrédio, 2009).

A Figura 2.3 ilustra uma transformação baseada em templates. O objetivo nesse exemplo é gerar uma página HTML (HyperText Markup Language) com campos definidos por um 
formulário, assim, é mais fácil para um não desenvolvedor definir campos do que criar uma página HTML. O arquivo de entrada possui as variáveis que serão preenchidas pelo usuário. Esse arquivo servirá como entrada do transformador, o qual usa um template para estruturar o código final. No template estão as transformações e nas transformações têm espaços que serão preenchidos de acordo com as variáveis definidas pelo usuário (na edição do arquivo de entrada) e que farão parte do código fonte gerado. O transformador processa então o arquivo e o template e gera o código fonte final.

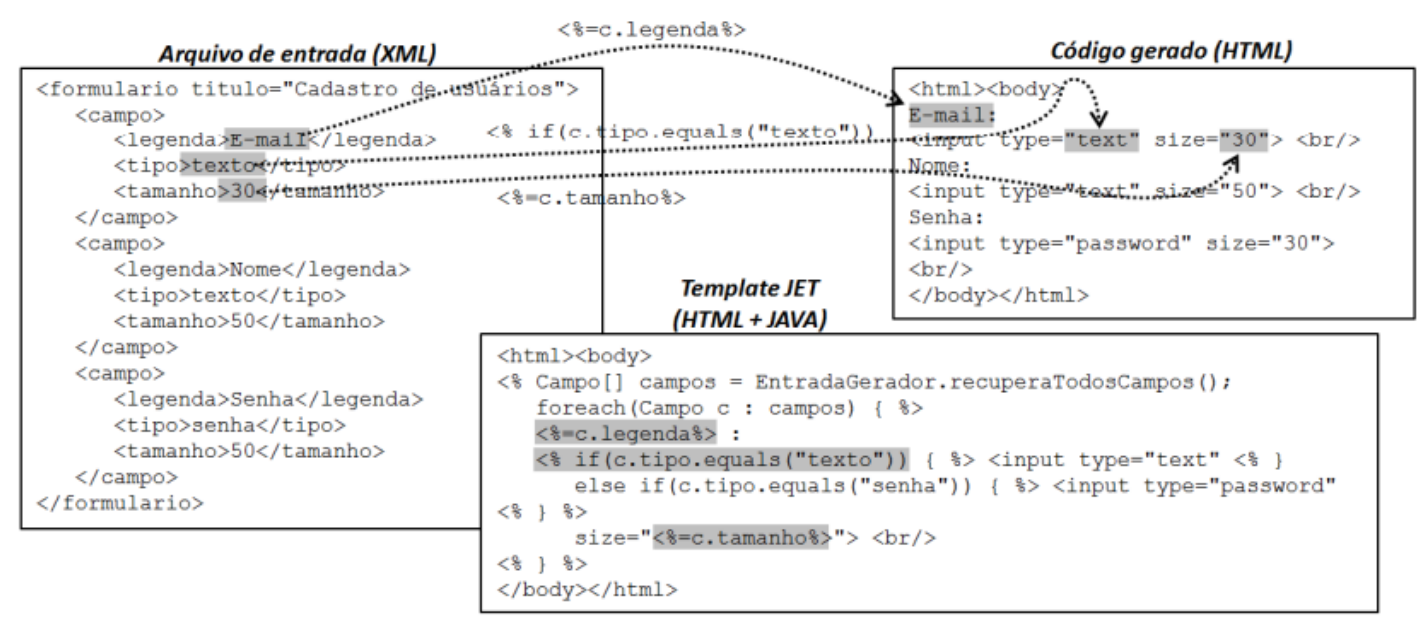

Figura 2.3: Geração de código usando templates (Lucrédio, 2009).

\subsection{Colaboração}

Colaboração significa duas ou mais pessoas trabalhando juntas para compartilhar e trocar dados, informações e conhecimento (McQuay, 2004). A colaboração é uma atividade que tem sido evidenciada cada vez mais com o aumento da complexidade do desenvolvimento de sistemas, pois para se desenvolver um sistema robusto e complexo, uma só pessoa dificilmente é o suficiente. Assim, o desenvolvimento e a manutenção de softwares complexos requerem a colaboração de diversos desenvolvedores (Sriplakich et al., 2006).

A colaboração tem duas dimensões: tempo e espaço (Rama e Bishop, 2006). O tempo pode ser síncrono ou assíncrono. O espaço pode ser distribuído ou compartilhado. A Figura 2.4 ilustra os quadrantes que a colaboração pode assumir.

Uma reunião presencial é exemplo de colaboração do primeiro quadrante, pois as pessoas estão compartilhando o mesmo tempo e espaço. Duas pessoas que trabalham no mesmo código fonte e no mesmo computador (logo, na mesma sala), só que em turnos diferentes, é um tipo de colaboração que se enquadra no segundo quadrante, pois elas estão compartilhando o mesmo espaço (computador, sala, código fonte) em horários diferentes. Uma ligação de telefone ou vídeo conferência são exemplos de colaboração do terceiro quadrante, pois estão 


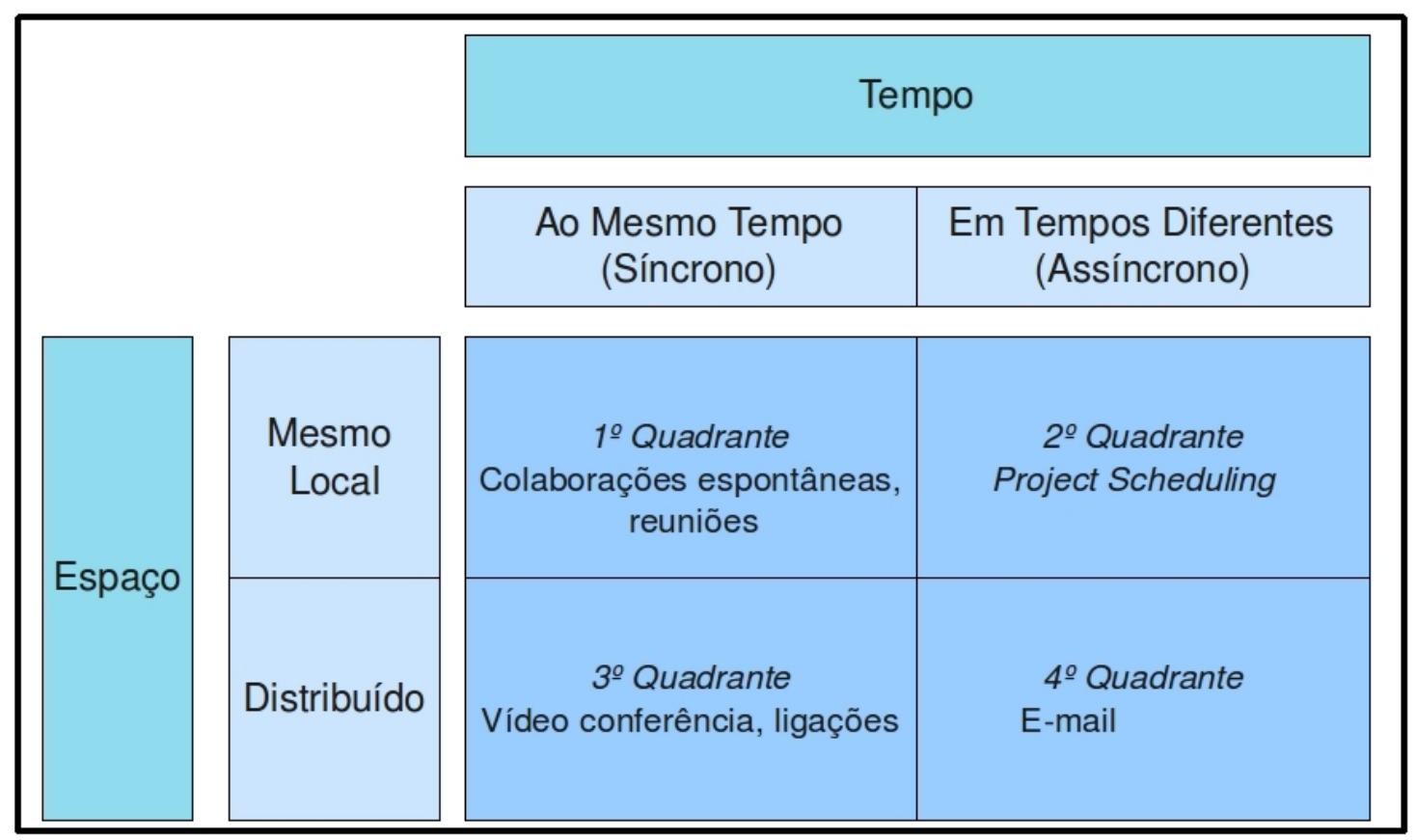

Figura 2.4: Quadrantes da colaboração (Rama e Bishop, 2006).

compartilhando o mesmo tempo em locais distintos. Um e-mail é um exemplo de colaboração do quarto quadrante, uma vez que estão em tempo e locais diferentes.

Neste trabalho, a abordagem proposta, CoMDD, explora o tipo de colaboração existente nos quarto e segundo quadrantes. O uso de wikis como apoio à modelagem incentiva a colaboração, pois em tempos diferentes, os desenvolvedores podem trabalhar sobre o mesmo projeto em desenvolvimento.

\subsection{Sistemas de Versionamento}

Segundo Pressman (2006), gestão de configuração ou SCM - Software Configuration Management - é uma atividade aplicada ao longo de todo o processo de desenvolvimento do software. A essência dessa atividade está em gerenciar/controlar as modificações e, por isso, possui quatro atividades: identificar quais modificações foram realizadas, controlar essas modificações, garantir que as modificações sejam implementadas e, por fim, permitir que os demais interessados nas modificações tenham conhecimento sobre essas. Em suma, gestão de configuração consiste em um conjunto de atividades que acompanham e auxiliam o projeto de software durante todas as fases de desenvolvimento, desde o projeto e elicitação de requisitos, até quando o software é retirado de operação.

Este trabalho considera controle de versão como uma das atividades colaborativas, dado que mais desenvolvedores trabalham constantemente no mesmo código fonte ou projeto. Pressman (2006) define controle de versão como sendo um conjunto de procedimentos e 
ferramentas para gerenciar diferentes versões de artefatos que são criados durante todo o processo de software.

Atualmente, existem vários sistemas de controle de versão, ou sistemas de versionamento, como por exemplo o $\mathrm{SVN}^{2}$ e o $\mathrm{GIT}^{3}$. A Figura 2.5 ilustra dois desenvolvedores trabalhando no mesmo código fonte. Ambos desenvolvedores solicitam a última versão do código fonte ao servidor (passo 1), o qual envia a última versão (v1.0) aos dois desenvolvedores (passo 2 check out). Após o desenvolvedor da esquerda realizar suas alterações, ele submete sua nova versão (v1.1) ao servidor. Em outro momento, o desenvolvedor da direita resolve submeter suas alterações (v1.1), entretanto, ocorre um conflito, pois a versão "v1.1"já foi submetida pelo desenvolvedor da esquerda.

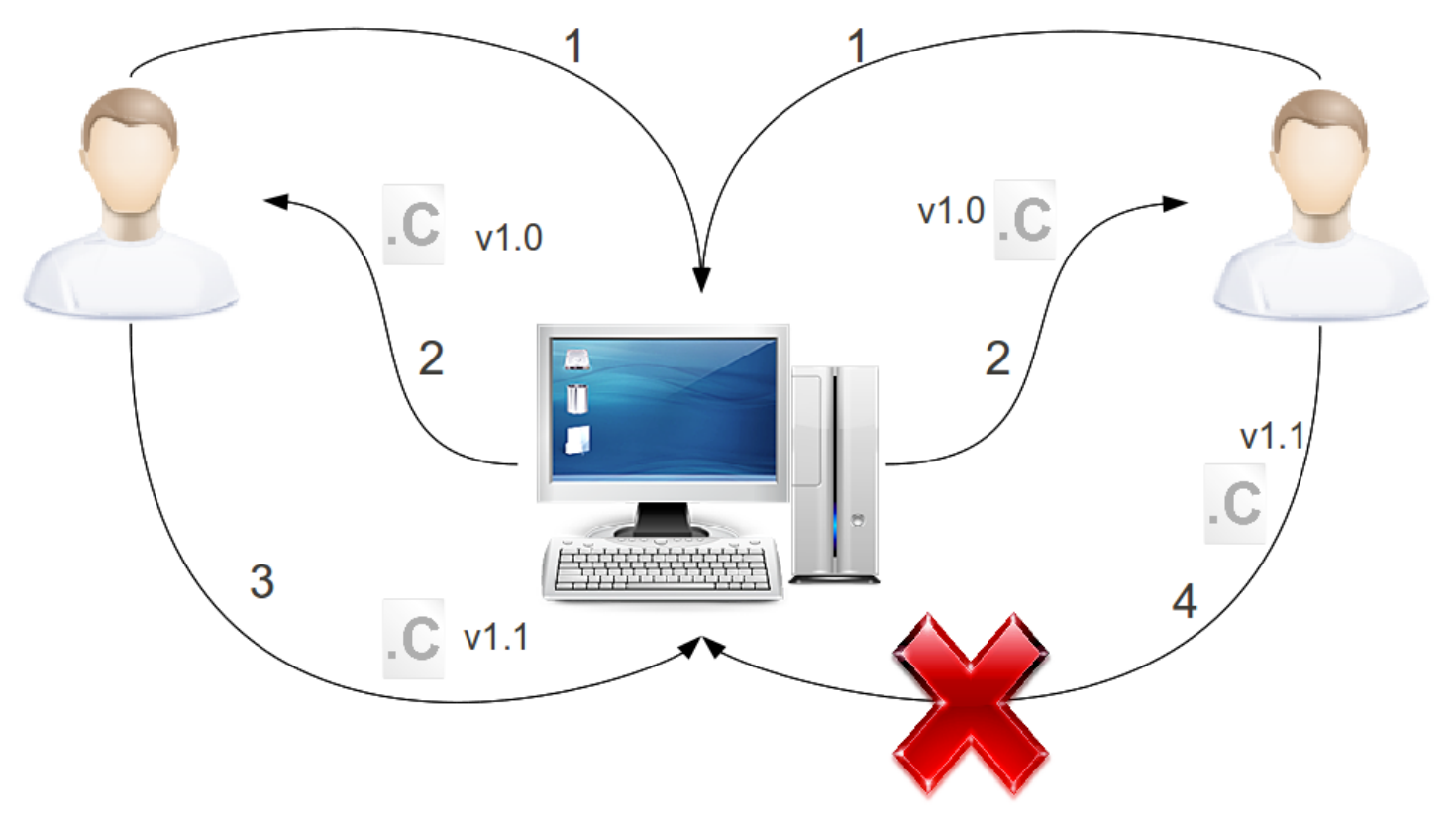

Figura 2.5: Versionamento de um arquivo

Esse cenário representa um versionamento que adota uma política otimistic, na qual dois desenvolvedores podem trabalhar ao mesmo tempo sobre o mesmo artefato e depois devem realizar a mesclagem dos artefatos para evitar conflitos (Sarma et al., 2003). Entretanto, assegurar a integridade e consistência de artefatos versionados em um ambiente que dá suporte ao acesso concorrente é um problema difícil (Zhang e Ray, 2007). Portanto, para evitar os conflitos de edição e merge, adotou-se no CoMDD uma abordagem pessimistic (como será apresentado no Capítulo 3), ou seja, uma política em que o artefato é bloqueado quando já está sendo editado por outra pessoa.

Aplicando uma política pessimistic, conflitos de edição são evitados e, com isso, desenvolvedores não gastarão tempo ou esforços resolvendo conflitos. Ainda, a política pessimistic pode ajudar na comunicação, pois os desenvolvedores saberiam quando outra pessoa estaria

\footnotetext{
${ }^{2}$ http://subversion.org

${ }^{3}$ http://git.org
} 
modificando o mesmo artefato, incentivando a comunicação entre os desenvolvedores com os mesmos interesses (Sarma et al., 2003).

\subsection{Wiki}

As wikis são consideradas ferramentas que tornam fácil a edição de páginas web por qualquer pessoa. Elas também são vistas como uma filosofia em relação à forma como os usuários devem editar páginas web (Louridas, 2006). Em sua essência, a wiki é uma página web, ou um conjunto editável de páginas web. Ela permite que qualquer pessoa possa, facilmente, adicionar ou revisar o conteúdo por meio de, praticamente, qualquer navegador web (Jang e Green, 2006).

As wikis ganham muita aceitação pelos usuários e são utilizadas no meio acadêmico e na indústria. Elas se mostram uma opção no mundo das ferramentas colaborativas e ganham cada vez mais espaço no setor privado, tornando-se uma tecnologia para apoiar a colaboração dentro e entre empresas (Majchrzak et al., 2006; Tetard et al., 2009; Jang e Green, 2006).

Sua natureza é essencialmente colaborativa e a qualidade do seu conteúdo melhora à medida que as pessoas contribuem. Todos os usuários habilitados podem editar uma wiki e revisar seu conteúdo, de maneira irrestrita e democrática. Dessa maneira, a wiki enfatiza velocidade e flexibilidade ao invés de controle restrito e o fato da wiki ser fácil de implementar e de entender é, provavelmente, a chave para sua popularidade (Tetard et al., 2009; Abeti et al., 2009; Mehta, 2009).

Além da colaboração, simplicidade, facilidade e do suporte à edição colaborativa do conteúdo como sendo uma das principais funcionalidades da wiki (Tetard et al., 2009), a wiki é a plataforma eleita pela engenharia de requisitos, uma vez que permite que diversos interessados, distribuídos, compartilhem a definição do sistema; além do que as wikis têm controle de versão de páginas, gerenciamento de alterações de conteúdo, comunicação entre usuários por meio de fóruns e chats (Abeti et al., 2009).

O que as torna especiais não é apenas a facilidade de contribuição, mas também seus recursos (Mehta, 2009), como:

- Simples sintaxe de marcação;

- Criação de links simples ou automáticos, mesmo quando a página de destino ainda é inexistente;

- Controle de acesso total de usuários e páginas;

- Histórico completo das revisões, com possibilidade de reverter a qualquer momento;

- Muitas wikis não precisam de banco de dados, o que as deixa portáveis;

- Categorizar páginas para melhor organização e 
- Customizáveis.

A colaboração que a wiki oferece permite muitos trabalhos científicos em um leque amplo de áreas, como pode-se notar em trabalhos que usam a wiki para gerenciar conhecimento (Jing e Fan, 2008) e requisitos (Abeti et al., 2009; Ferreira e Silva, 2009), auxiliar o ensino e aprendizado (Elrufaie e Turner, 2005; Tetard et al., 2009; Minocha e Thomas, 2007; Lotufo et al., 2009; Machado et al., 2011), compartilhar informações, entre outros.

Khalid Rames Al-asmari (2006) apresentam um estudo de wikis para o desenvolvimento de software distribuído. Segundo os autores, para dar suportar à comunicação e coordenação de grupos distribuídos de desenvolvimento, alguns mecanismos são usados, como: viagens, telefonemas, emails, vídeo conferências, softwares de gerenciamento de projeto on-line e softwares de gerenciamento de conteúdo. Os autores então realizaram um experimento no qual envolve cinco stakeholders, três desenvolvedores, um cliente primário e um mentor, de modo que as dez pessoas trabalharam no mesmo projeto, mas distribuídas. A principal conclusão dos autores sobre o trabalho é que as wikis, comparadas a outros métodos de comunicação, são fáceis de usar, confiáveis e de baixo custo e, portanto, são ferramentas ideais para o desenvolvimento de software distribuído.

Ainda na pesquisa das wikis para a área de desenvolvimento de software, as wikis têm aprimorado o suporte a atividades específicas do desenvolvimento de software, como por exemplo, documentação, em que há um estudo para manter a documentação e o código fonte sincronizados (Aguiar e David, 2005); e revisão de código fonte, bug tracking e teste funcional (Xiao et al., 2007). Outro exemplo de suporte às atividades do processo de desenvolvimento são as wikis $\operatorname{Trac}^{4}$ e Twiki ${ }^{5}$. A wiki Trac é um sistema de issue tracking para o gerenciamento de desenvolvimento de software, que permite o registro de bugs e atividades em páginas wiki. Já a Twiki auxilia no gerenciamento de projetos de eXtreme Programming.

Atualmente, existem centenas de wikis desenvolvidas, como: Mediawiki ${ }^{6}$, Dokuwiki ${ }^{7}, \mathrm{Xwiki}^{8}$, entre outras. A wiki usada neste trabalho é a Xwiki, por ser implementada em Java.

As wikis são os sistemas que melhor se encaixam na simplicidade e facilidade para o CoMDD, ou seja, são sistemas aceitos tanto pela academia quanto pela indústria no que diz respeito à troca de conhecimento de maneira simples e rápida. Este é o motivo do uso de uma wiki no CoMDD.

Uma outra possibilidade para promover a colaboração na web seria por meio de, por exemplo, os Content Management System - CMS. Os CMSs são ferramentas para desenvolver sites e que possibilitam criar uma hierarquia de permissões, na qual se pode ter um administrador geral, editores de seções, editores de páginas, etc (Mehta, 2009).

\footnotetext{
${ }^{4}$ http://trac.edgewall.org/

${ }^{5}$ http://twiki.org/

${ }^{6}$ http://www.mediawiki.org/wiki/Mediawiki

${ }^{7}$ http://www.dokuwiki.org/dokuwiki

${ }^{8}$ http://www.xwiki.org/xwiki/bin/view/Main/webHome
} 
A princípio, os CMSs poderiam também dar suporte a uma DSL, entretanto, pode-se dizer que criar e editar conteúdos em CMSs requer um procedimento mais sofisticado e, geralmente, mais restrito do que em wikis. As wikis são mais abertas e têm menos rigor no controle de permissão, diferentemente dos CMSs, em que cada usuário tem permissões específicas de acesso para determinadas páginas e permissões de ações. Enquanto o controle de permissão em CMSs é mais completo, as wikis são projetadas para serem fáceis e rápidas de editar. As wikis também são mais fáceis de linkar páginas por usuários finais, além de permitirem que usuários não técnicos gerenciem e acessem o conteúdo de maneira mais fácil do que nos CMSs (Zimmerly, 2009).

Abeti et al. (2009) também comparam as wikis com os CMSs. Eles afirmam que as wikis são mais fáceis de aprender pelos usuários, pois basta saber editar uma página; enquanto que nos CMSs deve-se conhecer a base do CMS. Nas wikis, as páginas não têm estrutura e são o conceito central para gerenciamento de conteúdo; enquanto que nos CMSs as páginas são estruturadas e possuem uma hierarquia de páginas, seções, itens etc, além da estrutura do site de um CMS ser gerenciada por um administrador.

As wikis focam na velocidade, flexibilidade, colaboração e compartilhamento de conteúdo; ao invés do controle restrito de acesso e edição (Abeti et al., 2009).

\subsection{Considerações Finais}

Este trabalho apresenta essencialmente uma abordagem para que desenvolvedores sejam capazes de utilizar MDD de uma forma mais colaborativa do que a forma usada tradicionalmente. Por isso foi realizado o estudo de quais as abordagens existentes para MDD, sendo a DSL a abordagem escolhida e apresentada neste capítulo. Em termos de colaboração, foi necessário conceituar o tipo de colaboração a qual o CoMDD pretende atender e também foi necessário fazer um levantamento das possíveis plataformas para implementar o CoMDD, sendo a wiki a plataforma escolhida essencialmente pelo seu caráter colaborativo e simplicidade de uso, o que estimula mais a colaboração do que ferramentas como os CMSs.

Este capítulo apresentou os principais conceitos necessários para o entendimento deste trabalho, como: MDD, DSL, wikis, sistema de versionamento e política otimistic e pessimistic. A discussão dos trabalhos relacionados será feita na Seção 3.5, onde serão apresentados os principais trabalhos relacionados e que utilizam wikis para desenvolvimento de software e modelagem.

O próximo capítulo apresenta o desenvolvimento do trabalho, o qual define a abordagem CoMDD e apresenta as abordagens relacionadas ao CoMDD existentes na literatura. 


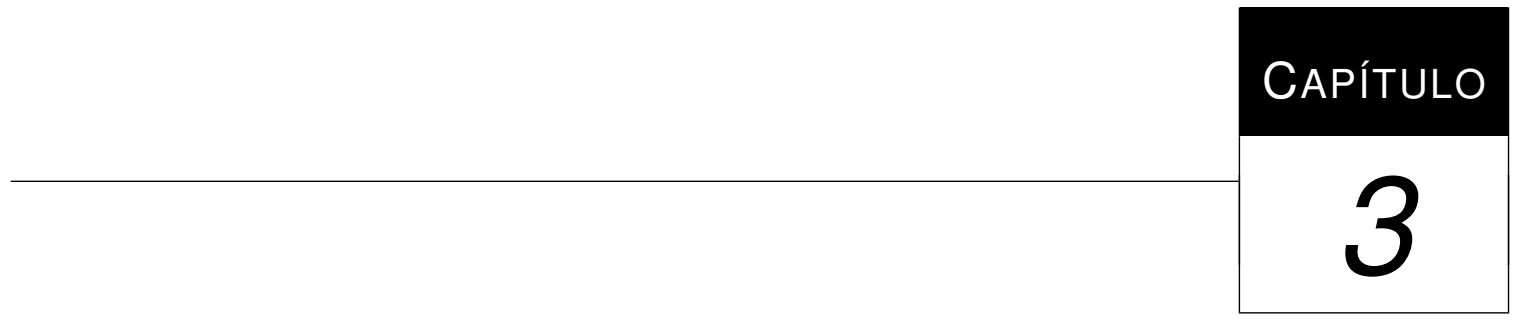

\section{A Abordagem CoMDD}

O Capítulo 1 mostrou que uma forma de se trabalhar colaborativamente com MDD é usando uma IDE associada a um sistema de versionamento, entretanto, essa abordagem exige dos usuários que instalem e configurem os programas necessários, bem como entendam todo o processo de check in/check out e ainda como a ferramenta de versionamento usada funciona. No caso de não desenvolvedores, isso pode ser um problema.

Um outro problema está relacionado a manter a documentação atualizada. Geralmente, o que ocorre é que a documentação usada para desenvolver o software fica desatualizada em relação ao código fonte (Lucrédio, 2009; Xiao et al., 2007). É um desafio para equipes de desenvolvimento manter o código fonte e documentação sincronizados ao longo de todo o ciclo de vida do desenvolvimento (Xiao et al., 2007).

Entre esses e outros motivos, foi idealizado o CoMDD, o qual será apresentado neste capítulo e que objetiva tentar resolver os problemas apresentados no Capítulo 1 e que alguns foram citados acima.

Este capítulo descreve a abordagem desenvolvida neste trabalho, cita suas funcionalidades e limitações, apresenta parte da sua implementação e por fim apresenta os trabalhos relacionados, fazendo um comparativo desses trabalhos com o CoMDD. 


\subsection{A Origem do CoMDD}

Este projeto começou a partir de uma ideia de um dos alunos de doutorado do grupo de pesquisa da professora Renata Pontin, que era ter um MDD em uma wiki. Até então, MDD poderia ser tanto uma abordagem genérica quanto específica, usando modelos gráficos ou textuais. Em virtude de um aluno de iniciação científica já ter desenvolvido uma ferramenta de modelagem na web, optou-se em tentar transformar esses modelos que eram apenas gráficos em modelos com significados, de modo que permitisse realizar transformações. Então, pensou-se em usar diagramas de estados, os quais eram possíveis de serem modelados pela ferramenta.

Durante a pesquisa de diagramas de estados, o aluno de mestrado teve a oportunidade de fazer parte do INCT-SEC (Instituto Nacional de Ciência e Tecnologia em Sistemas Embarcados Críticos). A participação do aluno ficou atrelada a uma parceria com o Laboratório de Robótica Móvel (LRM) da USP, que também fazia parte do INCT-SEC.

O LRM é responsável por desenvolver algoritmos que possibilitem que robôs possam navegar em ambientes ou executar tarefas de forma autônoma. $\mathrm{O}$ aluno passou a conhecer um pouco desse domínio, sendo auxiliado por um dos alunos de doutorado do grupo. Percebeuse então que o grupo de robótica móvel não usava diagrama de estados ou máquinas de estados para desenvolver seus programas, mas pensavam no algoritmo e o codificavam usando linguagens de alto nível, como $\mathrm{C} / \mathrm{C}++$.

Assim, a pesquisa mudou de usar modelos gráficos para usar modelos textuais que fossem capazes de representar melhor o domínio estudado. Para isso, ambos alunos (o pesquisador deste trabalho e o doutorando do LRM) partiram de um código fonte de um robô para um modelo que o representasse. Então, o pesquisador definiu as transformações e a sintaxe da linguagem no Eclipse, sendo a primeira versão da DSL do CoMDD.

Feito isso, tentou-se migrar a DSL para a wiki. Após algumas tentativas percebeu-se que fazer essa migração era complicado tecnicamente, uma vez que a DSL precisava de frameworks do Eclipse para funcionar. Assim, decidiu-se aprender sobre o ANTLR para desenvolver a segunda versão da DSL.

Antes de desenvolver a segunda versão, primeiro fez-se um hello world do ANTLR e migrou este para a wiki. A partir disso, o pesquisador e o doutorando do LRM desenvolveram a segunda versão da DSL com base em mais códigos fontes, que foram implementados pelo pesquisador. Mais detalhes da implementação do CoMDD serão apresentados a seguir. 


\subsection{CoMDD - Collaborative Model Driven Development}

O CoMDD é a abordagem desenvolvida que consiste no apoio ao desenvolvimento colaborativo orientado a modelos, em que a colaboração é referente à edição colaborativa de modelos. O CoMDD pode ser pensado nos seguintes cenários: seja mais de uma pessoa editando o mesmo modelo (em uma política pessimistic), ou várias pessoas editando vários modelos, de forma que cada modelo tenha apenas uma pessoa o editando e que esses modelos sejam dependentes entre si.

A Figura 3.1 ilustra duas pessoas editando um mesmo modelo. Um exemplo disso é quando dois desenvolvedores estão desenvolvendo um sistema, ou parte dele, e usando as mesmas classes. Esse caso é mais comum nas classes base do sistema, ou seja, classes que fazem parte da estrutura do sistema e as quais serão importadas por outras classes.

A Figura 3.2 ilustra três pessoas editando diferentes modelos, mas que são dependentes entre si. Esse caso não exclui o caso da Figura 3.1. Um exemplo é quando em um projeto cada desenvolvedor é responsável por implementar um conjunto de classes, mas que essas classes dependem de outras, que são implementadas por outros desenvolvedores.

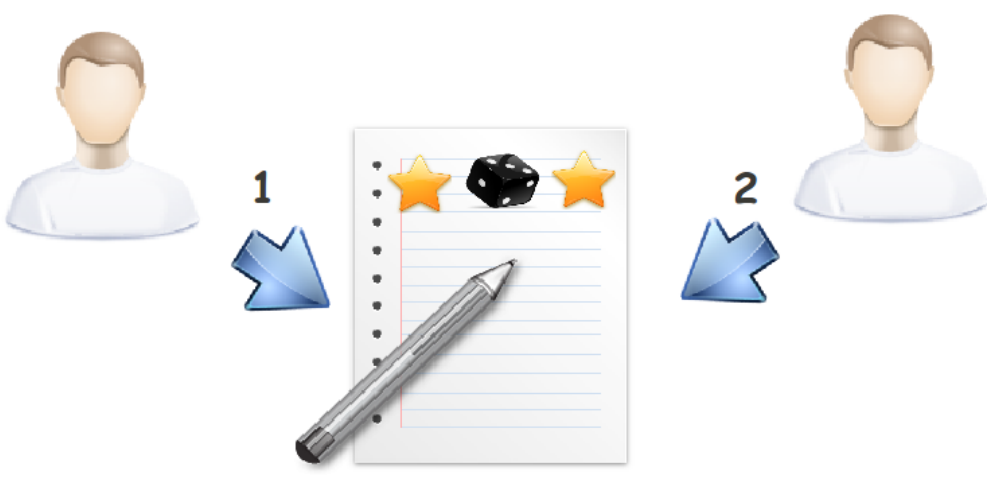

Figura 3.1: Duas pessoas editando o mesmo modelo.

Para evidenciar a hipótese de pesquisa deste trabalho, a abordagem CoMDD foi implementada usando uma DSL e uma wiki, para promover o MDD e a colaboração.

O desenvolvimento de software baseado em wikis é encorajado pelo fato de desenvolvedores trabalharem no mesmo projeto e, muitas vezes, estarem localizados em diferentes locais e pela observação de que as ferramentas on-line têm tido uma importância cada vez maior na comunicação e coordenação dessas equipes distribuídas (Xiao et al., 2007).

A DSL permite a edição de modelos e geração de código fonte, usando templates, em uma wiki. A wiki serve tanto como ferramenta de suporte a utilização da DSL, quanto ferramenta colaborativa, pois possibilita o trabalho em equipe e o versionamento de modelos.

A DSL definida neste trabalho visa especificar modelos no domínio de robôs móveis autônomos. No Apêndice A é apresentada a gramática da DSL. Essa DSL foi desenvolvida em 


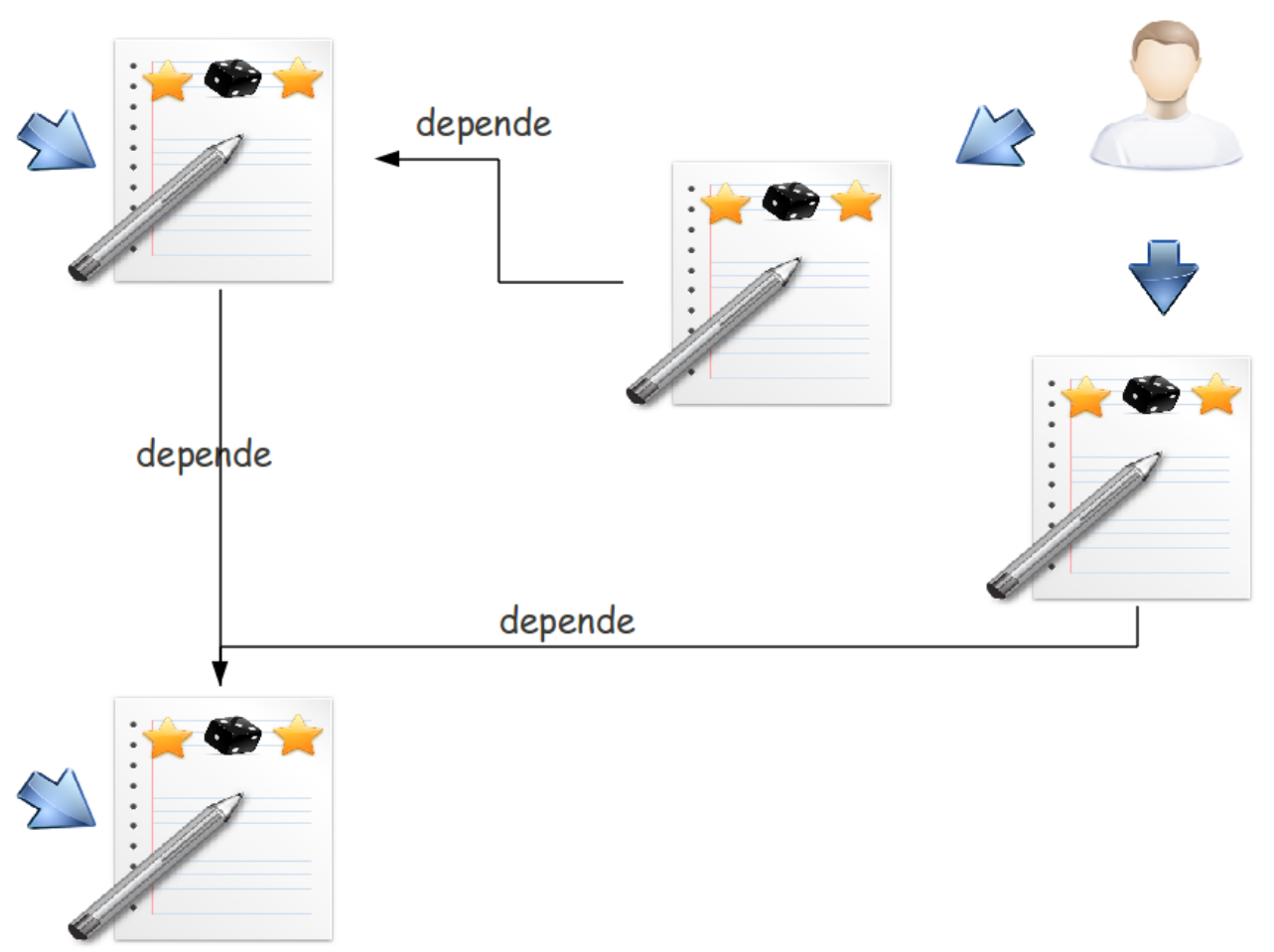

Figura 3.2: Três pessoas editando diferentes modelos que dependem entre si.

colaboração com o Laboratório de Robótica Móvel (LRM) da Universidade de São Paulo, a partir de um conjunto de códigos fonte que o LRM já possuía.

O primeiro passo para a criação dessa DSL foi a definição de quais códigos fonte a DSL iria atender, pois mesmo o domínio de robótica móvel autônoma é amplo e, por isso, foi necessário especificar ainda mais. Em seguida, foram identificadas semelhanças entre os códigos e, por fim, foram verificadas as partes variáveis e as partes fixas, de modo que foi possível definir um metamodelo para a DSL e um conjunto de transformações.

A seguir são descritos os recursos desenvolvidos no CoMDD, considerando a DSL definida. As interações disponibilizadas apresentam as principais funcionalidades relativas às tarefas dos desenvolvedores.

A Figura 3.3 ilustra um modelo sendo editado (passo 1), depois ele sendo salvo (passo 2) e depois, a Figura 3.4 mostra a geração de código fonte (passo 3).

A Figura 3.5 ilustra um modelo referenciando outras páginas que podem ser editadas enquanto outra pessoa cria essas páginas. Por exemplo, uma pessoa cria o modelo na página (Figura 3.5) e cria um link ainda não existente, por exemplo "[[main]]". Os colchetes "[[]]"indicam uma referência para um link, que quando a página é salva ficam identificados por um ponto de interrogação, o que significa que a página do link ainda não foi criada. 
BEDT: WYSIWY $~ T$

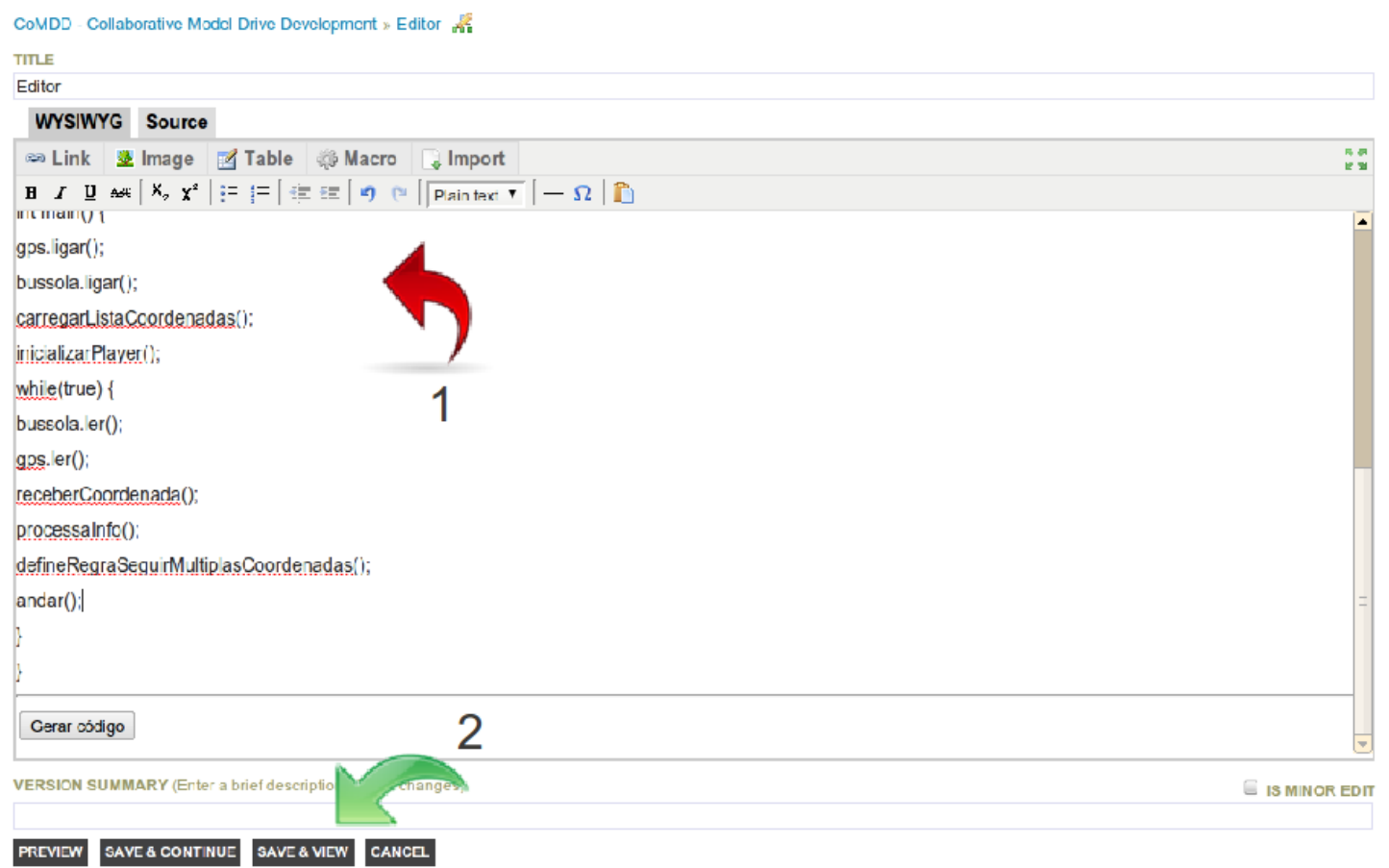

Figura 3.3: Edição e armazenamento de modelos.

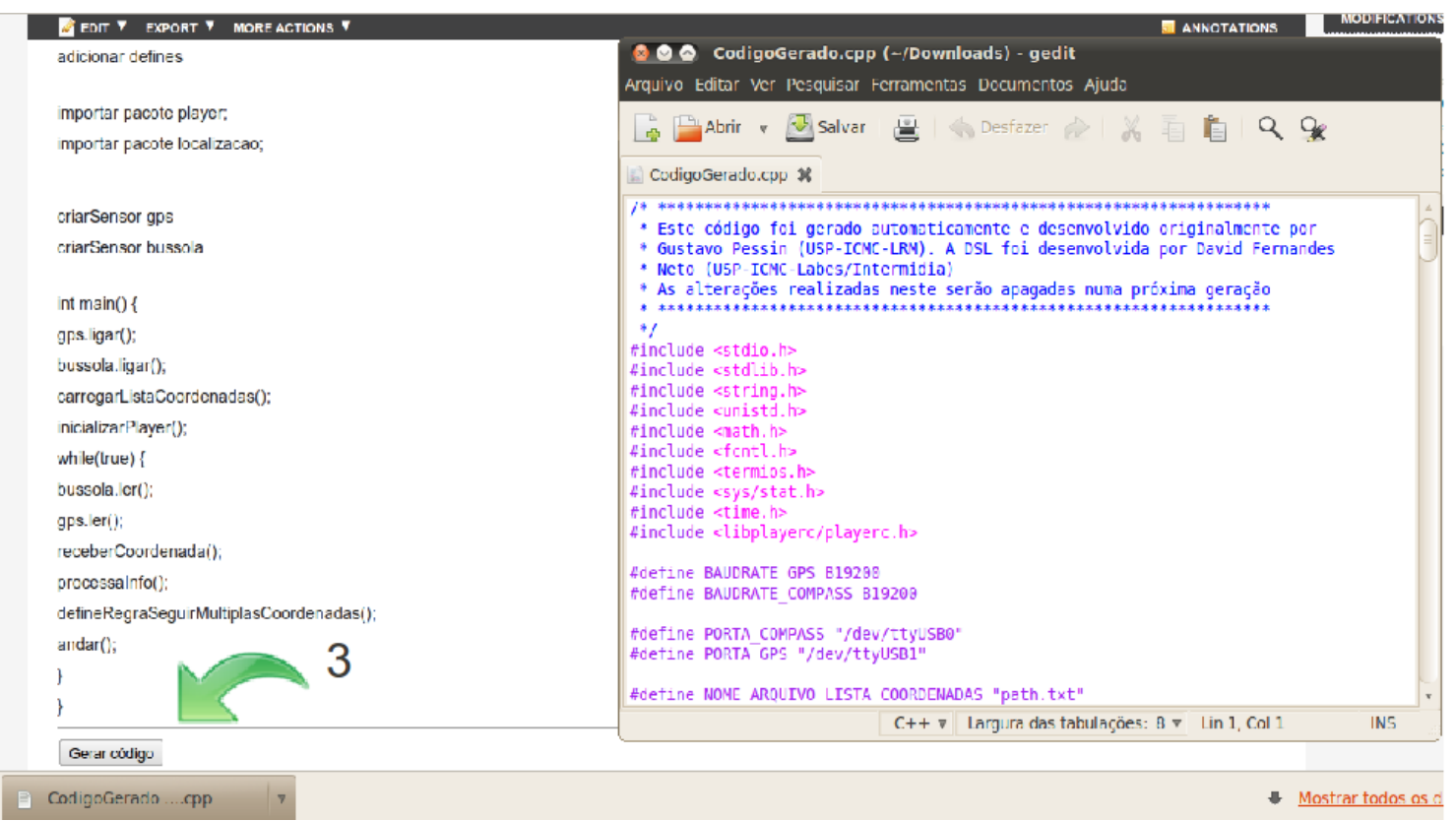

Figura 3.4: Geração de código fonte.

Assim, outro desenvolvedor pode criar a página "Main"que depende do modelo da página principal $^{1}$.

De forma geral, a implementação do CoMDD permite:

\footnotetext{
${ }^{1}$ Caso a implementação do CoMDD permitisse a edição de diferentes modelos, este trabalho se tornaria extenso e seria difícil avaliar essa funcionalidade; portanto, a implementação desta funcionalidade ficou para trabalhos futuros.
} 


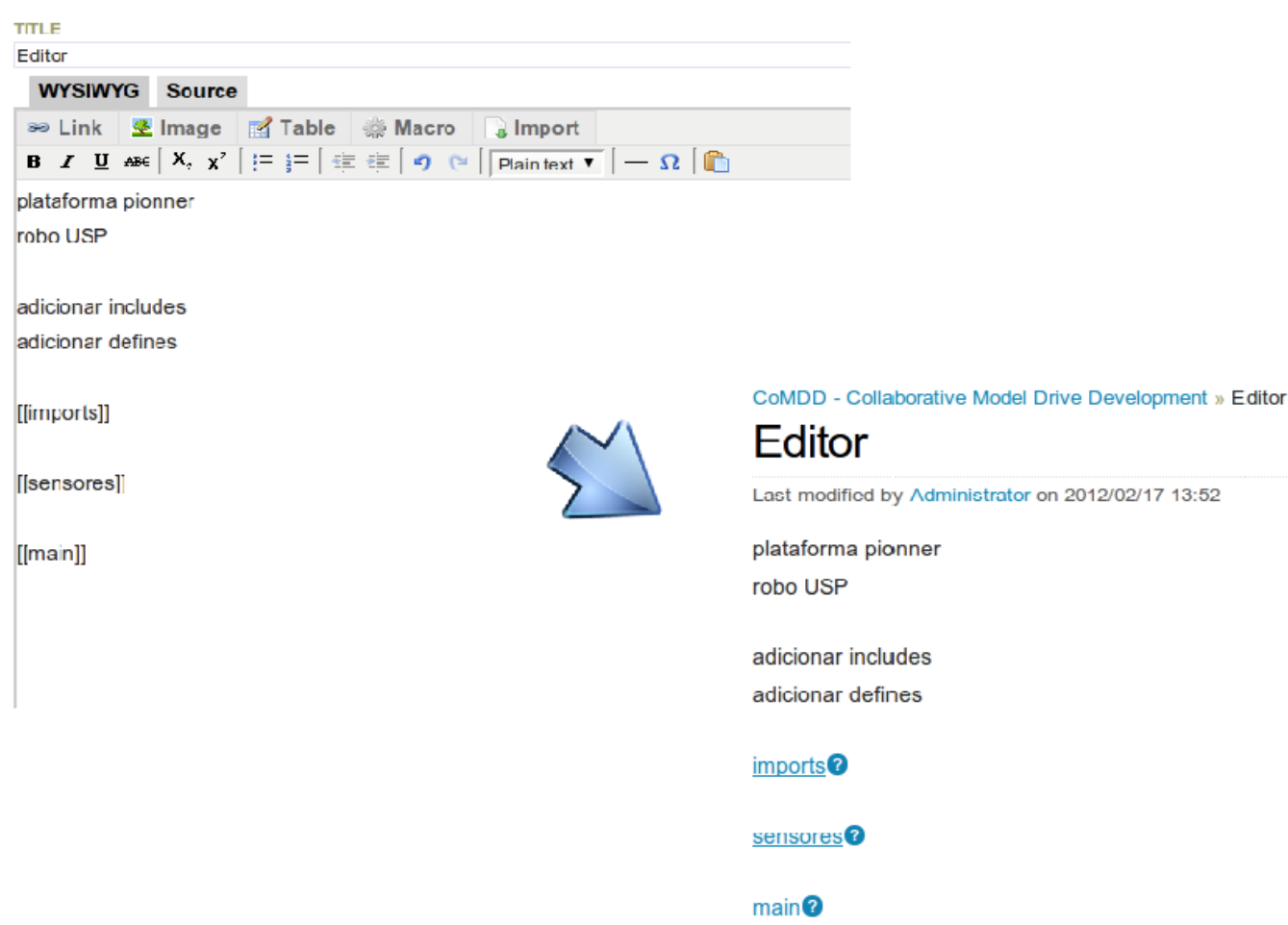

Figura 3.5: Edição de diferentes modelos dependentes entre si.

1. Edição de modelos: criar ou alterar modelos de acordo com o metamodelo definido ${ }^{2}$. Os modelos são editados na wiki e são a entrada do transformador;

2. Transformação de modelos em código fonte: o transformador, que funciona na wiki, gera o código fonte de acordo com o modelo de entrada;

3. Colaboração: a wiki permite que mais desenvolvedores possam editar o mesmo modelo usando uma política pessimistic;

4. Versionamento de modelos: a wiki armazena um histórico dos modelos com a possibilidade de comparar as versões e retornar à edições anteriores;

5. Controle de acesso por grupos: a wiki permite criar um grupo com permissão de edição de modelos e outro com permissão de apenas visualização, por exemplo;

6. Comentários: há dois tipos de comentários. Um é inserido em cada versão alterada e o outro é inserido na página editada. A Figura 3.6 ilustra comentários feitos na página de edição do modelo, ou seja, na mesma página em que o usuário está editando o modelo ele pode deixar um comentário no final da página. A Figura 3.7 ilustra comentários específicos para cada versão da página.

\footnotetext{
${ }^{2} \mathrm{O}$ metamodelo pode ser alterado na wiki, assim como as transformações, mas a princípio está sendo definido fora da wiki e esta funcionalidade ainda não foi implementada.
} 


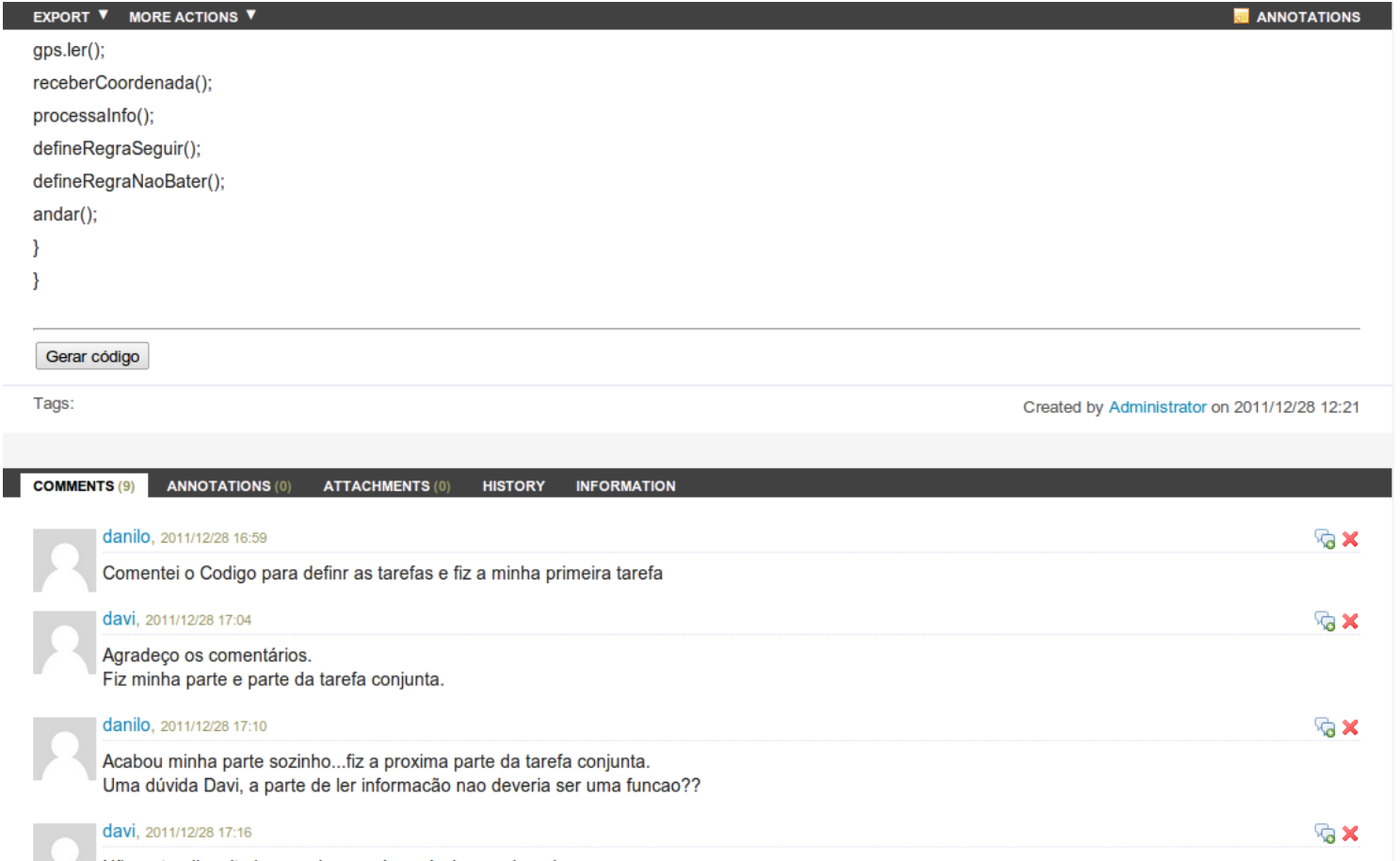

Figura 3.6: Comentários feitos na página de edição

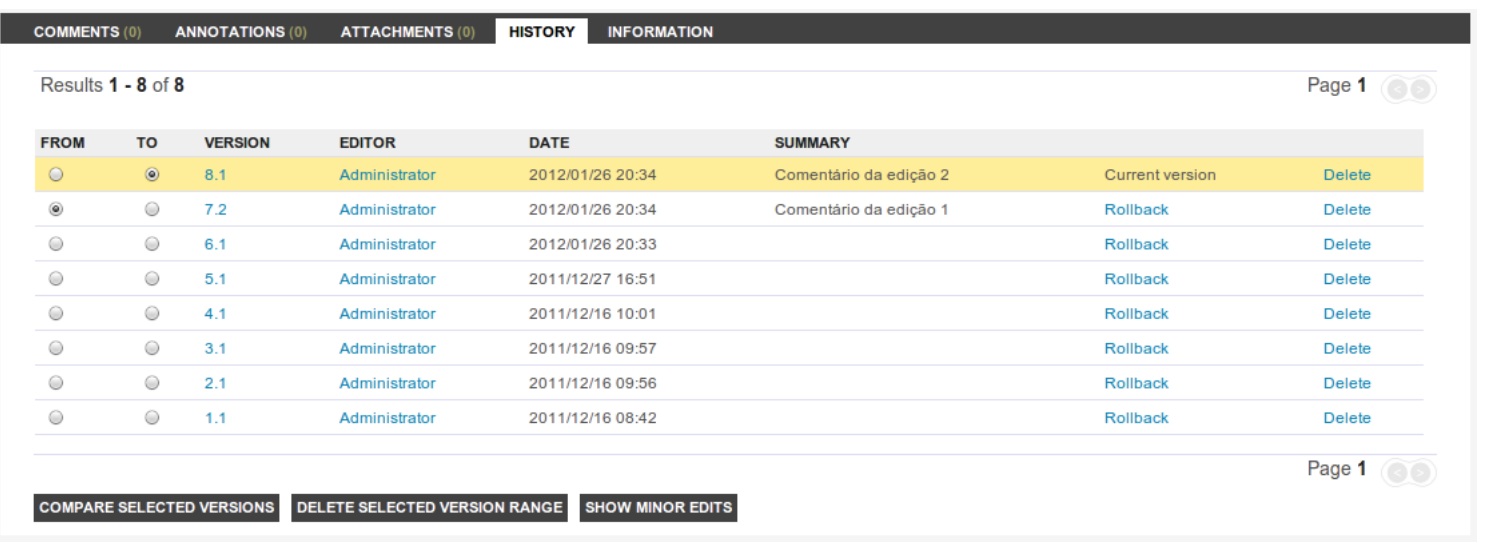

Figura 3.7: Comentários feitos para cada versão da página

\section{Processo Realizado na wiki}

A Figura 3.8 ilustra o processo de edição e transformação dos modelos realizados na wiki. Um desenvolvedor edita um modelo (passo 1). Esse modelo deve estar de acordo com o metamodelo (passo 2). É o metamodelo que define a estrutura do modelo, ou seja, é ele quem define, por exemplo, o que é um círculo e se ele vem antes ou depois do quadrado, por exemplo. Se o modelo estiver de acordo com o metamodelo, então são aplicadas transformações (passo 3) que geram o código fonte (passo 4). Embora não esteja ilustrado na figura, todo este processo, no CoMDD, ocorre na própria wiki.

O CoMDD pode ser visto em: http://143.107.183.158:8008/xwiki/bin/view/ Main/. 


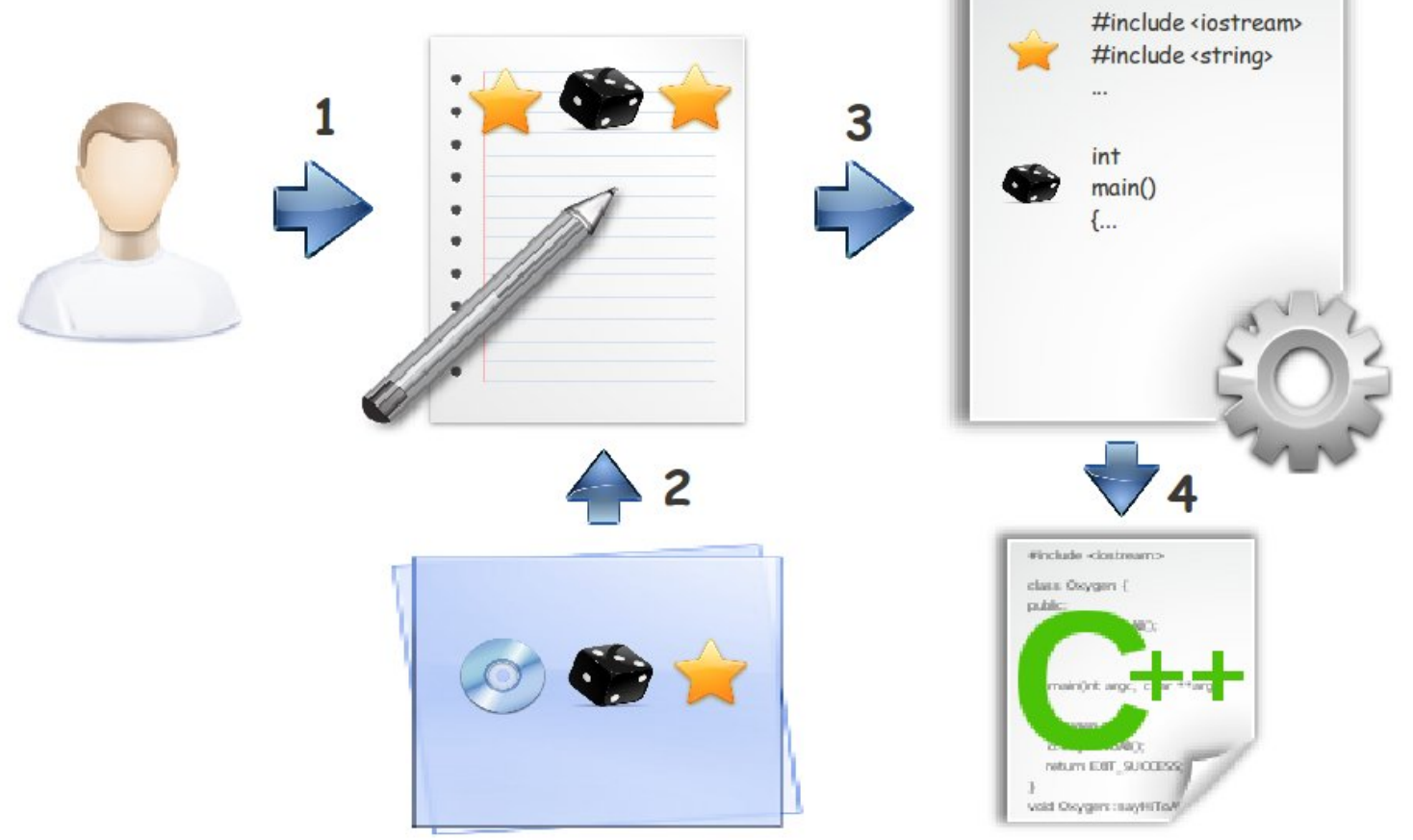

Figura 3.8: Processo de edição de modelos e geração de código fonte realizado na wiki.

\subsection{Arquitetura do CoMDD}

O CoMDD foi implementado usando o $\mathrm{ANTLR}^{3}$, no qual foi definido o metamodelo e as transformações; e a wiki utilizada foi a $\mathrm{Xwiki}^{4}$. A Figura 3.9 ilustra a arquitetura do CoMDD, na qual o desenvolvedor interage com modelos, que são processados e transformados em código fonte pelo transformador. O transformador precisa da definição do metamodelo para validar o modelo e poder gerar o código fonte. E tanto a modelagem, quanto as transformações, são realizadas na wiki.

A Figura 3.10 apresenta a arquitetura de implementação do CoMDD. Para desenvolver o metamodelo da DSL foi usado o ANTLR e para definir os templates das transformações foi usado o String Template ${ }^{5}$.

\subsection{A Implementação do CoMDD}

As Figuras 3.11 e 3.12 representam parte da gramática. Um modelo válido para esta gramática deve seguir sua estrutura, ou seja, deve começar com a palavra "plataforma"seguido de uma das três opções: "pionner", "srv"ou "golfe". Esta opção indica o tipo de robô que está sendo modelado e para cada tipo, um conjunto diferente de código será gerado. Em seguida,

\footnotetext{
${ }^{3}$ http://www.antlr.org

${ }^{4} \mathrm{http}: / /$ www.xwiki.org

${ }^{5}$ http://www.stringtemplate.org/
} 


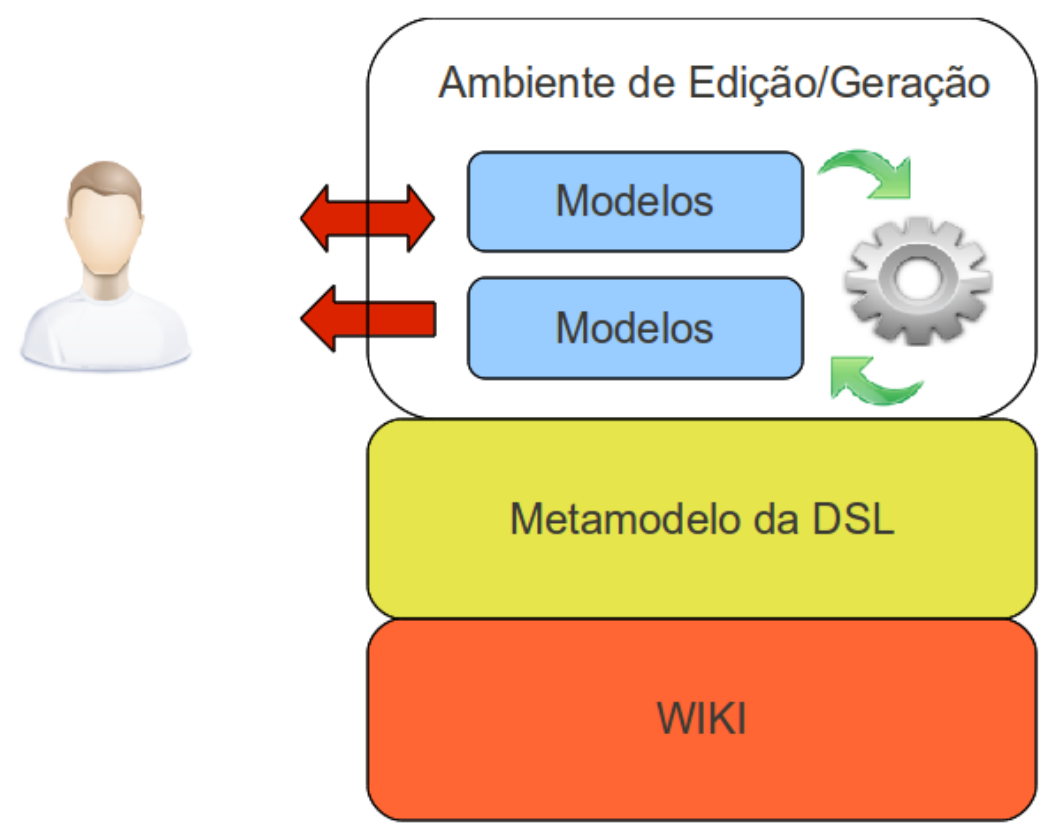

Figura 3.9: Arquitetura do CoMDD.

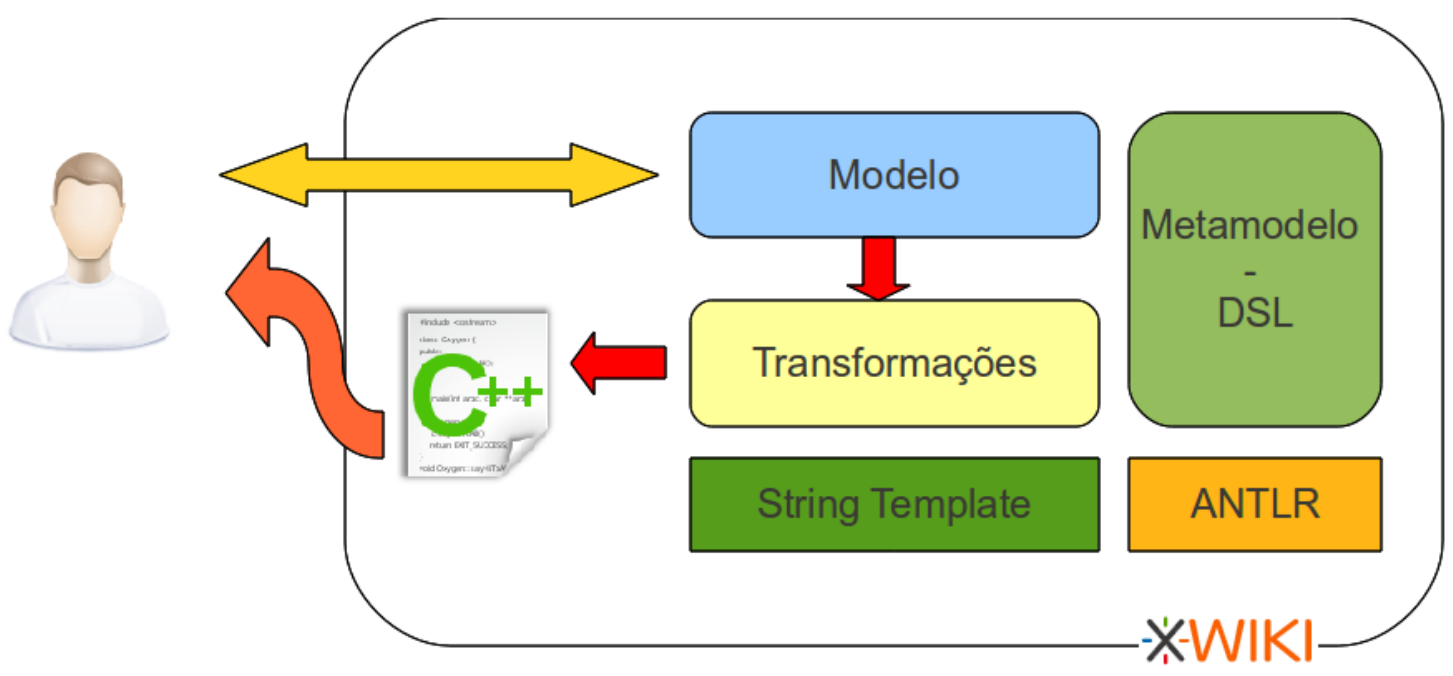

Figura 3.10: Arquitetura implementada para o CoMDD.

o modelo deve ter um cabeçalho que é composto de um ou mais sensores. Os sensores são definidos pela palavra "criarSensor"seguida do tipo de sensor: "gps", "bussola"e "camera". Esse é o início da gramática da linguagem do CoMDD. A gramática completa encontra-se no Apêndice A.

Para cada tipo de sensor é definida uma transformação específica, ou seja, se é uma bússola, o código gerado vai ser diferente do código gerado para um gps. As Figuras 3.13 e 3.14 ilustram parte das transformações citadas aplicadas ao modelo.

A partir da definição de uma gramática e das transformações, o ANTLR é responsável por gerar os analisadores léxicos e sintáticos da linguagem, ou seja, o transformador da linguagem. 


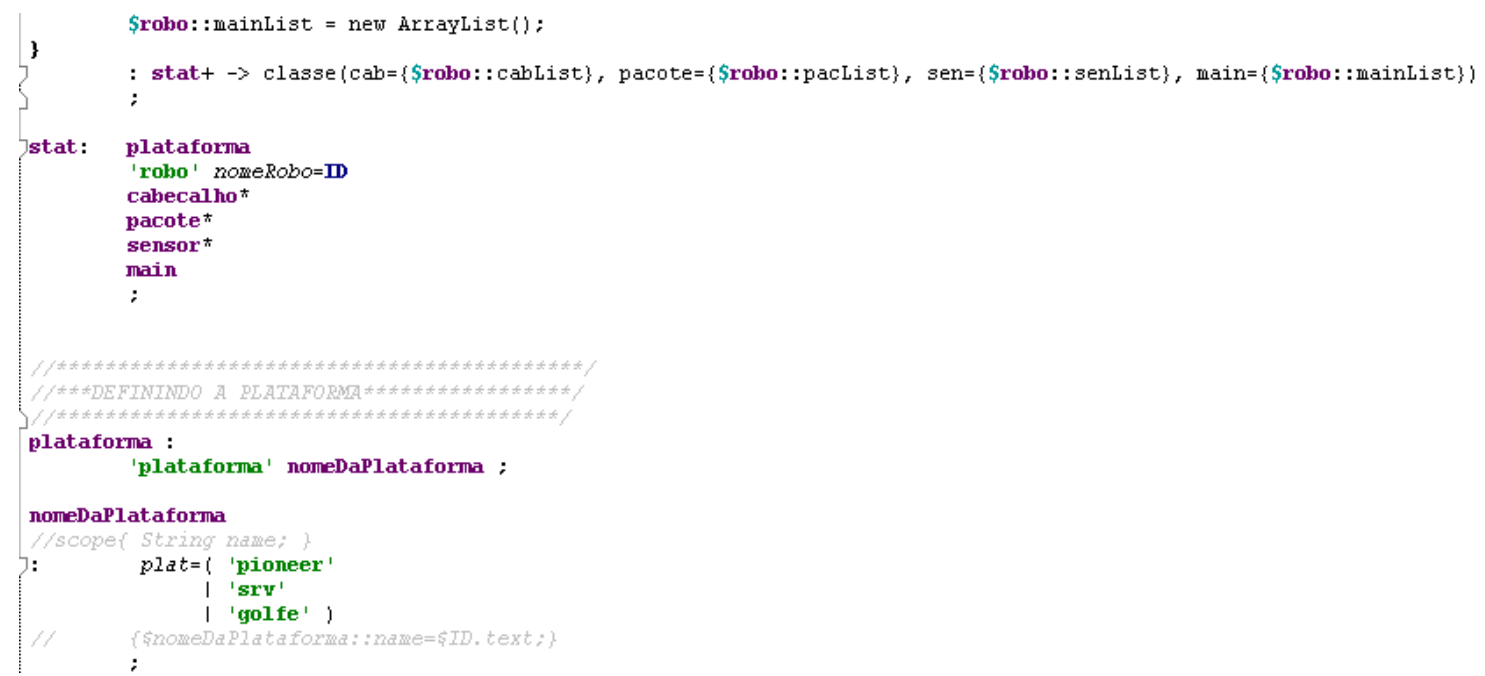

Figura 3.11: Gramática do CoMDD.

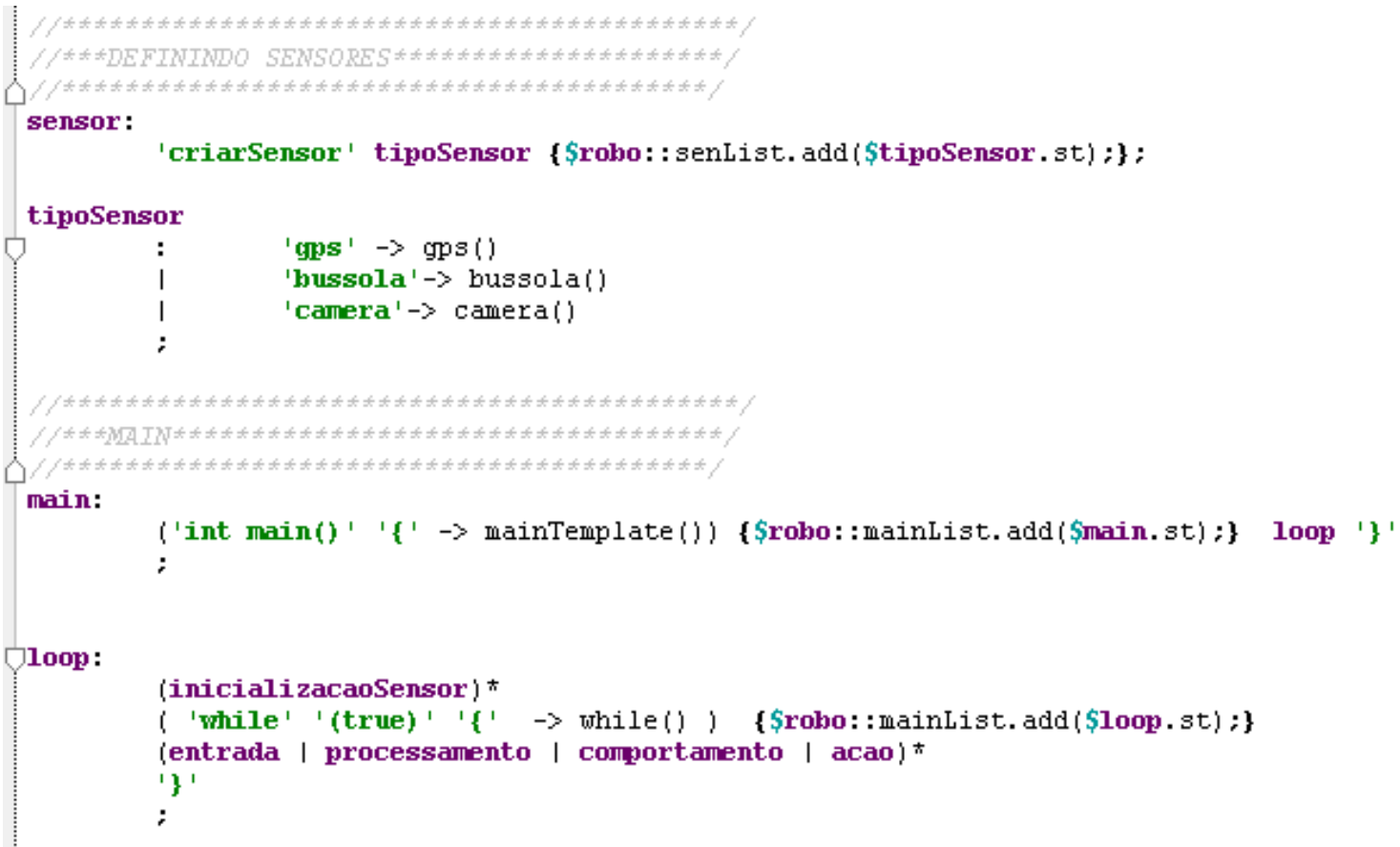

Figura 3.12: Gramática do CoMDD.

Foi criado então um componente para a Xwiki ${ }^{67}$ do transformador da linguagem, permitindo que a edição de uma página wiki fosse a edição de um modelo, que serviria então de entrada para o componente. O componente, por sua vez, é responsável em realizar o parser do modelo e gerar o código fonte com base nas transformações que ele possui.

Para o transformador ser executado na página wiki (modelo) ele deve ser invocado pela página wiki, através do seguinte código:

$\{$ velocity $\}$

\footnotetext{
${ }^{6}$ http://platform.xwiki.org/xwiki/bin/view/DevGuide/WritingComponents

${ }^{7}$ http://extensions.xwiki.org/xwiki/bin/view/Extension/Component+Module
} 


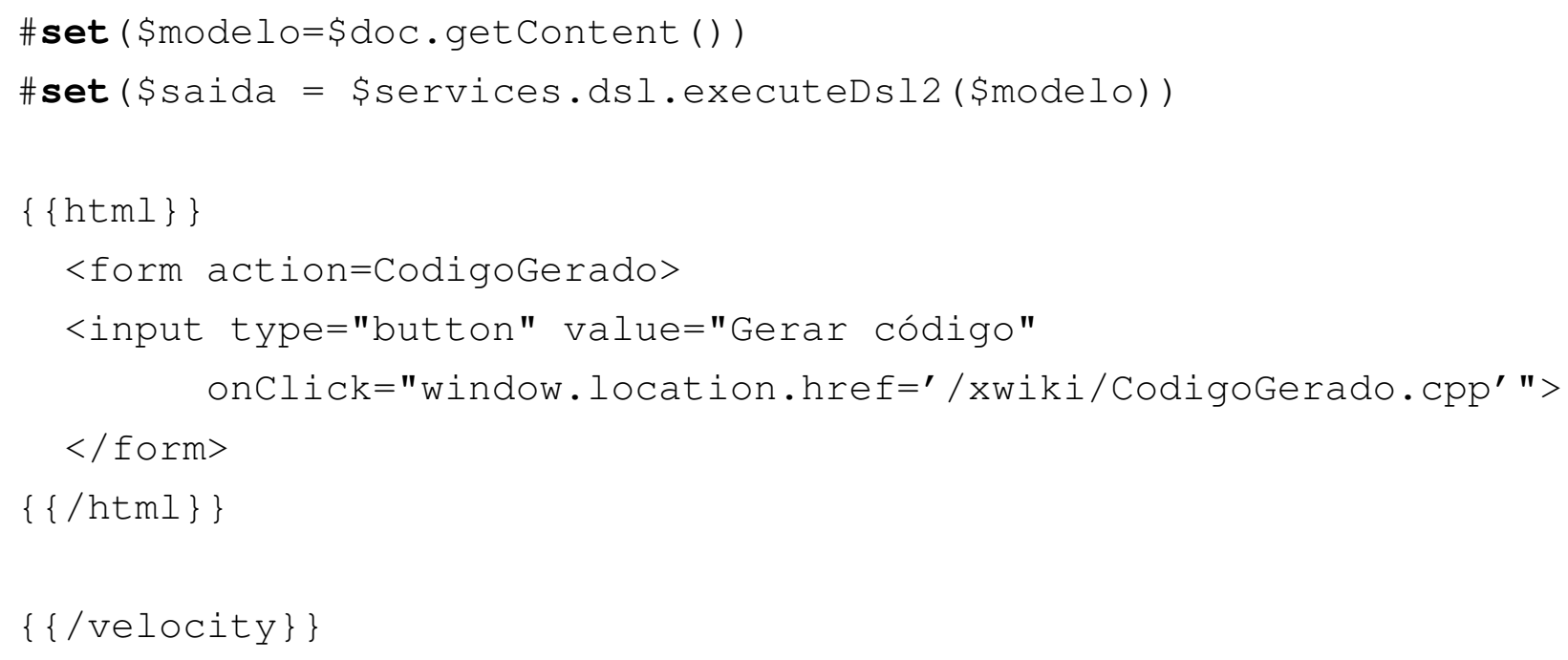

\section{$\{\{/$ velocity $\}$}

Este código é responsável por ler o modelo, executar o transformador (componente da xwiki) que usa o modelo como entrada e gera uma saída. Esta saída é o código fonte e é apresentado quando o botão "Gerar código"é pressionado.

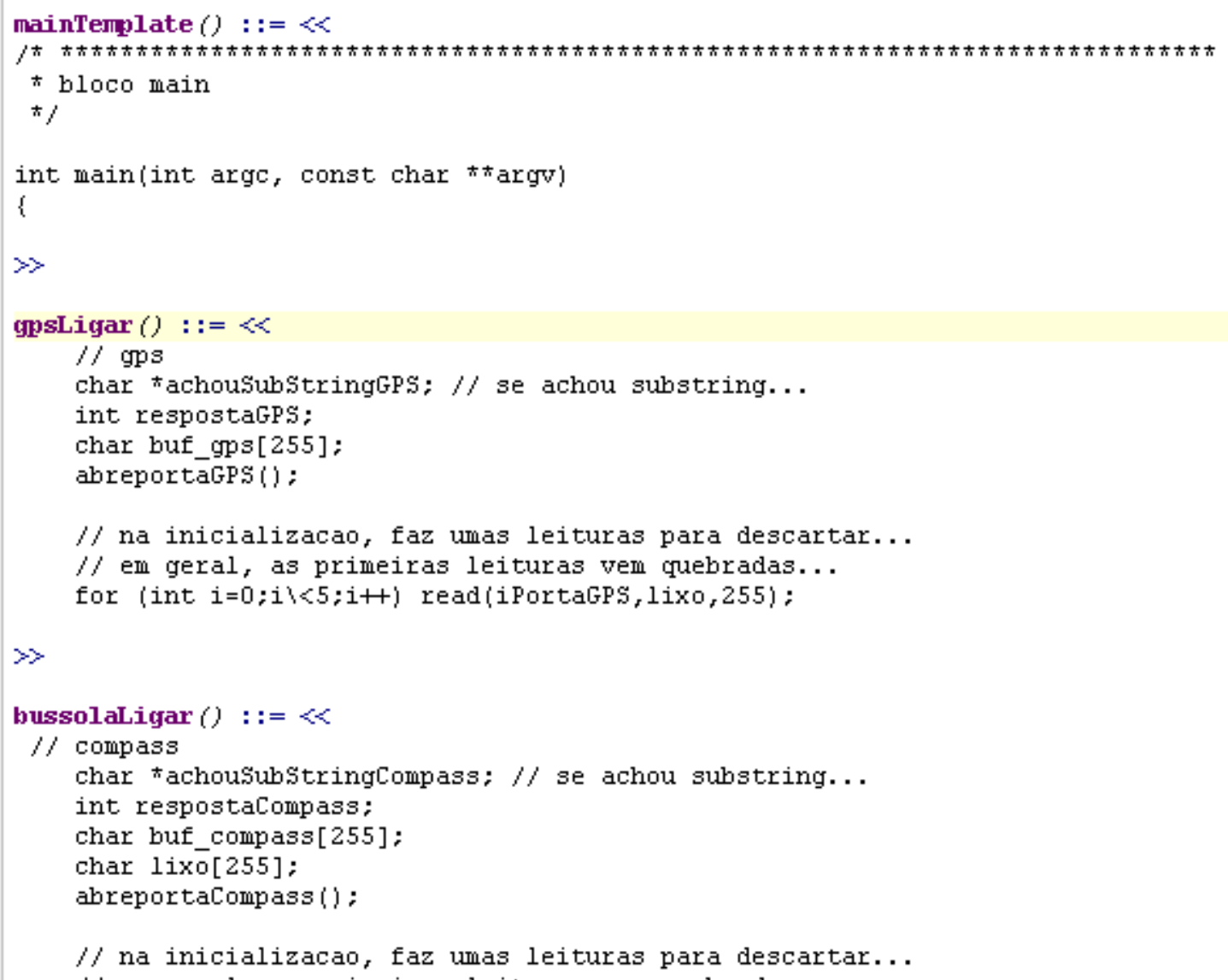

Figura 3.13: Transformações do CoMDD. 


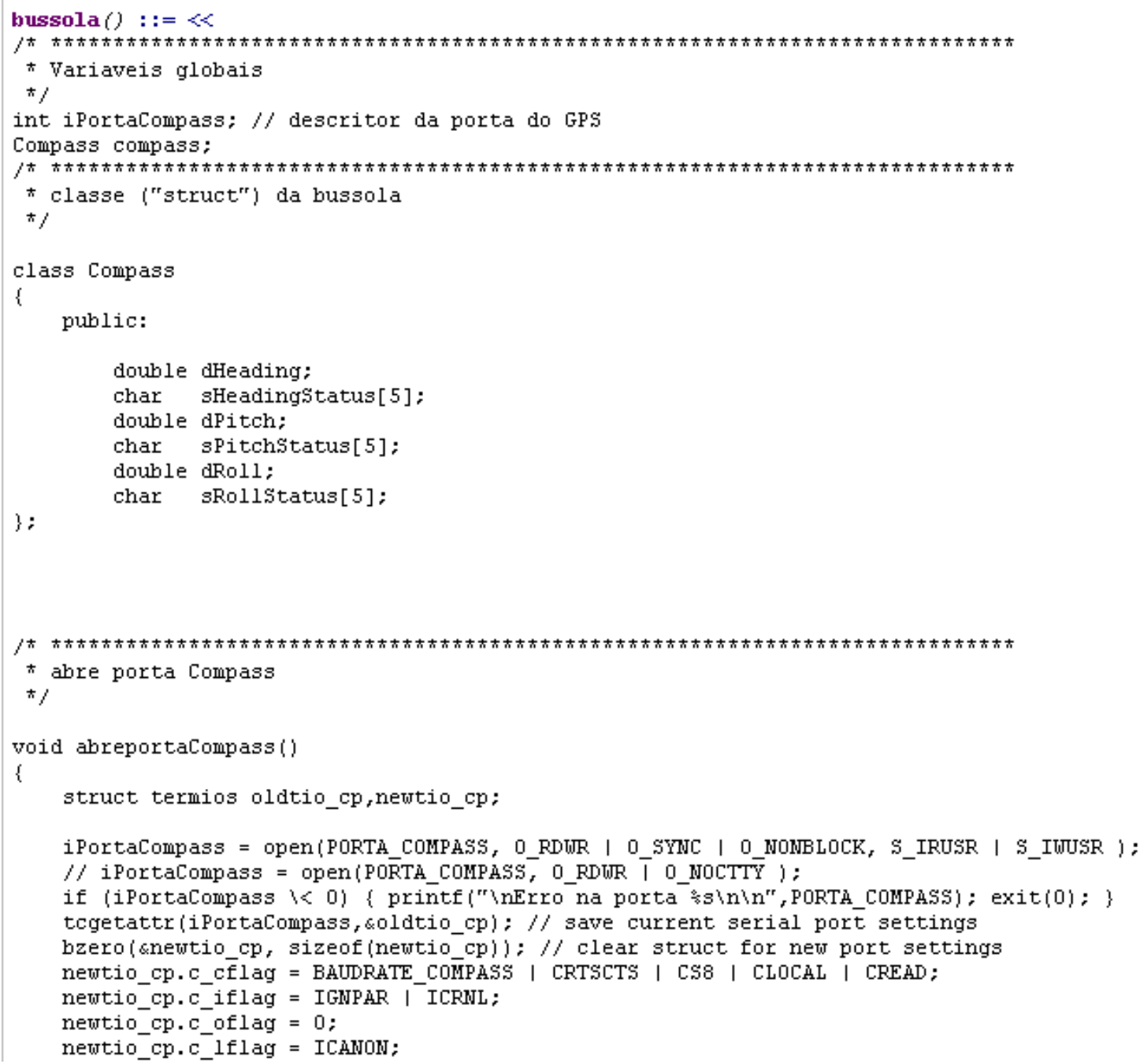

Figura 3.14: Transformações do CoMDD.

\subsection{Trabalhos Relacionados}

\section{Adessowiki}

Os trabalhos de Lotufo et al. (2009) e de Machado et al. (2011) apresentam o Adessowiki ${ }^{8}$, uma wiki para desenvolvimento, documentação, ensino e repositório de algoritmos científicos, com foco na área de processamento de imagens. Esse ambiente está sendo usado desde 2008 como um ambiente educacional, pela Unicamp ${ }^{9}$. O Adessowiki também é uma ferramenta colaborativa para escrita de artigos e outros textos científicos. Ele foi resultado de um projeto entre a Unicamp e o Centro de Tecnologia de Informação Renato Archer ${ }^{10}$.

Segundo os autores, o que torna o Adessowiki especial em relação às outras wikis e aplicações web é sua capacidade de incluir trechos de código em Python ou C++ que são executa-

\footnotetext{
${ }^{8}$ http://www.adessowiki.org

${ }^{9}$ www.unicamp.br

${ }^{10} \mathrm{http} / / /$ www.cti.gov.br/
} 
dos no servidor quando as páginas wiki são renderizadas. Dessa forma, os resultados desse código podem fazer parte de textos científicos, em forma de figuras, textos e tabelas.

O principal objetivo desse ambiente é desenvolver colaborativamente algoritmos numéricos. As páginas do Adessowiki permitem a inserção de código, o qual é executado quando a página é renderizada, incorporando figuras, textos e tabelas, gerando um documento científico.

Em relação ao ensino, o Adessowiki pode, como wiki, servir para registrar informações de curso, como notas e exercícios; como um ambiente de programação, serve de plataforma para atividades de programação solicitadas pelo professor, uma vez que o código pode ser inserido e os resultados visualizados nas páginas wiki.

A principal diferença entre o Adessowiki e o CoMDD está no foco dado por cada um. Enquanto o Adessowiki tem mais o caráter de ensino, de pesquisa científica, de elaboração de textos científicos, e se limita à área de processamento de imagem e computação gráfica; o CoMDD foca no desenvolvimento de sistemas de software usando modelos, incentivando a colaboração de desenvolvedores e não desenvolvedores; com o intuito de ser uma espécie de substituto à IDEs e versionadores instalados localmente. Outra diferença é que o Adessowiki usa Python ou $\mathrm{C}++$, enquanto que o CoMDD usa modelos.

Ainda, o método usado pelo CoMDD está na comparação entre a abordagem CoMDD e a tradicional (desenvolvimento usando Eclipse e SVN), enquanto que os autores do Adessowiki apresentam casos de uso que o ambiente atende.

\section{Galaxy wiki}

Xiao et al. (2007) desenvolveram o Galaxy wiki, uma wiki que permite que desenvolvedores possam criar, modificar e deletar código fonte, como também compilar, executar e debugar programas Java, e ainda colaborativamente, da mesma forma como é feito no Eclipse ${ }^{11}$. Nesse trabalho, Xiao et al. (2007) destaca a engenharia de software orientada a páginas. No Galaxy wiki é possível que um programador possa reusar um código fonte apenas referenciando uma página HTML.

Como complemento do Galaxy wiki, os autores desenvolveram um plugin para o Eclipse de modo que o Eclipse acesse as páginas de projeto, de classes e de bibliotecas armazenadas no Galaxy wiki e converta em projetos e arquivos Java e JARs, respectivamente, integrando assim o Galaxy wiki e o Eclipse.

Xiao et al. ainda apresentam alguns problemas do uso de IDEs, como:

1. É difícil entender o código fonte através a documentação, pois a documentação, geralmente, é descontinuada a medida que o código fonte é desenvolvido;

\footnotetext{
${ }^{11}$ http://www.eclipse.org/
} 
2. É difícil experimentar funcionalidades rapidamente sem nenhum software instalado localmente e

3. É difícil reusar uma biblioteca simplesmente acessando uma página HTML.

O trabalho do CoMDD e do Galaxy wiki estão próximos, uma vez que ambos trabalhos atentam para o uso de wikis que forneçam o suporte necessário para que desenvolvedores possam programar, livres de outras ferramentas e de instalações. Contudo, a principal diferença entre as abordagens está na natureza do CoMDD. Usar modelos ao invés de linguagens de programação tem com o intuito, além de aumentar a produtividade do desenvolvimento ${ }^{12}$, permitir que não desenvolvedores possam colaborar. Embora os próprios autores do Galaxy wiki citem essa como uma possível vantagem do Galaxy wiki, nota-se ao longo do artigo que esse não é o seu foco.

Um dos objetivos pensados e projetados no CoMDD é tornar o desenvolvimento de software o mais acessível possível para usuários não desenvolvedores, aproximando o especialista do problema do especialista da solução. Esse é um dos motivos de uso de MDD no lugar de Java, por exemplo. Assim, o principal diferencial entre as abordagens é que enquanto o Galaxy wiki permite o desenvolvimento de código em Java e a integração com o Eclipse, o CoMDD trabalha em um nível de abstração mais elevado e não permite a integração com IDEs.

\section{Cloud 9 IDE}

O Cloud $9 \mathrm{IDE}^{13}$ é uma IDE para Javascript e que funciona na web. Ele incorpora o desenvolvimento como um serviço (Software as a service) e seu código é aberto. O Cloud 9 possui, basicamente, as mesmas funcionalidades que uma IDE normalmente possui, como edição de código fonte com syntax highlight, compilação, debug, versionamento de código usando Github ${ }^{14}$ e outros. O Cloud 9 também possibilita o gerenciamento de projetos e ainda tem um mensageiro de comunicação incorporado, permitindo que os desenvolvedores possam se comunicar em tempo real.

As tecnologias usadas para desenvolver o Cloud 9 são basicamente HTML 5 e Ajax ${ }^{15}$. Segundo seus desenvolvedores, as prioridades do sistema estão entre: facilidade de desenvolvimento para programadores de Javascript, integração entre um repositório local e remoto, teste e deploy do projeto desenvolvido para nuvem e suporte a debug.

Quanto aos aspectos de tornar o desenvolvimento feito na web, o Cloud 9 IDE e o CoMDD são parecidos; entretanto, suas abordagens são distintas. O CoMDD trabalha com modelos,

\footnotetext{
${ }^{12}$ Nesse caso, está se referindo que uma abordagem na wiki usando modelos é mais produtiva do que uma mesma abordagem na wiki mas usando linguagens de programação. Ver vantagens do MDD na Seção 2.1

${ }^{13} \mathrm{http}: / / \mathrm{c} 9$. io

${ }^{14}$ https://github.com/

${ }^{15}$ Asynchronous Javascript and XML
} 
enquanto que o Cloud 9 permite apenas a programação em Javascript e HTML5. O CoMDD usa uma wiki como suporte de desenvolvimento, enquanto que o Cloud 9 é uma aplicação web desenvolvida especificamente para a programação. O CoMDD estimula a colaboração por não desenvolvedores e, por fim, ainda aborda o versionamento de modelos de maneira mais simples.

O CoMDD ainda pode agregar algumas funcionalidades do Cloud 9, pois ele é de código aberto.

\section{WikiReq}

Outro trabalho relativo à colaboração em modelagem de software é o trabalho de Abeti et al. (2009), no qual eles apresentam a WikiReq. Eles desenvolvem seu trabalho em uma plataforma wiki no contexto de gerenciamento de requisitos para Business Process Reengineering (BPR). Eles propõem um framework BPR que formalize o conhecimento empresarial por meio de um conjunto de modelos conectados com os requisitos do software e que também possibilite uma automação parcial da implementação do sistema. Esse framework provê uma wiki, denominada de wiki for Requirements (WikiReq), baseada na plataforma Semantic Mediawiki.

Para a representação do conhecimento, os autores combinam os benefícios de três notações: $\mathrm{Si}^{*}$, diagramas de Casos de Uso em UML e Business Process Management Notation (BPMN). Através da notação $\mathrm{Si}^{*}$, os stakeholders podem definir seus conhecimentos sobre Business Process (BP) e sobre os requisitos do negócio dentro da WikiReq; os diagramas de casos de uso são intuitivos e são os diagramas mais usados por stakeholders e a notação BPMN é uma notação de BP fácil de compreender por todas as empresas interessadas (Abeti et al., 2009).

Para a automação da implementação parcial do sistema, a WikiReq exporta para o Eclipse um conjunto de modelos que são conectados a BMPN e modelos de caso de uso em UML, por meio de um conjunto de plugins.

A partir do início do levantamento de requisitos e dos BPs da empresa adquiridos pelos stakeholders, combinar as funcionalidades da wiki com a modelagem MDA é uma tarefa fundamental para manter a rastreabilidade entre artefatos de sistemas e requisitos. As funcionalidades do MDA automatizam parcialmente o gerenciamento do conhecimento por meio das transformações de modelos (Abeti et al., 2009).

Esse trabalho se assemelha ao CoMDD por se tratar de modelagem em uma wiki, entretanto se diferencia pelo CoMDD usar modelos específicos do domínio e por gerar código fonte completo, além dos métodos dos trabalhos serem diferentes. A principal contribuição desse trabalho para o CoMDD foi o incentivo de uso de wikis. 


\subsection{Considerações Finais}

Este capítulo apresentou o CoMDD como uma abordagem colaborativa de desenvolvimento orientada a modelos, na qual foi implementada usando uma wiki e uma DSL. Também foram apresentadas a arquitetura do CoMDD, suas funcionalidades e parte da sua implementação. Por fim, o CoMDD foi comparado com abordagens e ferramentas existentes, como: Adessowiki, Galaxywiki, Cloud 9 IDE e WikiReq, sendo ressaltados seus diferencias positivos e suas limitações.

No capítulo a seguir o CoMDD é avaliado por três estudos de caso, sendo dois deles comparativos qualitativos do CoMDD com a abordagem tradicional, definida pelo uso do Eclipse com o plugin SVN, e um estudo de caso apenas qualitativo referente ao CoMDD. 


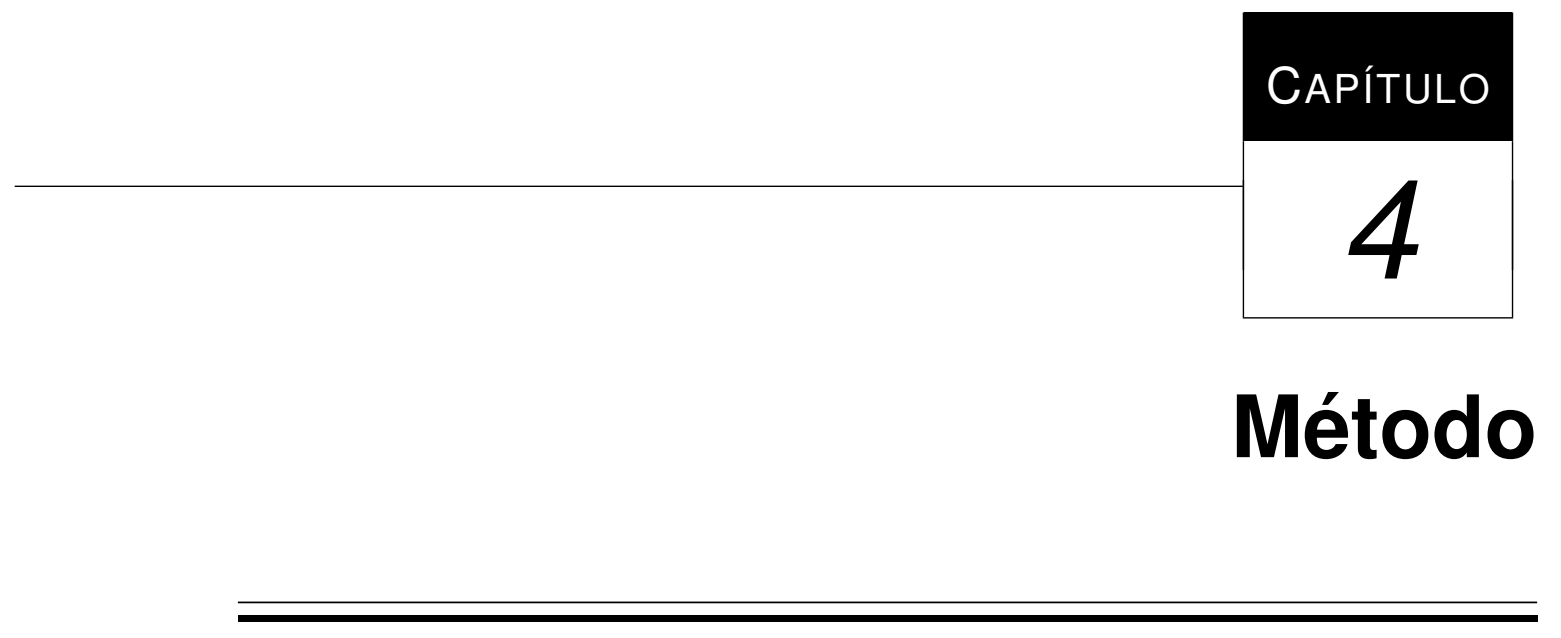

A aceitação de estudos empíricos na engenharia de software está crescendo, pois a pesquisa analítica não é o suficiente para investigar a real complexidade entre humanos e sua interação com a tecnologia (Runeson e Höst, 2009). Dessa forma, este trabalho realiza como método de pesquisa a elaboração e execução de estudos de caso para avaliar o CoMDD de maneira principalmente qualitativa.

Segundo Runeson e Höst (2009), um estudo de caso é um método empírico com o intuito de investigar um fenômeno em um contexto. Estudo de caso, em geral, é definido como uma abordagem qualitativa para coleta de dados acerca de um fenômeno a ser investigado. $\mathrm{O}$ estudo de caso deve ter três fases distintas: o desenvolvimento de um protocolo que norteie o estudo; coleta e análise dos dados e a interpretação desses dados.

Foram realizados três estudos de caso: EC-ND (Estudo de Caso dos Não Desenvolvedores ${ }^{1}$ ), EC-PG (Estudo de Caso dos Pós-Graduandos) e EC-IN (Estudo de Caso de Indústria)².

O EC-ND teve o intuito de avaliar o CoMDD por alunos concluintes do ensino médio. Dessa forma foi possível avaliar o nível de aceitação por não desenvolvedores.

O EC-PG teve a intenção de avaliar o CoMDD por alunos de pós-graduação em Ciências da Computação, e com bacharel também em Ciências da Computação, e que já tivessem uma

\footnotetext{
${ }^{1}$ Lembrando que este trabalho definiu o conceito de não desenvolvedor no Capítulo 1, como sendo a pessoa com poucos ou sem conhecimentos de programação e que está interessada no projeto.

${ }^{2}$ Nas respectivas seções de cada estudo de caso serão apresentados o perfil dos participantes, sendo ND, PG e IN generalizações com o intuito de facilitar a referência aos estudos de caso.
} 
experiência mínima de um ano na indústria ${ }^{3}$. Dessa forma, os resultados do EC-PG teriam uma visão intermediária entre academia e indústria.

Por fim, o EC-IN, teve o objetivo de avaliar o CoMDD principalmente, mas não essencialmente, por desenvolvedores e com experiência de desenvolvimento de software. Dessa maneira, os resultados do EC-IN teriam uma visão que refletisse maior as necessidades e interesses da indústria.

Assim, este trabalho realizou três estudos de caso com o intuito de evidenciar a hipótese de que é possível usar uma wiki para desenvolver um sistema colaborativamente usando MDD. É importante ressaltar que o objetivo do estudo era coletar a opinião dos participantes acerca do CoMDD, para assim poder avaliá-lo qualitativamente. Portanto, não foram definidas métricas de avaliação.

\subsection{Estudo de Caso I - EC-ND}

O objetivo do primeiro estudo de caso foi avaliar o CoMDD por pessoas que não possuíam experiência em desenvolvimento de software. A avaliação consistiu em verificar como os participantes, alunos do ensino médio, sem conhecimentos de programação e sem conhecimentos do domínio, conseguiriam entender os conceitos e a linguagem do CoMDD.

\subsubsection{Descrição dos participantes}

Os participantes desse estudo de caso eram quatro alunos de pré-iniciação científica do Laboratório de Robótica Móvel da Universidade de São Paulo. Eles tinham entre 16 e 17 anos e todos haviam concluído o ensino médio. Já tinham programado para o robô $\mathrm{SRV}^{4}$ com o intuito educacional, usando uma API própria do robô, de simples entendimento. Não possuíam conceitos de algoritmos ou de programação orientada a objetos e por isso foram considerados sem conhecimentos de programação.

\subsubsection{Instruções e Problema Apresentado}

Foram formadas duas equipes com dois integrantes cada uma delas. Cada equipe ficava em um único computador, ou seja, eram dois computadores com duas pessoas em cada um dos computadores. A distribuição foi definida dessa forma para estimular a comunicação e facilitar a resolução do problema. Estima-se que se fosse uma pessoa por computador o estudo iria durar o dobro do tempo, se tornando inviável de conseguir pessoas para participar.

\footnotetext{
${ }^{3}$ Neste trabalho, o termo indústria refere-se à indústria de desenvolvimento de software.

${ }^{4}$ http: //www.surveyor.com/SRV_info.html
} 
Antes de apresentar o comando, foram lidos, junto com os participantes, dois textos, o primeiro explicando o que é o CoMDD (ver Texto I: O que é o CoMDD? no Apêndice B.1) e o segundo texto explicando como usar a DSL criada para o estudo de caso (ver Texto II: Como programar para o CoMDD no Apêndice B.2).

Após a leitura, o seguinte comando foi apresentado:

O código é de um robô que ao receber uma lista de coordenadas deve ser capaz de passar por elas. Seu algoritmo de funcionamento é o seguinte:

Os sensores devem ler a informação

O robô recebe a próxima coordenada

O robô processa a informação

O robô recebe uma regra a aplicar

O robô anda

Esse algoritmo deve ficar sendo executado eternamente, até o robô ser desligado.

Agora você deve a partir do algoritmo e das explicações no site ser capaz de escrever um código usando a linguagem do CoMDD.

Requisitos:

O robô deve ser da plataforma pionner

O robô deve usar os pacotes de localização e os pacotes do player

O robô deve usar um gps e uma bússola

O robô deve seguir um conjunto de coordenadas

O tempo entre o momento que o pesquisador começou a falar com os participantes até o final do estudo foi de aproximadamente $2 \mathrm{~h} 45$. Este tempo inclui a instrução do pesquisador aos participantes, a resolução do problema e a avaliação feita pelos participantes.

\subsubsection{Resultados}

A partir do problema apresentado, esperava-se que as esquipes conseguissem apresentar algo parecido com o seguinte modelo: 


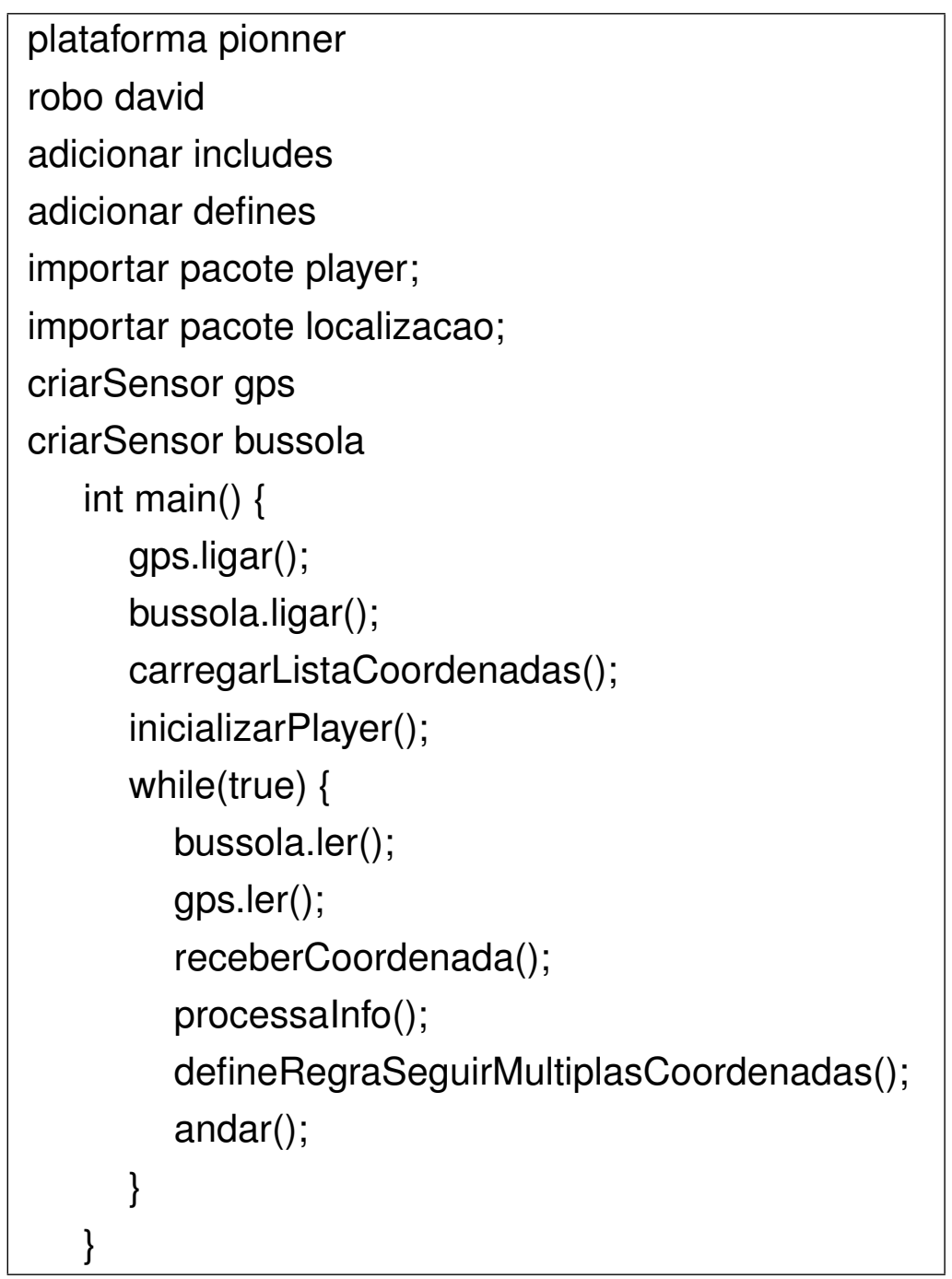

Resultados da equipe A A equipe A apresentou a seguinte resposta, observando que a identação apresentada é proporcional à original: 


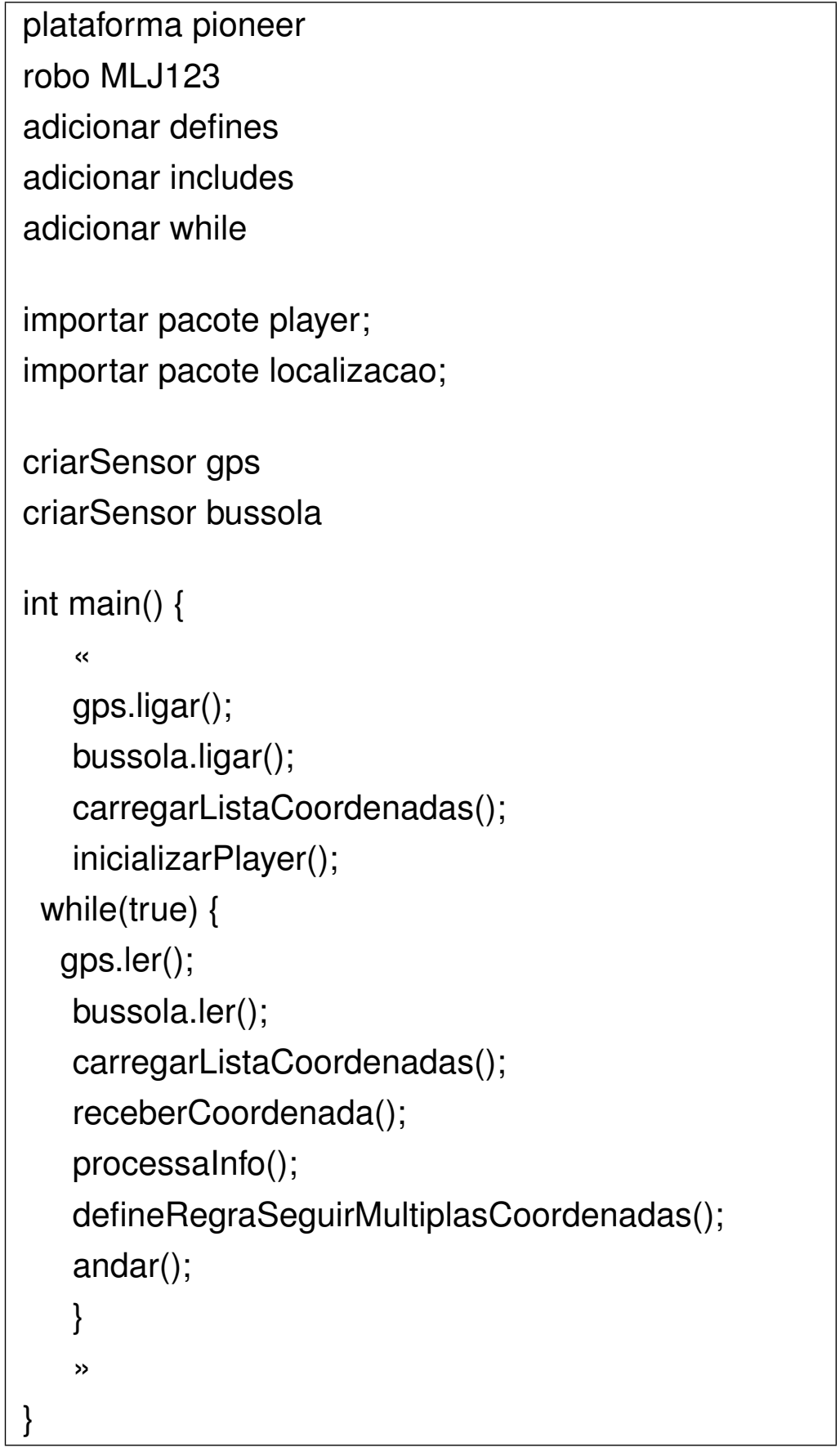

Resultado da equipe B A equipe B apresentou a seguinte resposta, observando que a identação apresentada é proporcional à original: 


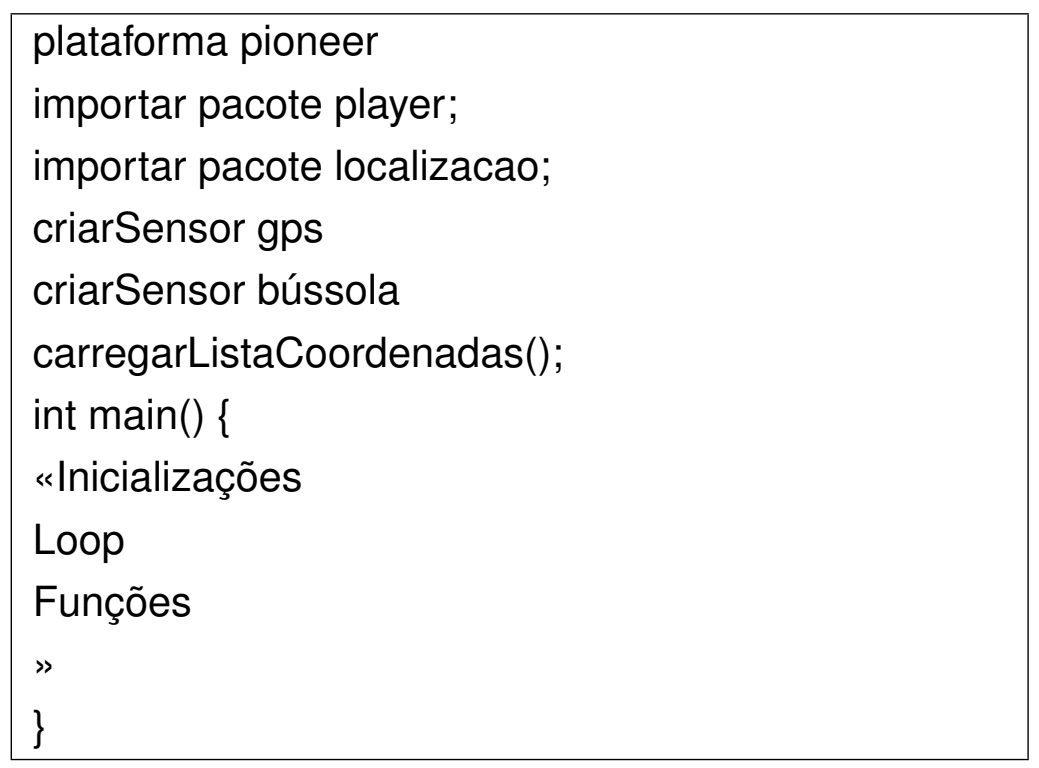

\subsubsection{Opiniões dos participantes}

Prós: A linguagem é fácil de entender e o fato de ser em português facilita.

Contras: Foi mais complicado entender as instruções do problema do que a linguagem; ficou confusa a função carregarListaCoordenadas().

\subsubsection{Observações do EC-ND}

A seguir, as observações do primeiro estudo de caso realizado:

1. O estudo foi transmitido a distância, por vídeo-conferência e com a ajuda de um aluno de doutorado do LRM que acompanhou os participantes e auxiliou o grupo A, enquanto o pesquisador auxiliava o grupo B. Não se pode precisar quanto foi o auxílio que o grupo A recebeu;

2. Os participantes tinham dificuldade ou preguiça de lerem o texto que ensinava como programar para o CoMDD (B.2)

3. O grupo A leu uma segunda vez o texto II (Como programar para o CoMDD no Apêndice B.2);

4. O grupo A teve melhores resultados que o grupo B. Os resultados do grupo A foram considerados corretos, enquanto que os do grupo B foram considerados incorretos;

5. Os grupos, principalmente o grupo $\mathrm{B}$, tinham o hábito de perguntarem constantemente se o que faziam estava certo e

6. Os participantes copiavam do texto II (Como programar para o CoMDD no Apêndice B.2) e colavam na página de edição. 


\subsubsection{Lições aprendidas}

Como aprendizado do EC-ND, tem-se:

1. Organizar melhor a infra estrutura: verificar quantos computadores serão necessários; se a comunicação for on-line, preparar os softwares necessários e orientar bem uma pessoa que possa ajudar e que esteja presente com os participantes. No caso desse estudo de caso houve um mal planejamento da infra estrutura e da orientação ao ajudante;

2. Para um estudo de caso desse tipo, o ideal é evitar ajudar os participantes após passar o problema. Dessa forma, tem-se uma visão mais real de como os não desenvolvedores se comportariam com o CoMDD. Os participantes estiveram muito dependentes do pesquisador e estima-se quatro hipóteses não excludentes que expliquem essa dependência: (i) relativa baixa instrução dos participantes, (ii) ruídos provocados pela distância, (iii) mal planejamento ou instrução por parte do pesquisador e/ou (iv) a disposição do pesquisador para tirar dúvidas.

\subsection{Estudo de Caso II - EC-PG}

O objetivo do segundo estudo de caso foi avaliar comparativamente, entre desenvolvedores, o CoMDD com a abordagem tradicional. A avaliação consiste na coleta de opiniões por parte desses usuários. Nesse caso, a abordagem tradicional é definida pelo uso do Eclipse com o plugin SVN instalado e será referenciada por "Eclipse+SVN".

Para realizar esse estudo de caso foi implementado para o Eclipse a mesma linguagem usada no CoMDD, ou seja, cada equipe teria que programar usando a mesma linguagem, entretanto uma equipe usaria o Eclipse+SVN para isso e a outra equipe usaria o CoMDD. Para implementar a linguagem do CoMDD no Eclipse foi usado o Xtext ${ }^{5}$ para definir a linguagem, e o Xpand $^{6}$ para definir as transformações.

\subsubsection{Descrição dos participantes}

Todos os quatro participantes são formados em Ciências da Computação, atuaram na indústria desenvolvendo sistemas e estão cursando mestrado ou doutorado na Universidade de São Paulo em Ciências da Computação.

\footnotetext{
${ }^{5}$ http://www.eclipse.org/Xtext/

${ }^{6} \mathrm{http}: / /$ wiki.eclipse.org/Xpand
} 


\subsubsection{Instruções e Problema Apresentado}

Os quatro integrantes foram divididos em duas equipes: equipe A (usando o CoMDD) e equipe B (usando Eclipse+SVN). Ambos integrantes de cada equipe estavam em locais (mais especificamente cidades) diferentes no momento da avaliação do CoMDD. A equipe A realizou a avaliação em um dia diferente da equipe B. O problema foi apresentado aos participantes por um software de conferência por voz $\left(\mathrm{Skype}^{7}\right)$.

Antes de apresentar o problema, ambos grupos receberam instruções comuns e instruções específicas. As instruções comuns foram:

1. Ler o texto base. O texto base da equipe A é o Texto I: O que é o CoMDD? (ver Apêndice B.1) e da equipe B é o Texto III: Instalação do Eclipse+SVN e importação da DSL (ver Apêndice B.3);

2. Ler o Texto II: Como programar para o CoMDD (ver Apêndice B.2);

3. Pode-se comentar na edição do modelo usando "//";

4. A função carregarListaCoordenadas() já está configurada para a lista de coordenadas, dessa forma vocês não devem se preocupar em passar um lista de coordenadas, apenas chamar a função;

5. O desenvolvimento é feito em turnos e em cada turno apenas um desenvolvedor pode trabalhar no código (editá-lo), para evitar conflitos e merges. Cada turno tem três minutos para desenvolver e mais dois minuto para comentar no CoMDD (equipe A) ou fazer o commit (equipe B). Por exemplo:

0'-3': O desenvolvedor 1 começa programando enquanto o desenvolvedor 2 fica esperando (enquanto isso, os desenvolvedores podem se comunicar via email ou gtalk);

3'01s - 5': o desenvolvedor 1 tem de salvar suas alterações e comentar o código caso ache necessário;

5'01s - 6': ninguém faz nada para que o servidor atualize os dados;

6'01s-9': o desenvolvedor 2 assume o comando de edição do código e o desenvolvedor 1 fica aguardando ou conversando via e-mail ou gtalk com o desenvolvedor 2 caso este precise;

9'01s-11': o desenvolvedor 2 tem de salvar suas alterações e comentar o código caso ache necessário;

11'01s-14': o ciclo se repete

O seguinte comando foi apresentado:

\footnotetext{
${ }^{7}$ http://www.skype.com
} 
O código é de um robô que ao receber uma lista de coordenadas deve ser capaz de passar por elas. Seu algoritmo de funcionamento é o seguinte:

Os sensores devem ler a informação

O robô recebe a próxima coordenada

O robô processa a informação

O robô recebe uma regra a aplicar, de acordo com os requisitos

O robô atua no ambiente

Esse algoritmo deve ficar sendo executado eternamente, até o robô ser desligado.

Agora vocês devem a partir do algoritmo e das explicações no site serem capazes de escrever um código usando a linguagem do CoMDD.

Requisitos:

O robô deve ser da plataforma pionner

Dev1

O nome do robô deve ser uma concatenação dos nomes dos desenvolvedores-

- Dev2

O robô deve usar os pacotes de localização

Dev1

O robô deve usar os pacotes do player

Dev2

O robô deve usar um gps

Dev1

O robô deve usar uma bússola-

Dev2

O robô seguir um conjunto de coordenadas

Dev1 +

Dev2

\subsubsection{Equipe A: CoMDD}

Além das instruções comuns apresentadas na Seção 4.3.2, para equipe A foram apresentadas as seguintes instruções:

1. Pode-se usar todas as funcionalidades da wiki como comentários, histórico e comparação de versões ${ }^{8}$ e

\footnotetext{
${ }^{8} \mathrm{Um}$ exemplo de edição normal (sem ser usando a DSL) foi apresentado para que os participantes pudessem saber como e onde editar, comentar e comparar versões.
} 
2. Dar preferência para comunicação que a própria wiki fornece, que são os comentários de página, caso contrário usar um mensageiro instantâneo ou o e-mail e depois fornecer a conversa para o pesquisador.

\subsubsection{Equipe B: Eclipse+SVN}

Além das instruções comuns apresentadas na Seção 4.3.2, para equipe B foram apresentadas as seguintes instruções:

1. Pode-se usar todas as funcionalidades do plugin SVN como check-in/check-out, comentários, histórico e comparação de versões ${ }^{9}$;

2. Dar preferência para comunicação que o próprio SVN fornece, que são os comentários do check-in/check-out e informações do histórico, caso contrário usar um mensageiro instantâneo ou o e-mail e depois fornecer a conversa para o pesquisador e

3. Não usar as funções comuns de uma IDE como highlight, autocomplete, etc ${ }^{10}$.

\subsubsection{Resultados}

A resposta considerada correta é a mesma apresentada na Seção 4.1.3.

Resultados da Equipe A O pesquisador acompanhou a equipe e foi responsável por informar quando um desenvolvedor devia editar ou esperar, para evitar conflitos de edição; contudo, o tempo apresentado nas instruções não foi rígido. A equipe A apresentou a seguinte resposta:

\footnotetext{
${ }^{9}$ Os participantes já conheciam o plugin.

${ }^{10} \mathrm{O}$ Eclipse tem um ambiente que não possui as funcionalidades citadas, como highlight e autocomplete, assim as equipes ficam mais próximas do mesmo ambiente de edição de modelos, uma vez que no CoMDD essas funcionalidades não foram implementadas.
} 


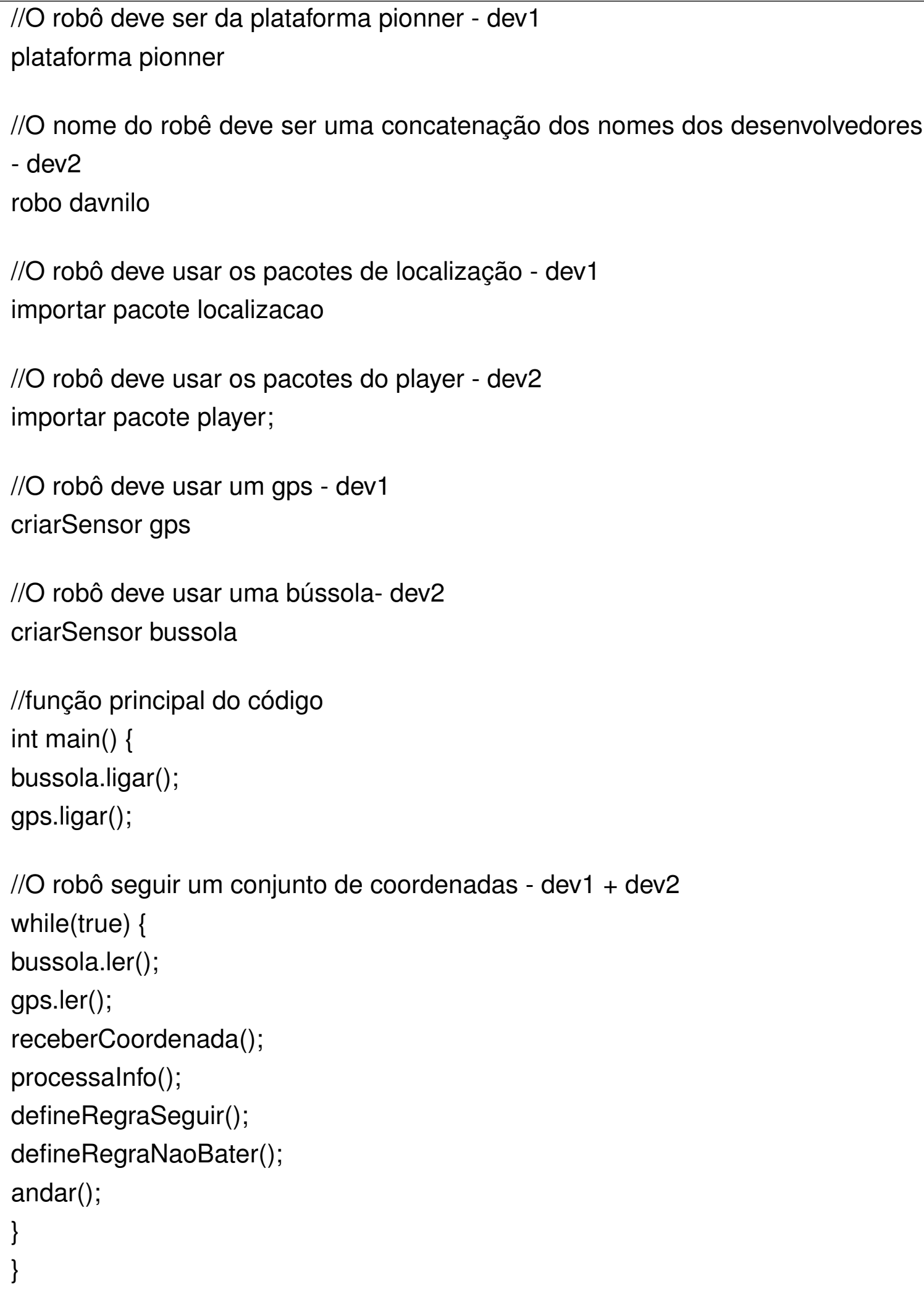

A Figura 4.1 registra a comunicação realizada pelo grupo. O grupo usou os comentários da página de edição e não usou os comentários de versões. Observando a Figura 4.1, pode-se dizer que o grupo usou esse comentário como um mensageira instantâneo. 


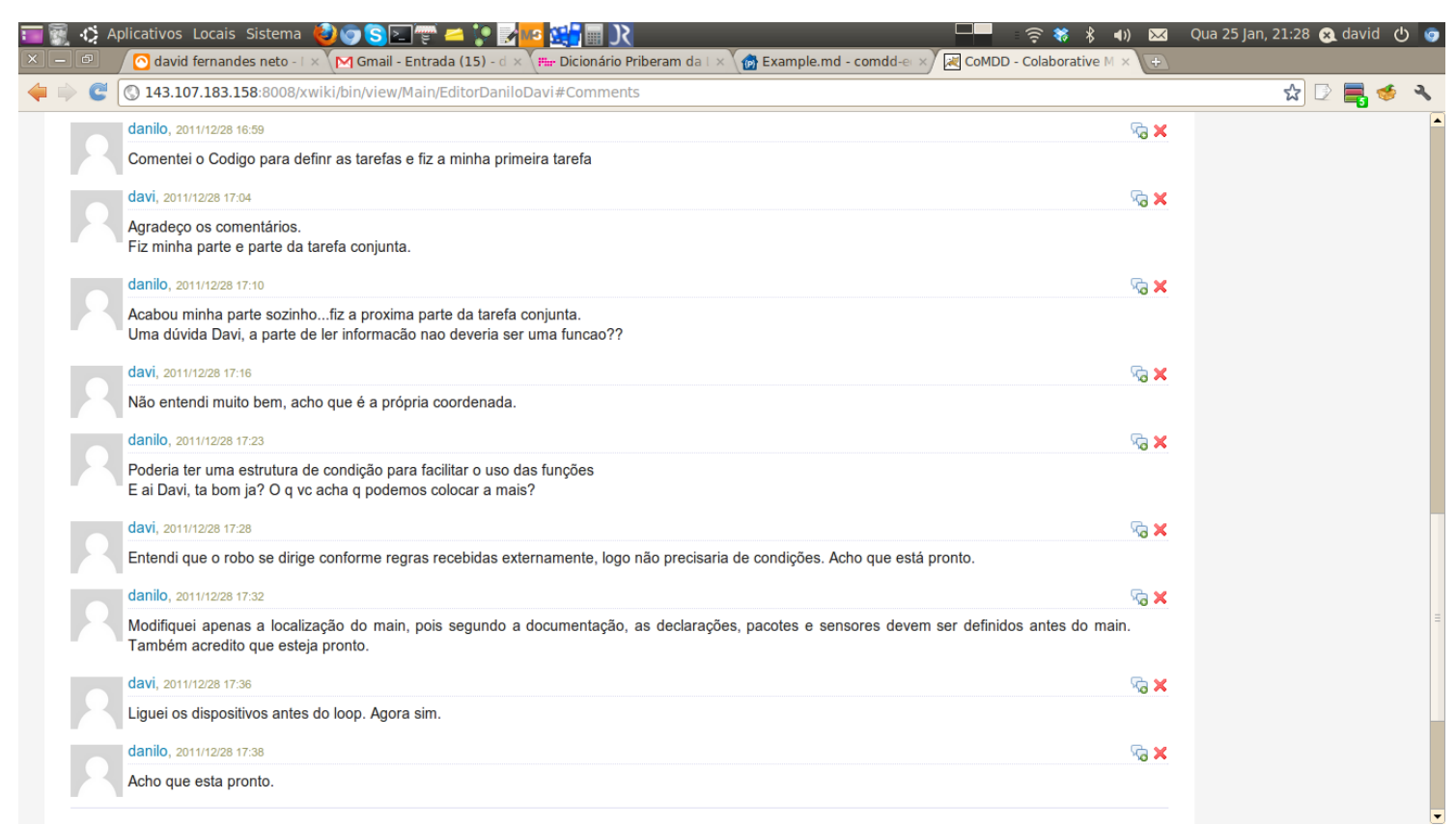

Figura 4.1: $\log$ da conversa entre o desenvolvedor 1 e o desenvolvedor 2

Resultados da Equipe B O pesquisador acompanhou a equipe e foi responsável por informar quando um desenvolvedor devia editar ou esperar, para evitar conflitos de edição; contudo, o tempo apresentado nas instruções não foi rígido. A equipe B apresentou a seguinte resposta: 


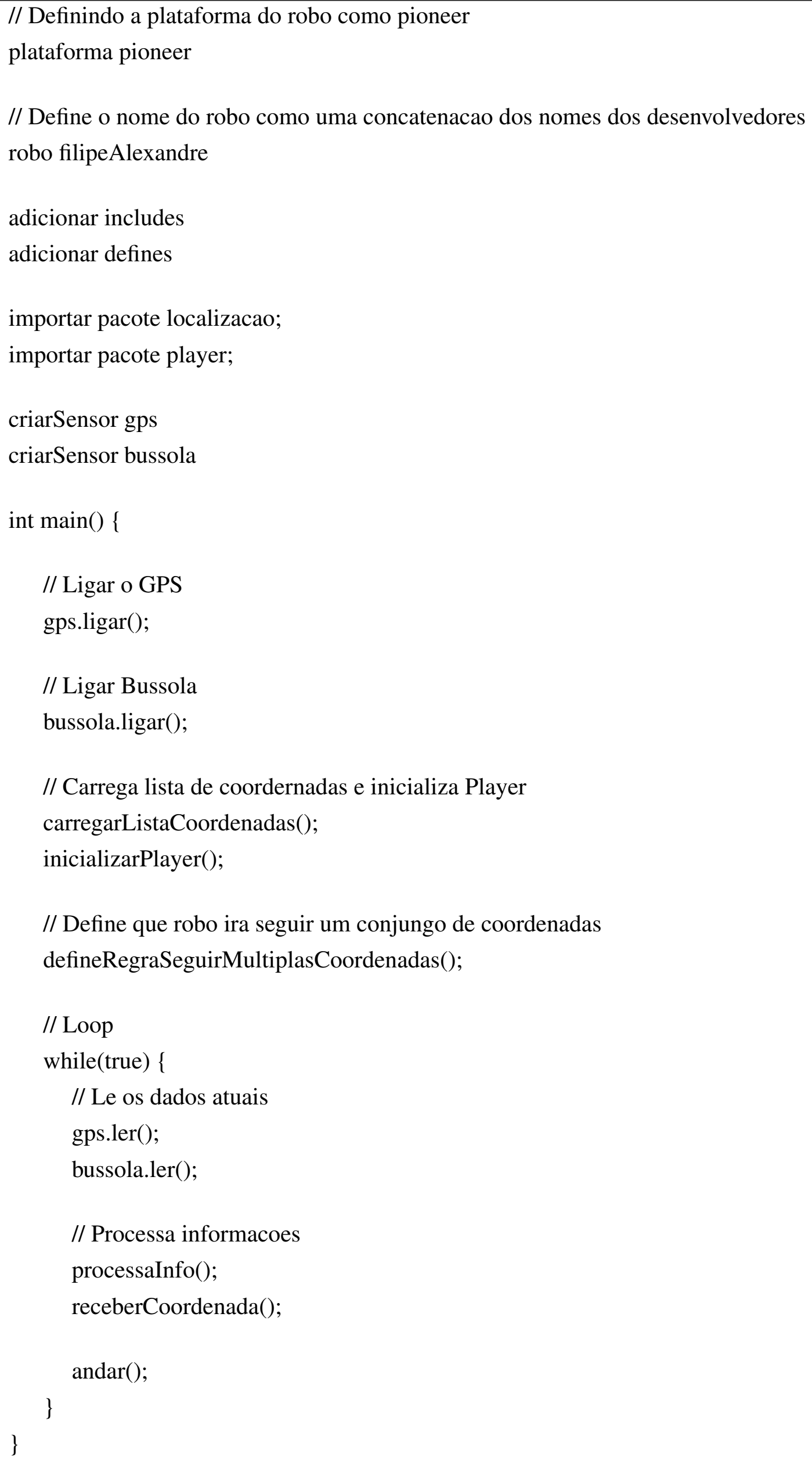




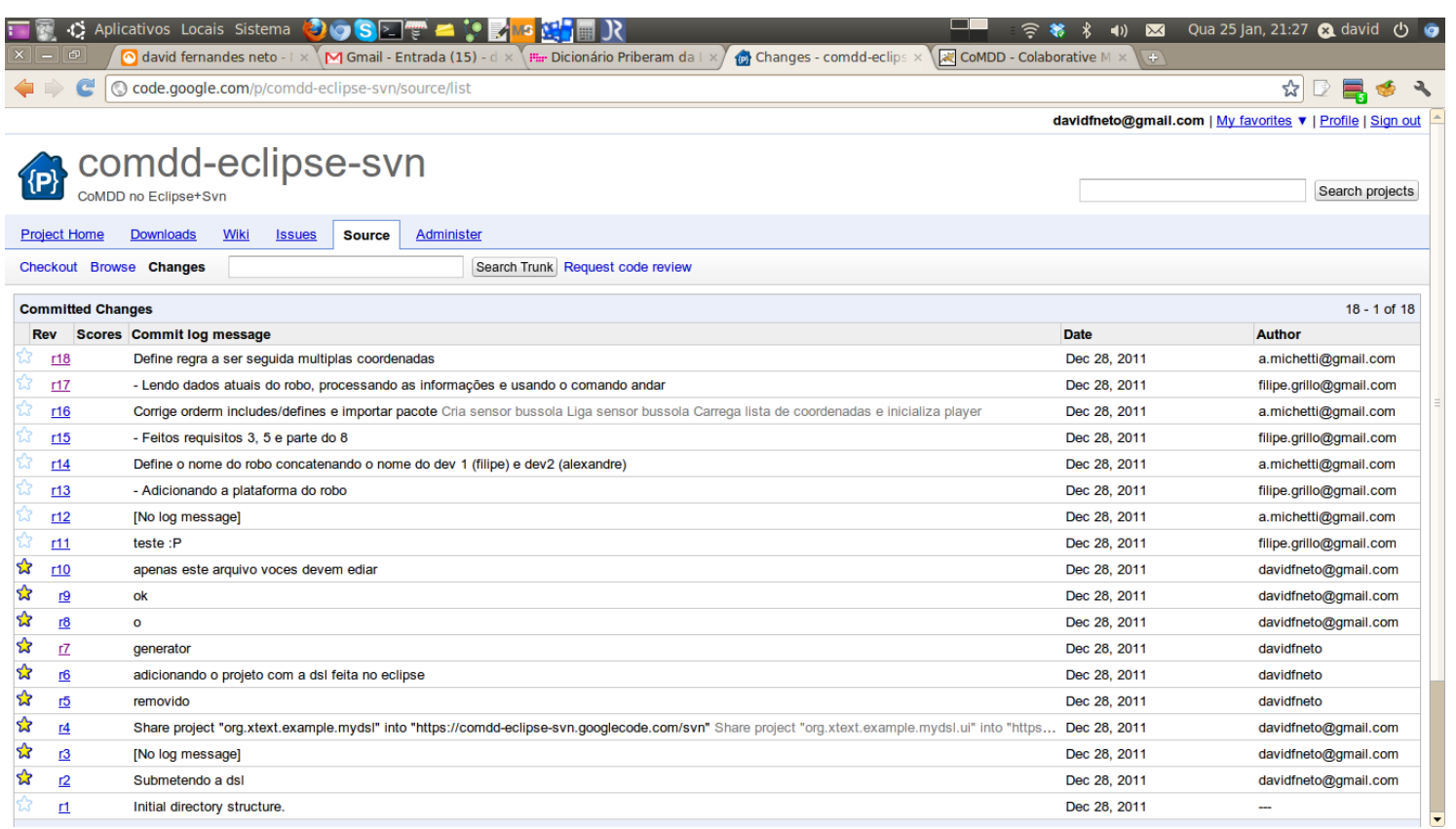

Figura 4.2: Log da conversa entre o desenvolvedor 1 e o desenvolvedor 2

A Figura 4.2 registra a comunicação realizada pelo grupo. O grupo usou os comentários do check-in do SVN (mas não como uma espécie de conversa, como foi feito pelo grupo A). Quando o grupo estava terminando de resolver o problema apresentado, passaram a se comunicar usando um mensageiro instantâneo. O log da conversa é apresentado no Apêndice C.

Depois de terminarem a tarefa, a equipe B foi apresentada ao CoMDD e então foi questionada pelo pesquisador.

\subsubsection{Opiniões dos Participantes e Observações do Pesquisa- dor}

Serão apresentadas as opiniões dos participantes juntamente com as observações do pesquisador.

Equipe A Quando os participantes da equipe A foram questionados sobre a linguagem usada, eles responderam que precisava melhorar aspectos pontuais como deixar toda em inglês ou em português, mas que era fácil de aprender. Em relação aos comentários que a wiki propicia, eles são úteis, mas sentiram falta de um mensageiro instantâneo.

De uma maneira geral, a equipe usaria a abordagem CoMDD, principalmente pela facilidade de edição, flexibilidade e independência de softwares instalados. Eles acham a necessidade de instalar programas como IDEs e SVNs algo trabalhoso. Entretanto, sentiram falta do processo de compilação, sendo essa a maior barreira apontada pela equipe A para usar o CoMDD. 
A equipe A usou os comentários da página de edição, mas não os comentários de versionamento e comentaram no modelo. A comparação de modelos não foi necessária.

No Apêndice D é apresentado o questionário apresentado à Equipe A, com as respostas coletadas pelo pesquisador.

Equipe B Quando os participantes da equipe B foram questionados sobre a linguagem usada, eles responderam que era fácil e simples, com poucos comandos e com uma curva de aprendizagem rápida, mas que a parte dos includes estava confusa. Em relação aos comentários que o SVN propicia, eles não foram úteis, pois o problema apresentado era simples e, por isso, apenas os comentários no código e o diálogo no instant messanger era o suficiente.

De uma maneira geral, a equipe aprovaria o uso do CoMDD para um projeto de pequeno porte e apontaram como a "familiaridade"a maior barreira para usar o CoMDD, pois os desenvolvedores estão habituados com o uso de IDEs e SVNs.

A equipe B usou o check-in/check-out e comentaram no modelo. A comparação de modelos não foi necessária.

No Apêndice D é apresentado o questionário apresentado à Equipe B, com as respostas coletadas pelo pesquisador.

\subsubsection{Observações do EC-PG}

A seguir, algumas observações do segundo estudo de caso realizado:

1. Os comentários ao longo do modelo foram importantes para permitir que duas pessoas editassem a mesma classe, podendo separar as atividades de cada um;

2. A equipe B usou um mensageiro instantâneo quando estavam terminando de resolver o problema para concluírem se já haviam terminado de resolver o problema ou não;

3. Com a wiki, foi mais fácil e simples dos participantes colaborarem.

\subsubsection{Lições aprendidas}

O EC-PG possibilitou uma análise qualitativa inicial das duas abordagens; contudo, foi necessário esforço para reunir pessoas que estivessem dispostas a realizar um estudo de caso que durasse em torno de duas e três horas; preparar o estudo e acompanhar cada uma das equipes durante a execução.

A partir dessas observações, surgiu a ideia de fazer dois vídeos: um apresentando o CoMDD e o outro apresentando o Eclipse+SVN. Esses vídeos seriam transmitidos para desenvolvedores da indústria, preferencialmente, e seriam acompanhados de um questionário. Assim, 
além de um estudo qualitativo, seria possível um estudo quantitativo. Esse foi o princípio para condução do terceiro estudo de caso, descrito a seguir.

\subsection{Estudo de caso III - EC-IN}

Os objetivos do terceiro estudo de caso são os mesmos dos objetivos do segundo estudo de caso: avaliar comparativamente, entre desenvolvedores o CoMDD com a abordagem tradicional. Entretanto, enquanto o segundo estudo de caso teve um caráter qualitativo, o terceiro estudo de caso tem um caráter também quantitativo. A avaliação também consiste na coleta de opiniões por parte desses usuários.

\subsubsection{Descrição dos participantes}

O EC-IN teve a participação de 48 pessoas, sendo que $92 \%$ delas eram formadas em algum curso de computação, $81 \%$ já fizeram ou faziam mestrado/doutorado, $98 \%$ já desenvolveram sistemas em equipe, $92 \%$ já trabalharam ou trabalham em empresas e $79 \%$ dos participantes já trabalharam ou trabalhavam com uma IDE associada a um programa de versionamento. A média de experiência em anos por participante é de 8.37 e a moda é de 8 anos. A Figura 4.3 apresenta o número de pessoas pelo tempo em que elas programam em anos.

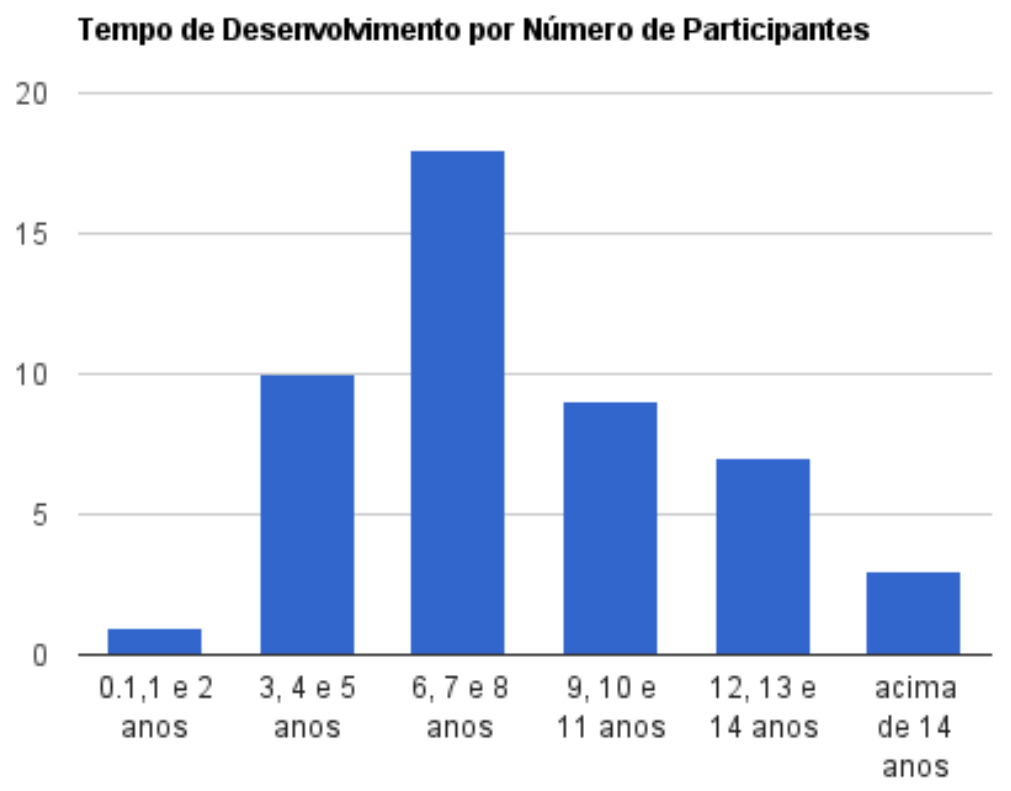

Figura 4.3: Experiência em programação dos participantes em anos por quantidade de participantes. 


\subsubsection{Instruções e Problema Apresentado}

Foram apresentados dois vídeos para cada participante. Um vídeo do CoMDD realizando as atividades de edição de modelos com comentário da versão de alteração, comentário na página de edição, comparação entre modelos, retorno para uma versão anterior do modelo e geração de código ${ }^{11}$. No outro vídeo, foram feitas as mesmas atividades, mas no contexto do Eclipse+SVN ${ }^{12}$. Por fim, foi apresentado um questionário.

No Apêndice E está o email enviado solicitando a participação dos desenvolvedores, bem como todas as perguntas feitas aos participantes.

\subsubsection{Resultados do EC-IN}

Quando os participantes foram questionados sobre qual era o mecanismo de colaboração que eles tinham/tiveram na sua empresa ou na sua equipe de desenvolvimento, ou seja, como eles colaboram na resolução de problemas, foram definidos nove itens a partir das respostas e que assim as classificariam $^{13}$. São os nove itens:

1. Reuniões:são discussões ou conversas, informais ou não, para solucionar um problema, esclarecer uma dúvida ou distribuir tarefas;

2. Divisão de tarefas: quando há um planejamento do que será feito pela equipe ou por um gerente e então cada membro é responsável por uma tarefa;

3. Sistema de versionamento: quando mencionavam algum programa de versionamento;

4. Email: ou lista de email;

5. Bugger tracker ou issue tracker;

6. Quadro branco;

7. Programação/Revisão em pares;

8. Wiki;

9. Skype.

Essas foram as palavras e/ou expressões mais citadas pelos participantes. Dessa forma, levantou-se o gráfico apresentado na Figura 4.4.

\footnotetext{
${ }^{11}$ http://vimeo.com/36209527

${ }^{12}$ http: //vimeo.com/36206167

${ }^{13} \mathrm{~A}$ análise dos resultados foi feita a partir da leitura e interpretação das respostas subjetivas, de modo que possibilitasse o agrupamento dos dados e assim extrair uma possível informação. Por exemplo, dada a pergunta "Que tipo de colaboração você tem/teve na sua empresa ou na sua equipe de desenvolvimento. Ou seja, como vocês colaboram na resolução de problemas?"um participante respondeu: "Nas empresas que trabalhei não havia nenhuma metodologia definida de engenharia de software. Nós programávamos individualmente nas máquinas e assim a colaboração geralmente eram em conversas informais". Esta resposta foi classificada como "Reunião".
} 
Formas de Colaboração Citadas por Número de Participantes

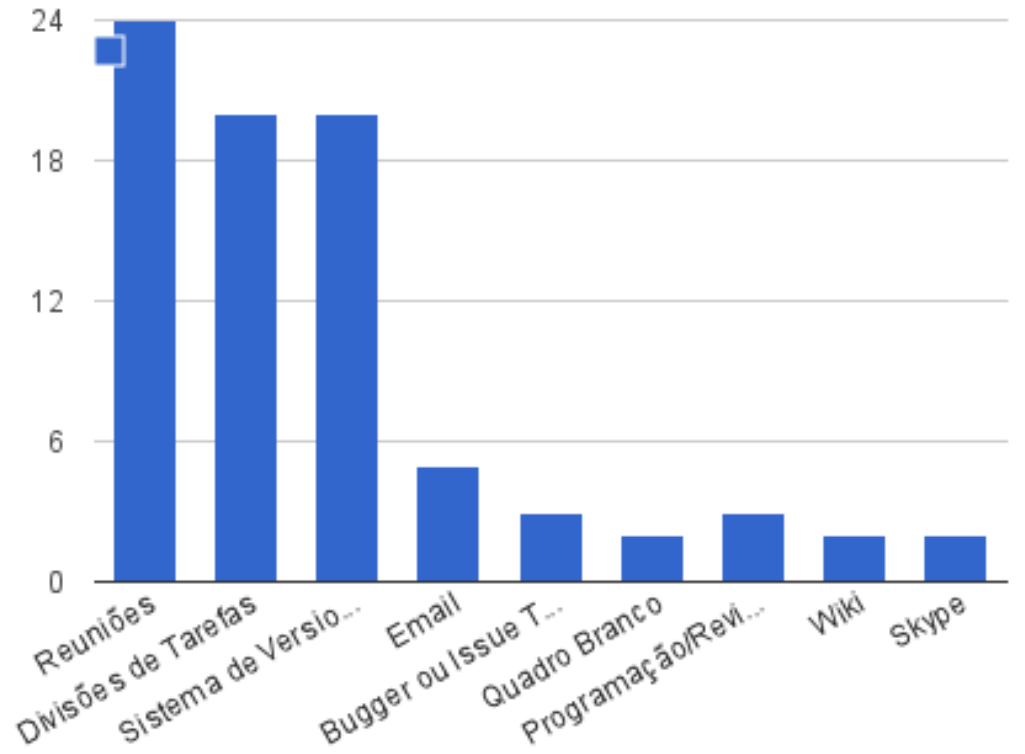

Figura 4.4: Formas de colaboração citadas.

Quando os participantes foram questionados quais funcionalidades de uma ferramenta de versionamento eles achavam mais importante e/ou quais funcionalidades eles mais usavam, foram levantadas seis funcionalidades ${ }^{14}$ (ver Figura 4.5):

1. Rollback: capacidade de reverter um artefato para uma versão anterior;

2. Histórico: ou log de versões, com o intuito de controlar alterações, engloba todas as informações de um commit, como data, autor, comentário etc;

3. Comparação de versões;

4. Mesclagem ou resolução automática de conflitos;

5. Criação de branches;

6. Integração com outras ferramentas, como IDEs, por exemplo.

Quando os participantes foram questionados se usariam o CoMDD no lugar do Eclipse+SVN, algumas respostas foram expressamente sim ou não; entretanto, outras tiveram que ser interpretadas se o participante usaria ou não. Dessa forma, 42,22\% (19 de 45 respostas válidas) usariam o CoMDD, com ou sem restrições para seu uso e 35,55\% não usariam (16 de 45).

Não foi subentendido nada de uma resposta, ou seja, se o participante citasse divisão de tarefas, mas não citasse reuniões ou diálogos ou mencionasse que havia conversas entre os líderes e desenvolvedores, a resposta era classificada apenas como "Divisão de tarefas"e não "Reunião".

${ }^{14}$ Apenas 25 participantes citaram check-in/check-out e, por isso, essa funcionalidade foi descartada, pois provavelmente os participantes acharam que essa funcionalidade já estava implícita, visto que dificilmente alguém que compara versões não irá fazer check-in ou não tenha feito check-out 


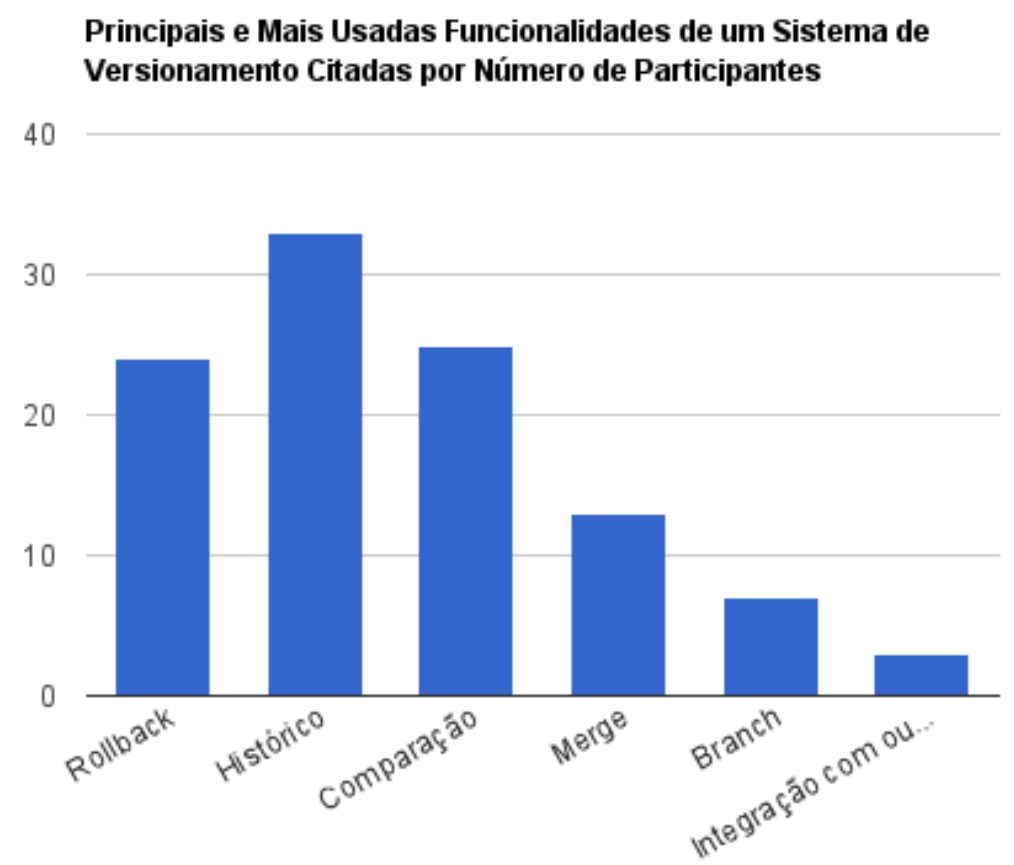

Figura 4.5: Principais e mais usadas funcionalidades de um sistema de versionamento citadas.

Ou seja, entre os $42,22 \%$ que disseram que usariam o CoMDD, alguns deles disseram que precisava melhorar em alguns aspectos, assim como, entre os 35,55\% dos que disseram que não usariam o CoMDD, disseram que não usariam por alguns aspectos.

Esses aspectos foram definidos como as barreiras para uso do CoMDD. A Figura 4.6 apresenta essas barreiras citadas pelos participantes.

Quando os participantes foram questionados se o CoMDD seria capaz de suprir suas necessidades em termos de ferramenta de versionamento, $74 \%$ dos participantes disseram que sim; e 72\% dos participantes afirmaram que levando em consideração que o CoMDD é um protótipo e não uma ferramenta de produção, ele atende aos propósitos que o Eclipse+SVN traz em termos de desenvolvimento de software e compartilhamento. Se o CoMDD tivesse syntax highligth e autocomplete, $77 \%$ dos participantes o usariam satisfeitos e $12 \%$ usariam, mas insatisfeitos em termos de versionamento, o que indica que syntax highligth e autocomplete são elementos muito importantes nas IDEs.

Dentre os participantes, $84 \%$ dos participantes não viam como uma barreira ter que instalar softwares para desenvolver; entretanto, quando questionados se isso seria uma barreira para um não desenvolvedor, $86 \%$ disseram que sim.

Quando os participantes foram questionados se usariam o CoMDD para desenvolver usando modelos, o qual é o propósito do CoMDD e não desenvolver usando código fonte, $86 \%$ dos participantes disseram que usariam; 72\% dos participantes acham o CoMDD uma abordagem mais fácil e simples de usar e levando em consideração que o CoMDD é um protótipo 
Principais Barreiras Para o Uso do CoMDD Citadas por Número de Participantes

8

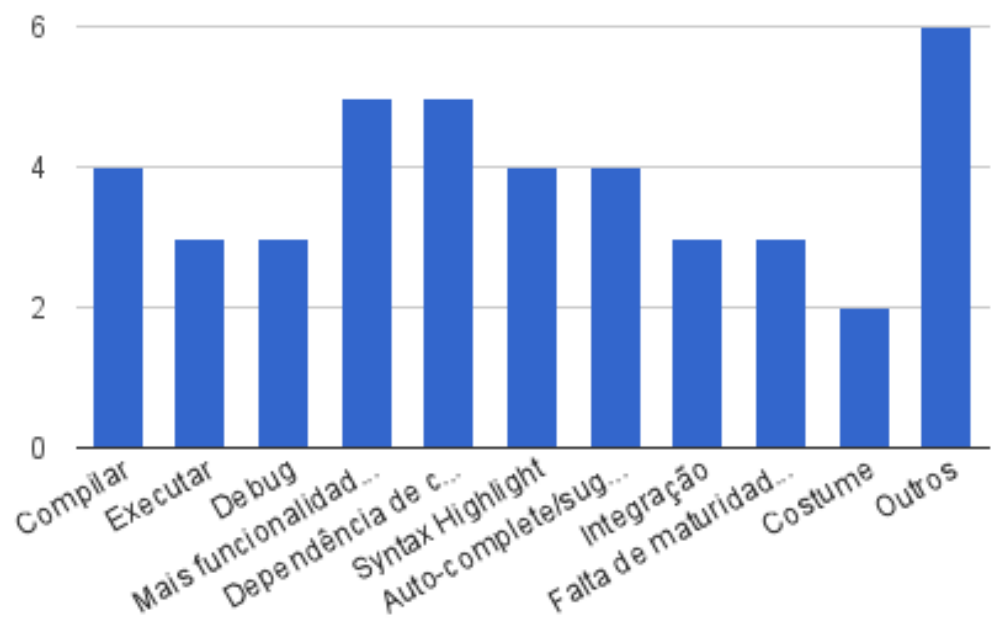

Figura 4.6: Principais barreiras para o uso do CoMDD citadas.

e não uma ferramenta de produção, $84 \%$ dos participantes acham que o CoMDD traria produtividade no desenvolvimento de software em uma equipe.

\subsubsection{Opiniões dos Participantes}

Serão apresentadas algumas opiniões dos participantes, sendo que cada item é de um participante selecionado:

- "Talvez aumentaria a produtividade de equipes formadas por desenvolvedores com pouca experiência que não utilizam todos os recursos das ferramentas já disponíveis";

- "Acredito que a ferramenta não seja adequada/ideal para o desenvolvimento de sistemas em geral, mas com algumas melhorias poderia ser muito útil na área de ensino de programação, no desenvolvimento em pares (ex: XP), desenvolvimento de exemplos/snippets e na resolução de alguns bugs mais chatos por uma equipe. No caso de equipes separadas geograficamente, os ganhos seriam ainda maiores. O motivo é que desenvolvedores costumam possuir gosto muito variado pelas ferramentas, e dificilmente uma equipe completa vai se sentir a vontade utilizando uma única ferramenta para o desenvolvimento, fazendo a produtividade cair. Mesmo dentro de uma mesma ferramenta ou ambiente, é muito comum um alto grau de customização pessoal, que não seria possível nesse caso";

- "Acho mais proveitoso incorporar o CoMDD a uma IDE do que fazer com que ele se comporte como uma"; 
- "Parabéns pelo trabalho e principalmente pela implementação e pela preocupação em saber o que os desenvolvedores pensam sobre a sua abordagem. Com certeza enriquece muito um trabalho de pesquisa. Mesmo que seja um protótipo, você consegue provar que muito da teoria pode ser aplicada";

- "O seu trabalho tem tudo a ver com um dos itens do manifesto ágil: Indivíduos e interação entre eles mais que processos e ferramentas. Mesmo utilizando uma ferramenta de ES vc consegue de diversas formas promover a colaboração entre os desenvolvedores o que é muito importante";

- "Usabilidade bastante agradável o que facilita na aceitação de uma nova ferramenta";

- "Se a equipe for muito grande, talvez a wiki não seja adequada para o desenvolvimento. Como a wiki se comporta quando mais de um usuário tenta alterar os mesmo código ao mesmo tempo?";

- "Acho que a comparação entre o CoMDD e o Eclipse/SVN não é justa. Cada uma tem suas vantagens e desvantagens. SVN e Eclipse já vem sendo usados com sucesso há muito tempo, e não precisam de melhorias, pois já fazem muito bem aquilo a que se propõem. Já o uso de uma wiki pode ser uma tendência futura. Talvez com a evolução do software em nuvem leve a uma aplicação tão poderosa quanto o Eclipse. Outra questão que não entendi muito bem é essa parte da geração de código. Os vídeos não explicam isso direito, nem no CoMDD e nem no Eclipse/SVN".

\subsection{Conclusões dos Estudos de Caso}

As seguintes conclusões foram extraídas do EC-ND:

1. Ao observar as equipes, estima-se a necessidade de pelo menos duas horas adicionais para que elas aprendessem a usar e instalar o Eclipse e SVN;

2. Apenas um dos grupos conseguiu atingir o resultado esperado e

3. Era esperado que os participantes, mesmo sem conhecimento de programação, tivessem mais facilidade em aprender a linguagem.

As seguintes conclusões foram extraídas do EC-PG:

1. Ambas equipes conseguiram chegar na resposta correta, entretanto a equipe A com menos esforços por não precisarem instalar ferramentas locais;

2. A equipe A usou os comentários da página de edição para se comunicarem como se fosse um instant messanger. Através desses comentários, cada integrante da equipe estava ciente do que o outro estava fazendo e puderam compartilhar conhecimento para resolver a tarefa, compartilhando dúvidas e conclusões. Essa comunicação ficou registrada na página do modelo, o que pode ser útil para documentação; 
3. Um ponto positivo do SVN é que ele "obriga"que o usuário comente ao fazer o checkin; entretanto, a leitura dos comentários da wiki é mais simples;

4. Para o problema dado, desconsiderando os recursos de uma IDE, os quatro participantes das duas equipes afirmam que usariam o CoMDD no lugar do Eclipse+SVN e

5. Os quatro participantes das duas equipes concordaram que o CoMDD é melhor para usuários não desenvolvedores do que o Eclipse+SVN.

Por fim, a partir do EC-IN foram extraídas as seguintes conclusões:

1. Os sistemas de versionamento são mais usados do que wikis para colaborar; contudo, acredita-se que se uma wiki pode ser usada para desenvolvimento, ela será muito mais usada para compartilhar e versionar artefatos de implementação (ver Figura 4.4);

2. Ver o histórico e comparar códigos são as tarefas mais usadas em versionadores, funcionalidades que o CoMDD atende;

3. Os usuários ainda sentem falta de um ambiente mais estilo de IDE, por isso que as principais barreiras para o uso do CoMDD estão relacionadas a funcionalidades de uma IDE, assim, a medida que essas funcionalidades são implementadas na wiki, como por exemplo syntax highlight, a aceitação e uso do CoMDD tende a aumentar e

4. Dado que é um protótipo, os desenvolvedores acreditam que o CoMDD atenderia às suas necessidades em termos de IDE e de versionamento, e o CoMDD seria mais útil ainda aos não desenvolvedores interessados em participar do projeto.

A Tabela 4.1 apresenta um resumo das principais conclusões de cada estudo de caso.

Tabela 4.1: Principais Resultados dos Estudos de Caso

\begin{tabular}{|c|c|c|c|}
\hline Estudo de Caso & Perfil dos Participantes & Resultado & Aceitação \\
\hline $\mathrm{EC}-\mathrm{ND}$ & $\begin{array}{l}\text { Alunos do ensino mé- } \\
\text { dio }\end{array}$ & $\begin{array}{l}\text { Apenas um grupo con- } \\
\text { seguiu chegar no resul- } \\
\text { tado esperado }\end{array}$ & $\begin{array}{l}100 \% \text { dos participantes } \\
\text { afirmaram ter gostado } \\
\text { da ferramenta }\end{array}$ \\
\hline $\mathrm{EC}-\mathrm{PG}$ & $\begin{array}{l}\text { Alunos de pós- } \\
\text { graduação em Ciências } \\
\text { da Computação e com } \\
\text { experiência na indústria }\end{array}$ & $\begin{array}{l}\text { Todas as equipes chega- } \\
\text { ram no resultado espe- } \\
\text { rado }\end{array}$ & $\begin{array}{l}100 \% \text { gostaram da } \\
\text { abordagem, } \\
\text { tudo ainda se sentem } \\
\text { mais seguros no } \\
\text { Eclipse+SVN }\end{array}$ \\
\hline $\mathrm{EC}-\mathrm{IN}$ & $\begin{array}{l}\text { Com média de } 8 \text { anos } \\
\text { de experiência em de- } \\
\text { senvolvimento e } 81 \% \text { já } \\
\text { fizeram ou faziam mes- } \\
\text { trado/doutorado }\end{array}$ & $\begin{array}{l}\text { Levantamento de dados } \\
\text { como: barreiras para } \\
\text { usar o CoMDD; prin- } \\
\text { cipais funcionalidades } \\
\text { usadas nas IDEs e nos } \\
\text { versionadores }\end{array}$ & $\begin{array}{l}86 \% \text { usariam o } \\
\text { CoMDD para de- } \\
\text { senvolver modelos } \\
\text { mas achavam que o } \\
\text { CoMDD precisava } \\
\text { melhorar }\end{array}$ \\
\hline
\end{tabular}




\subsection{A Evolução dos Estudos de Caso}

Inicialmente a ideia era apenas avaliar o CoMDD por não desenvolvedores. Dessa forma, acreditava-se que bastaria apresentar um problema para duas equipes (quatro pessoas) que não tivessem conhecimentos de programação e depois coletar suas opiniões sobre o CoMDD que seria o suficiente para poder avaliá-lo. Contudo, percebeu-se ao final desse estudo de caso que ele não era o suficiente para essa avaliação, embora talvez fosse o suficiente para validar a hipótese de pesquisa.

Outro ponto que o primeiro estudo de caso não tratava, era a comparação do CoMDD com o que já existia, ou seja, como propor uma solução se não compará-la com as já existentes? Assim, analisando essas deficiências do estudo de caso realizado até então, planejou-se o segundo estudo de caso, que visava avaliar o CoMDD em comparação com Eclipse+SVN, onde uma equipe usaria o CoMDD colaborativamente e a outra usaria o Eclipse+SVN colaborativamente. Os resultados do segundo estudo de caso foram mais satisfatórios, entretanto, ainda era a opinião de apenas quatro pessoas. Por isso decidiu-se expandir o estudo de caso para mais pessoas e assim foi planejado o terceiro e último estudo de caso.

O terceiro estudo de caso foi uma adaptação do segundo para que permitisse a participação do maior número de desenvolvedores e, por isso, foram produzidos dois vídeos que mostravam basicamente o que as equipes do segundo estudo de caso haviam feito. Também foi feito um questionário com base nas perguntas do segundo estudo de caso, entretanto, esse questionário foi mais abrangente.

Com isso pode-se perceber a importância do relato dos três estudos de caso, que além de trazer uma conclusão própria, serviu de base e incentivo para o seguinte.

\subsection{Considerações Finais}

Este capítulo apresentou o método usado para avaliar o CoMDD como sendo a realização de três estudos de caso. O objetivo geral dos estudos era coletar a opinião dos participantes sobre o CoMDD, mas cada estudo teve também objetivos específicos. No EC-ND o objetivo específico era avaliar a linguagem do CoMDD por pessoas sem conhecimentos de programação. No EC-PG era verificar se as equipes que usavam o CoMDD e o Eclipse+SVN chegariam aos mesmos resultados. E por fim, o EC-IN teve o objetivo específico de avaliar o CoMDD com mais detalhes, levantando os prós e contras quando comparado ao Eclipse+SVN, por um número maior de pessoas; sendo o terceiro estudo de caso de caráter qualitativo e quantitativo. 



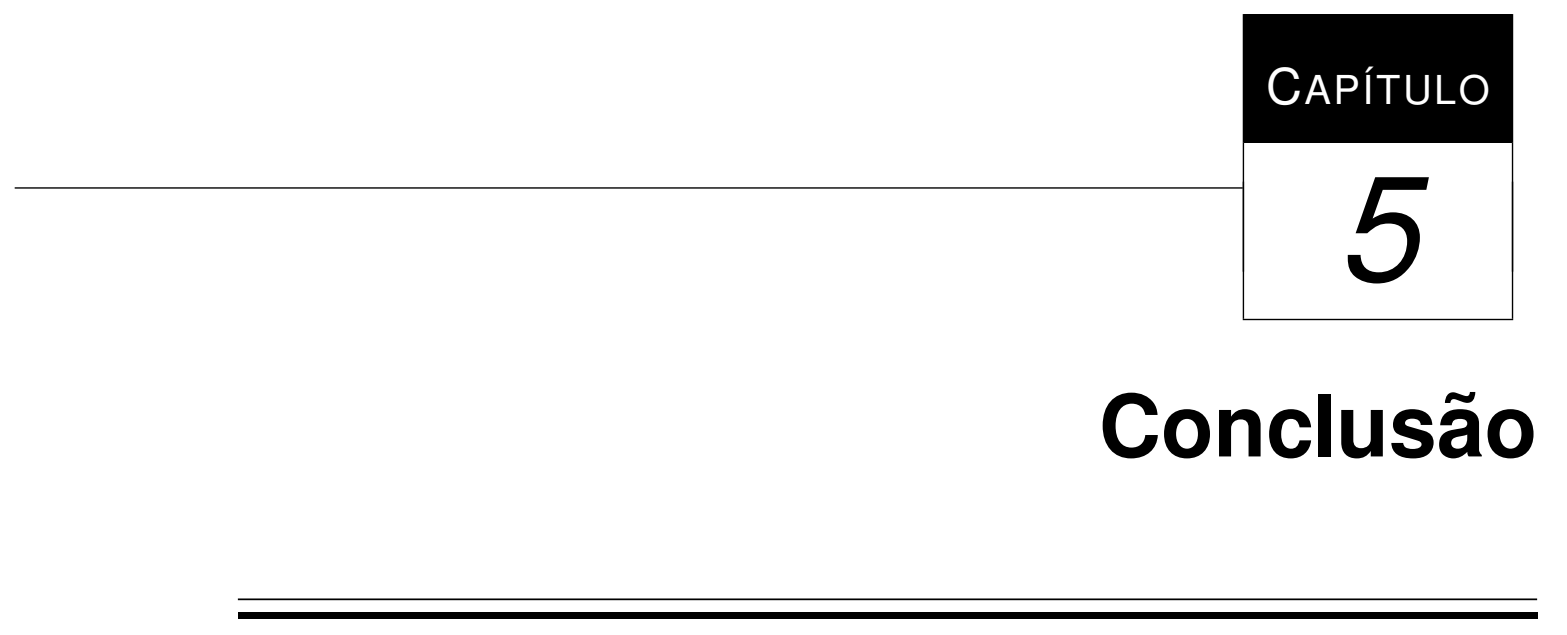

Este trabalho apresentou uma abordagem colaborativa orientada a modelos. O CoMDD objetiva simplificar o processo de desenvolvimento de software a partir do uso de uma DSL e de uma wiki. Assim, desenvolvedores e não desenvolvedores teriam mais liberdade para colaborar, uma vez que bastaria ter conhecimentos de como editar uma página na wiki e do funcionamento da DSL.

O CoMDD diferencia-se essencialmente das outras abordagens por inserir o MDD em uma wiki, algo não encontrado na literatura. Neste capítulo, serão apresentadas as considerações finais e contribuições do trabalho. Também são apresentadas as limitações do trabalho, as lições aprendidas e, por fim, as atividades e resultados realizados pelo aluno ao longo do mestrado.

\subsection{Contribuições}

A principal contribuição deste trabalho é evidenciar que o uso de MDD associado a uma wiki é possível para resolver determinados problemas, da mesma forma que é possível usando uma IDE e um sistema de versionamento. E que usando esta abordagem a equipe pode ter ganhos de produtividade e intensificar a colaboração da equipe, principalmente por não desenvolvedores.

O CoMDD permite a edição de modelos, geração de código fonte e a colaboração entre desenvolvedores e interessados, sem a necessidade de ferramentas/ambientes individuais instalados nas estações de trabalho. O CoMDD também pode ser adaptado para diferentes 
domínios, permitindo que o grupo fortaleça a pesquisa de desenvolvimeto em wikis usando modelos.

Por fim, este trabalho incentiva o uso de aplicações web ao invés de aplicações locais, permitindo que uma pessoa possa trabalhar de qualquer computador.

Quando não é necessário ferramentas locais para se criar ou editar modelos, ganha-se em termos de velocidade e colaboração, pois menos tempo é necessário para uma pessoa começar a contribuir. Quando se facilita o processo de desenvolvimento/colaboração com o uso de uma wiki no lugar de uma IDE/sistema de versionamento, mais pessoas podem colaborar. Com o uso de modelos de alto nível no lugar de linguagens de programação, mais fácil torna-se o entendimento de não desenvolvedores e consequentemente mais eles podem participar.

O CoMDD ainda pode ser útil para ensinar programação, uma vez que não é necessário programas locais e o próprio CoMDD poderá compilar/simular, mas para isso a ferramenta precisa evoluir, como será discutido na Seção 5.2.

\subsection{Limitações do Trabalho}

O CoMDD pode ser útil no desenvolvimento de algoritmos; contudo, isso não foi avaliado.

O ideal seria agregar funcionalidades de uma IDE às wikis, permitir o desenvolvimento simultâneo e a edição em tempo real que hoje tem o Google Docs ${ }^{1}$, por exemplo. Dessa forma o CoMDD teria mais chances de vigorar na comunidade de desenvolvedores.

Em relação ao domínio, espera-se que para qualquer domínio o CoMDD possa ser interessante assim como foi para os estudos de caso.

O CoMDD não indicava erros de sintaxe, o que deixava os participantes do EC-PG relativamente confusos por não saber se a sintaxe dos modelos estava correta.

A abordagem pessimistic possui suas desvantagens, como deixar um desenvolvedor ocioso por esperar a permissão para editar um arquivo que está sendo editado por outro desenvolvedor (Ben Collins-Sussman e Pilato, 2011).

A DSL foi projetada para que fosse simples de forma que pessoas pudessem compreendê-la facilmente. Do contrário, seria mais difícil realizar um estudo de caso. Entretanto, entendese que uma DSL mais robusta e que atendesse mais casos estaria mais próxima da realidade.

Em relação ao domínio escolhido, o código gerado não podia ser testado uma vez que precisava ser inserido no robô; assim, se o desenvolvedor pudesse simular o código gerado seria uma informação de retorno importante. Ainda, o cerne do domínio de robótica móvel autônoma são os algoritmos que tornam os robôs autônomos; entretanto, a colaboração foi mais na definição dos sensores e atuadores que esses robôs usam.

\footnotetext{
${ }^{1}$ https://docs.google.com
} 
Dessa forma, seria mais proveitoso para o domínio se o CoMDD fosse usado para a elaboração de algoritmos. Contudo, nesse caso, seria melhor uma edição concorrente igual ao Google Docs. Assim, entende-se que o domínio escolhido foi beneficiado pelo uso de uma DSL, mas não tanto pelo uso da colaboração.

\subsection{Lições aprendidas}

A seguir são listadas algumas lições pessoais aprendidas pelo aluno ao longo do mestrado e com a leitura de livros e artigos sobre metodologia de pesquisa científica, que embora pareçam um pouco óbvias, podem ser úteis àqueles que estão iniciando na vida acadêmica.

- Definir bem a hipótese e como prová-la ou evidenciá-la. Não basta ter um hipótese sem saber como prová-la;

- Pensar bem no método antes de começar a implementar. Acredita-se que este trabalho teria sido muito mais simples se tivesse sido planejado os estudos de caso antes da implementação. Para isso, era importante já ter o conhecimento do quê o trabalho procurava avaliar e quais tipos de resultados ele gostaria de apresentar;

- Apresentar o trabalho para o máximo número de pessoas. Mesmo durante a concepção das ideias. As pessoas farão perguntas que ajudam no processo de formulação da hipótese, objetivos, método, etc. Saber explicar algo complexo para pessoas que não são da área, de maneira simples e objetiva, é um grande exercício e qualidade;

- Complexidade e simplicidade. Se algo está muito complexo, provavelmente deve ter algo errado ou há uma forma melhor e mais simples de fazer. Se não encontrar um forma mais simples, quebrar o problema em pedaços tão pequenos a ponto de serem simples de fazer pode ser uma boa solução;

- Questionários. Questionários são excelentes ferramentas, mas é importante ter bem formado em mente quais conclusões deseja-se extrair do questionário. Do contrário, acaba-se fazendo perguntas desnecessárias que além de tornar o trabalho do participante mais enfadonho e com isso menos pessoas respondendo o questionário, a análise dos resultados torna-se mais complicada, demorada e pode-se até mesmo ter dados inúteis. Lembrando que ter a participação de pessoas respondendo questionários ou testando uma ferramenta é algo difícil e trabalhoso;

- Publicações. Não é porque um artigo foi publicado, mesmo em um congresso de qualidade, que significa que o artigo é bom ou que o que os autores estão falando é verdade ou está correto. É importante a análise crítica mesmo desses artigos;

- DSL. Se for fazer uma, comece pelo código fonte que deseja que ela gere. É importante o especialista do domínio participar desse processo e 
- Scrum ${ }^{2}$. O processo incremental de desenvolvimento de software pode ser útil na pesquisa ou na implementação da ferramenta. Este trabalho iniciou fazendo uma DSL para o Eclipse. Com a DSL pronta tentou-se tirar ela do Eclipse e integrá-la em uma wiki. Após algumas tentativas, optou-se por aprender uma nova tecnologia (ANTLR) e refazer a DSL, pois acreditou-se que isso levaria menos tempo do que insistir em tirar a DSL do Eclipse. No ANTLR não foi repetido o erro do Eclipse. Primeiro foi feito um "hello world"no ANTLR e integrado na wiki, para depois fazer toda a DSL no ANTLR e finalmente integrá-la na wiki;

\subsection{Trabalhos Futuros}

Algumas perguntas foram levantadas no decorrer deste trabalho e espera respondê-las em trabalhos futuros. São elas:

1. Pode-se dizer que a wiki comportou-se bem com o MDD; contudo como ela se comportaria com uma abordagem tradicional orientada a código? Ou seja, como seria programar em Java, por exemplo, em uma wiki? E será que um código fonte seria tão colaborativo quanto um modelo?

2. As equipes do segundo estudo de caso foram de dois integrantes apenas, como o CoMDD se comportaria com equipes maiores e com mais pessoas compartilhando o mesmo artefato?

3. O código gerado pelo modelo foi validado por um especialista do domínio que ajudou e acompanhou a criação da DSL usada no CoMDD; contudo, como validar os modelos ao invés do código fonte, de forma que garanta que o código fonte gerado esteja correto e de forma que permita o retorno de erros de sintaxe aos desenvolvedores?

4. Nessa abordagem, as transformações e o metamodelo foram definidos fora da wiki; entretanto, poderiam ser definidos pela própria wiki. Quais benefícios a edição colaborativa das transformações e dos metamodelos traria no desenvolvimento de software?

5. A abordagem do CoMDD implementada e avaliada contou com o desenvolvimento colaborativo seguindo uma abordagem pessimistic, contudo como a abordagem se comportaria caso tivesse outras formas de colaboração como: $i$. Edição concorrente e mesclagem de modelos (adotando a abordagem otimistic); ii. Edição em tempo real estilo Google Docs; iii. Edição de outros artefatos que fossem dependentes ${ }^{3}$;

6. Como seria o nível de aceitação caso o CoMDD tivesse funcionalidades mais próximas de uma IDE, como: highligth, autocomplete e link entre palavras, de forma que ao clicar em um método é apresentado a definição dele, por exemplo?

\footnotetext{
${ }^{2}$ http://www.scrum.org/scrumguides/

${ }^{3}$ Pode-se criar facilmente links de uma página para outra na wiki
} 
7. Para quais outros domínios o CoMDD pode ser útil?

8. Estudo de estratégias otimistic ou até mesmo na adoção de ambas como propõe o trabalho de Prudêncio et al.(2012).

\subsection{Considerações Finais}

Este trabalho apresentou uma proposta para contornar os problemas apresentados na Seção 1.1, o CoMDD. O CoMDD é uma abordagem que defende o uso do MDD colaborativo, da forma mais simples possível, de modo que maximize a colaboração por desenvolvedores e/ou por não desenvolvedores. No caso, foi usado uma wiki, mas poderia ser outra plataforma web de simples uso e que promovesse velocidade e colaboração. Com as atuais tecnologias, a wiki é a que melhor se encaixa nesse perfil.

A partir da análise da pesquisa realizada na Seção 3.5, nenhum trabalho encontrado na literatura apresenta a proposta do CoMDD e nem apresenta resultados comparando abordagens tradicionais de MDD colaborativo com um desenvolvimento web (Seção 4). Por isso, podese dizer que este trabalho é inédito na literatura.

O CoMDD permite a modelagem colaborativa por vários usuários; a geração de código fonte desses modelos; fornece um sistema de versionamento de modelos, permitindo também o rollback e a comparação de modelos; e permite também a documentação colaborativa. Essas são as funcionalidades essenciais do CoMDD.

Entre as vantagens do CoMDD, pode-se citar:

1. Possibilidade de aumento de produtividade: pelo fato do CoMDD usar essencialmente MDD e por MDD ser considerada uma abordagem que apresenta ganhos de produtividade, acredita-se que o CoMDD também possa trazer os mesmos benefícios do MDD, como aumento de produtividade, por exemplo;

2. Estímulo a colaboração: o uso de modelos e de wiki torna o CoMDD uma abordagem atraente para não desenvolvedores e a simplicidade e velocidade para comentar, compartilhar, editar etc faz com que o CoMDD seja uma abordagem que estimule a colaboração;

3. Versionamento simplificado: o sistema de versionamento do CoMDD é simples, de modo que os usuários têm acesso às outras versões e mudanças de maneira fácil;

4. Independência de softwares locais: tudo no CoMDD funciona na web, então só é necessário um navegador instalado localmente e

5. Uso pedagógico: o CoMDD também pode ser útil para o ensino, pois nele pode-se ter desde o material de aula à execução dos excercícios. 
Em relação aos estudos de caso, o EC-ND (Seção 4.1), o CoMDD mostrou-se acessível à usuários não desenvolvedores. Com o EC-PG, (Seção 4.2), o CoMDD mostrou-se capaz de atingir os mesmo resultados que a abordagem Eclipse+SVN e por fim, o EC-IN mostrou pontos em que o CoMDD precisa melhorar, mas também mostrou que o CoMDD foi aceitável pela comunidade de desenvolvedores participantes do estudo de caso.

Também é possível concluir que, para os estudos de caso, o uso do CoMDD mostrou-se mais fácil que o uso do Eclipse+SVN, principalmente por não desenvolvedores. Portanto, pode ser interessante adotar o CoMDD como estratégia para não desenvolvedores participarem do desenvolvimento.

O CoMDD exige menos conhecimentos para colaborar do que são exigidos em um sistema de versionamento e ainda o tempo necessário para atualizar um modelo é menor.

É importante ressaltar que este trabalho, bem como os ECs realizados, não pode generalizar suas conclusões para qualquer cenário ou domínio. Por isso, todas as conclusões apresentadas aqui são para o domínio e cenário definidos nos ECs. Entretanto, acredita-se que os resultados obtidos nesses estudos são indicadores positivos de que a abordagem pode ser válida também para outros domínios/cenários.

Fazendo uma análise geral, pode-se dizer que o CoMDD teve uma aceitação de $84 \%$ para resolver problemas usando DSLs em uma wiki, contra $16 \%$ que ainda usariam o Eclipse+SVN para também resolver problemas usando DSLs.

Ainda, as wikis precisam evoluir com funcionalidades de IDE para que possam, de fato, serem usadas como ferramentas de desenvolvimento e não se limitarem à ferramentas de documentação e afins.

Este trabalho está longe de criar um ambiente de desenvolvimento tão robusto e avançado quanto hoje são as IDES e os sistemas de versionamento, tampouco substituir as demais ferramentas de suporte à colaboração. Até porque essas ferramentas já atingiram um grau de maturidade que as torna usáveis em produção. Este trabalho objetivou sim, mostrar que o alinhamento de duas tecnologias aparentemente não interligáveis é possível e benéfico, além de motivar novos estudos na área.

Os estudos de caso serviram para evidenciar que é possível ter uma abordagem que integre o MDD a uma wiki e serviram também para mostrar que o CoMDD é aceito como um possível substituto de abordagens tradicionais desde que traga algumas funcionalidades das IDEs.

Assim, o MDD agrega um ganho de produtividade no desenvolvimento de software e as wikis incentivam a colaboração devido sua simplicidade de edição e tornam o processo de colaborar/editar mais ágil. Portanto, conclui-se que com o CoMDD pode-se ter ganhos de produtividade e maior colaboração entre desenvolvedores e não desenvolvedores. 


\subsection{Publicações e Atividades Realizadas}

Nessa seção são separadas as publicações mais relacionadas com o trabalho das demais publicações e atividades realizadas durante o período do mestrado.

\section{Publicações Relacionadas com o Trabalho}

1. FERNANDES, D.N. ; FROTA, P. C. ; FORTES, R. P. M. . Uma Abordagem Distribuída para o Desenvolvimento Orientado a Modelos. In: V Workshop de Desenvolvimento Distribuído de Software, 2011, São Paulo. Uma Abordagem Distribuída para o Desenvolvimento Orientado a Modelos, 2011;

2. FERNANDES, D.N. ; FORTES, R. P. M. . CoMDD: uma Abordagem Colaborativa para Auxiliar o Desenvolvimento Orientado a Modelos em Sistemas Embarcados. 2010. Simpósio Brasileiro de Sistemas Colaborativos. (Apresentação de Trabalho);

3. WATANABE, W. M. ; FERNANDES, D.N. ; BITTAR, T. J. ; FORTES, R. P. M. . WCAG Conformance approach based on Model-Driven Development and webML. In: SIGDOC - ACM International Conference on Design of Communication, 2010, São Carlos. Proceeding of 28th SIGDOC 2010, 2010. v. 1. p. 167-174;

4. BITTAR, T. J. ; LOBATO, L. L. ; FORTES, R. P. M. ; FERNANDES, D.N. . Accessible organizational elements in wikis with model-driven development. In: 28th Sigdoc ACM International Conference on Design of Communication, 2010, São Carlos. Proceedings of the 28th Sigdoc. New York : ACM, 2010. v. 1. p. 49-56;

5. BITTAR, T. J. ; FERNANDES, D.N. ; LOBATO, L. L. ; LUCREDIO, D. ; FORTES, R. P. M. . Definição de metamodelos para web incorporando boas práticas de acessibilidade e usabilidade. In: XXXVI Conferência Latino-Americana de Informática CLEI 2010, 2010, Assunção. Anais do CLEI 2010, 2010 e

6. BITTAR, T. J. ; LOBATO, L. L. ; FERNANDES, D.N. ; FORTES, R. P. M. . Apoio à colaboração em wikis a partir de modelagem gráfica visando ganhos na arquitetura da informação e acessibilidade. In: Simpósio Brasileiro de Sistemas Colaborativos II, 2010, Belo Horizonte. Anais do Simpósio Brasileiro de Sistemas Colaborativos II. Washington DC : IEEE Computer Society Press, 2010. v. 2. p. 12-15;

\section{Demais Publicações e Atividades de Pesquisa}

1. OLIVEIRA, R. R. ; SANCHEZ, R. V. V. ; FERNANDES, D.N. ; FROTA, P. C. ; FORTES, R. P. M. . Notificação de wiki por meio de Mensageiros Instantâneos via bot reforçando a colaboração na web. In: XVII Simpósio Brasileiro de Sistemas Multimí- 
dia e web webMedia, 2011, Florianópolis. Anais do webmedia 2011, 2011. v. 1. p. $1-7$

2. PESSIN, G. ; OSÓRIO, F. S. ; DIAS, M. A. ; FERNANDES, D.N. . Avaliação de Técnicas de Otimização Aplicadas à Formação e Atuação de Grupos Robóticos. In: III Workshop on Computational Intelligence, 2010, Porto Alegre. Joint Conference 2010 Workshop Proceedings (SBIA/SBRN/JRI), 2010. p. 494-499;

3. SANCHEZ, R. V. V. ; OLIVEIRA, R. R. ; FERNANDES, D.N. ; FORTES, R. P. M. ; PIMENTEL, M. G. C. . Services Mobile: Incorporando serviços da web 2.0 aos dispositivos móveis mediante o uso de informações de contexto. In: XVII Simpósio Brasileiro de Sistemas Multimídia e web webMedia, 2011, 2011, Florianópolis. Anais do webmedia 2011, 2011. v. 1. p. 1-4;

4. FERNANDES, D.N. ; PEZUTTI, E. B. S. ; FORTES, R. P. M. . Conteúdo RSS para Dispositivos Móveis. In: webmedia - Simpósio Brasileiro de Sistemas Multimídia e web (15. : 2009 : Fortaleza, CE), 2009, Fortaleza. Anais webmedia 2009: XV Simpósio Brasileiro de Sistemas Multimídia e web, 2009. v. 2.

5. Participação no projeto de desenvolvimento de um sistema de gerenciamento de projetos científicos durante o período de março de 2011 a junho de 2011, no qual o trabalho com ferramentas de versionamento ajudaram na definição dos estudos de caso;

6. Estágio realizado, como bolsista da $\mathrm{BAYLAT}^{4}$, na Technische Universität München ${ }^{5}$ e no instituto de pesquisa aplicada Fortiss ${ }^{6}$ Munique - Alemanha, sob supervisão do professor Bernhard Schätz e do pesquisador Dr. Daniel Ratiu, no desenvolvimento de uma DSL para prédios inteligentes, usando a ferramenta MPS da Jetbrains ${ }^{7}$, durante o período de agosto de 2011 à novembro de 2011;

7. Parceria com o LRM e participação no Instituto Nacional de Ciência e Tecnologia em Sistemas Embarcados Críticos (INCT-SEC);

8. Curso Introduction to Product Line Enginnering ministrado pela Fraunhofer Institute for Experimental Software Engineering e

9. Outros cursos sobre DSLs e MDD os quais o aluno participou ao longo de eventos e congressos durante o mestrado.

\footnotetext{
${ }^{4}$ http://www.baylat.org/

${ }^{5}$ http://portal.mytum.de/welcome/

${ }^{6}$ http://www.fortiss.org/

${ }^{7}$ http://www.jetbrains.com/
} 


\section{Referências Bibliográficas}

Abeti, L.; Ciancarini, P.; Moretti, R. Wiki-based requirements management for business process reengineering. In: Wikis for Software Engineering, Vancouver, BC, Canada. WIKIS4SE '09. ICSE Workshop on, 2009, p. 14-24.

Aguiar, A.; DAvid, G. Wikiwiki weaving heterogeneous software artifacts. In: Proceedings of the 2005 international symposium on Wikis, WikiSym '05, New York, NY, USA: ACM, 2005, p. 67-74

Aho, P.; Merilinna, J.; Ovaska, E. Model-driven open source software development - the open models approach. In: 4th International Conference on Software Engineering Advances, ICSEA 2009, Porto, Portugal, 2009, p. 185-190.

Ben Collins-Sussman, B. W. F.; Pilato, M. Version control with subversion. 2011. Disponível em: http://svnbook.red-bean.com/en/1.6/. Acessado em 22 de outubro de 2011.

Bendix, L.; EmAnuelsson, P. Collaborative work with software models - industrial experience and requirements. In: International Conference on Model-Based Systems Engineering, 2009. MBSE '09. Herzeliya, Israel, 2009, p. 60-68.

Deursen, A.; Klint, P.; Visser, J. Domain-specific languages: an annotated bibliography. SIGPLAN Not., v. 35, n. 6, p. 26-36, 2000.

Elrufaie, E.; Turner, D. A. A wiki paradigm for use in it courses. International Conference on Information Technology: Coding and Computing, Las Vegas, Nevada, USA v. 2, p. 770-771, 2005.

FERreira, D.; SilVA, A. Wiki-based tool for requirements engineering according to the projectit approach. , 2009, p. 359-364. 
France, R.; Rumpe, B. Model-driven development of complex software: A research roadmap. In: 29th International Conference on Software Engineering 2007 - Future of Software Engineering, Minneapolis, MN, USA: IEEE Computer Society, 2007, p. 37-54.

HAIlPern, B.; TARr, P. Model-driven development: the good, the bad, and the ugly. IBM, v. 45, n. 3, p. 451-461, 2006.

JANG, S.; GREEN, T. M. Best practices on delivering a wiki collaborative solution for enterprise applications. In: Collaborative Computing: Networking, Applications and Worksharing, 2006. CollaborateCom 2006., 2006, p. 1-9.

JING, H.; FAN, Y. Usability of wiki for knowledge management of knowledge-based enterprises. International Symposium on Knowledge Acquisition and Modeling, p. 201$205,2008$.

JONES, M.; SCAFFIDI, C. Obstacles and opportunities with using visual and domainspecific languages in scientific programming. In: Visual Languages and Human-Centric Computing (VL/HCC), 2011 IEEE Symposium on, 2011, p. 9-16.

Khalid RAMES Al-ASMARI, L. Y. Experiences in distributed software development with wiki. In: Software Engineering Research and Practice, 2006, p. 389-293.

KlePPe, A. G.; WARMER, J.; BASt, W. Mda explained: The model driven architecture: Practice and promise. Boston, MA, USA: Addison-Wesley Longman Publishing Co., Inc., 2003.

Liggesmeyer, P.; Trapp, M. Trends in embedded software engineering. IEEE Software, v. 26, p. 19-25, 2009.

Lotufo, R. A.; Machado, R. C.; Körbes, A.; Ramos, R. G. Adessowiki on-line collaborative scientific programming platform. In: Proceedings of the 5th International Symposium on Wikis and Open Collaboration, New York, NY, USA: ACM, 2009, p. 10:110:6 (WikiSym '09).

LOURIDAS, P. Using wikis in software development. IEEE, v. 23, n. 2, p. 88-91, 2006.

LUCRÉDIO, D. Uma abordagem orientada a modelos para reutilizacão de software. Tese de Doutoramento, Universidade de São Paulo, Instituto de Ciências Matemáticas e de Computacão, 2009.

Machado, R. C.; Rittner, L.; Lotufo, R. A. Adessowiki - collaborative platform for writing executable papers. Procedia Computer Science, v. 4, p. 759 - 767, 2011. 
MajchrzaK, A.; Wagner, C.; YATES, D. Corporate wiki users: results of a survey. In: WikiSym '06: Proceedings of the 2006 international symposium on Wikis, New York, NY, USA: ACM, 2006, p. 99-104.

MCQUAY, W. Distributed collaborative environments for systems engineering. In: Digital Avionics Systems Conference, 2004. DASC 04. The 23rd, 2004.

Menta, N. Choosing an open source cms: Beginner's guide. Packt Publishing, 2009.

MEIJlER, T. Requirements for an integrated domain specific modeling, modeling language development, and execution environment. In: Proceedings of NWUML'2005: The 3rd Nordic Workshop on UML and Software Modeling, 2005.

Mellor, S. J.; Clark, A. N.; Futagami, T. Guest editors' introduction: Model-driven development. IEEE Software, v. 20, p. 14-18, 2003.

Minocha, S.; Thomas, P. Collaborative learning in a wiki environment: Experiences from a software engineering course. New Review of Hypermedia and Multimedia, v. 13, n. 2, p. 187-209, 2007.

Pressman, R. S. Engenharia de software. McGraw-Hill, 2006.

Prudencio, J.; Murta, L.; Werner, C.; CePeda, R. To lock, or not to lock: That is the question. Journal of Systems and Software, v. 85, n. 2, p. 277-289, 2012.

RAMA, J.; BISHOP, J. A survey and comparison of cscw groupware applications. In: SAICSIT '06: Proceedings of the 2006 annual research conference of the South African institute of computer scientists and information technologists on IT research in developing countries, 2006, p. 198-205.

Runeson, P.; Höst, M. Guidelines for conducting and reporting case study research in software engineering. Empirical Software Engineering, v. 14, p. 131-164, 2009.

Sánchez, P.; Moreira, A.; Fuentes, L.; Araúdo, J.; Magno, J. Model-driven development for early aspects. Information and Software Technology, 2009.

SArma, A.; Noroozi, Z.; HoEK, A. Palantir: raising awareness among configuration management workspaces. In: Software Engineering, 2003. Proceedings. 25th International Conference on, 2003, p. $444-454$.

SELIC, B. The pragmatics of model-driven development. IEEE Software, v. 20, n. 5, p. 19-25, 2003.

Sriplakich, P.; Blanc, X.; Gervais, M.-P. Supporting collaborative development in an open mda environment. In: Software Maintenance, 2006. ICSM '06. 22nd IEEE International Conference on, 2006, p. 244-253. 
Stahl, T.; Voelter, M.; CZARnecki, K. Model-driven software development: Technology, engineering, management. John Wiley \& Sons, 2006.

Teppola, S.; Parviainen, P.; Takalo, J. Challenges in deployment of model driven development. In: Software Engineering Advances, 2009. ICSEA '09. Fourth International Conference on, 2009, p. 15 -20.

Tetard, F.; PATOKORPi, E.; PACKAlEn, K. Using wikis to support constructivist learning: A case study in university education settings. In: HICSS '09: Proceedings of the 42nd Hawaii International Conference on System Sciences, Washington, DC, USA: IEEE Computer Society, 2009, p. 1-10.

XIAO, W.; ChI, C.; YANG, M. On-line collaborative software development via wiki. In: Proceedings of the 2007 international symposium on Wikis, New York, NY, USA: ACM, 2007, p. 177-183

ZHANG, J.; RAY, I. Towards secure multi-sited transactional revision control systems. 2007 , p. $365-375$.

ZIMMERLY, B. Entendendo o software wiki. 2009.

Disponível em: http://www.ibm.com/developerworks/br/library/ os-social-mediawiki/index.html. Acessado em 14 de outubro de 2011. 


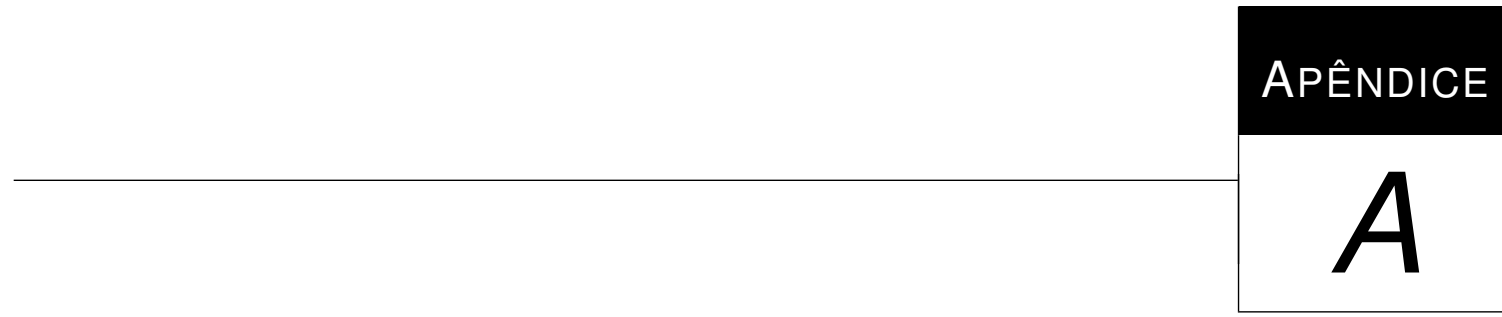

\section{Gramática do CoMDD}

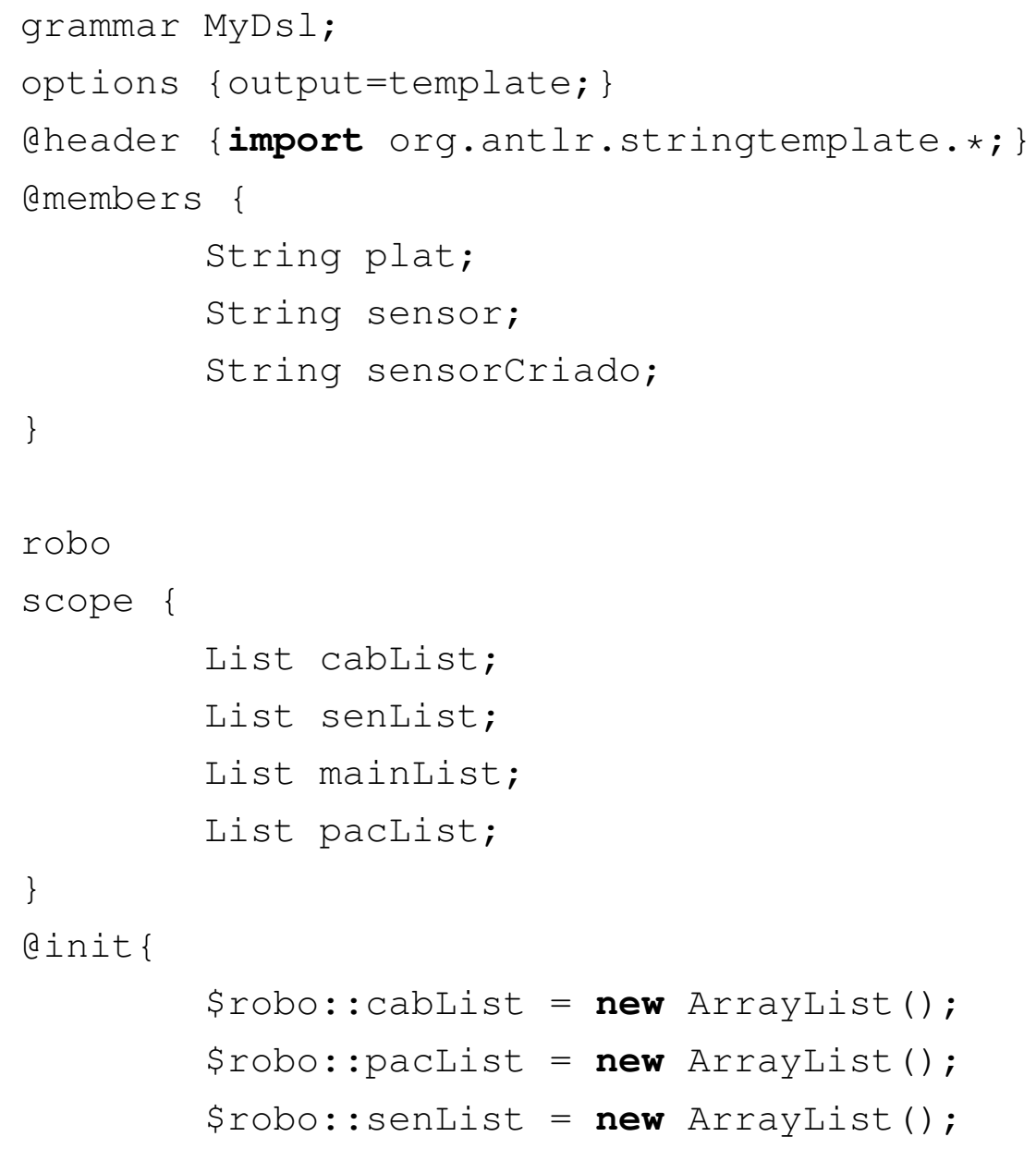


\$robo: :mainList $=$ new ArrayList ();

\}

: stat+ $->$ classe (cab $=\{$ \$robo: : cablist $\}$, pacote $=\{\$ r o b o:$ :pacList $\}, \operatorname{sen}=\{\$ r o b o:$ : senList $\}$, main $=\{$ \$robo: : mainList $\}$ )

;

stat: plataforma

'robo' nomeRobo=ID

cabecalho*

pacote*

sensor*

main

;

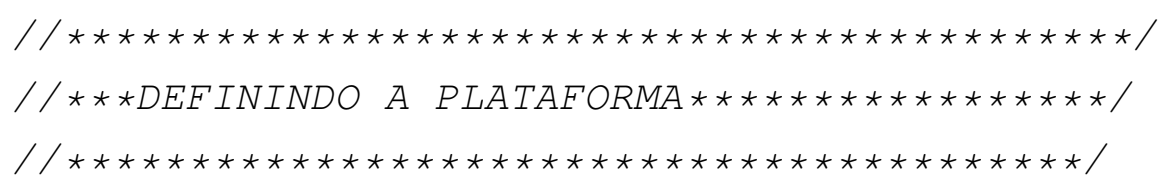

plataforma :

'plataforma' nomedaPlataforma ;

nomeDaPlataforma

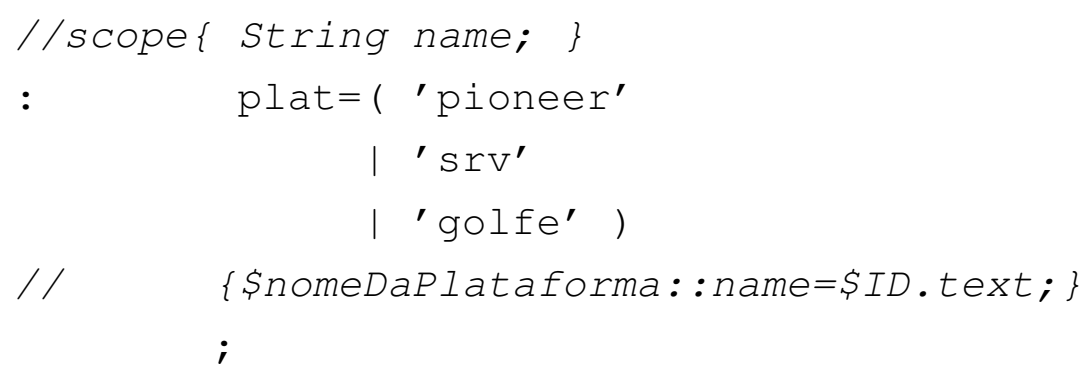

cabecalho:

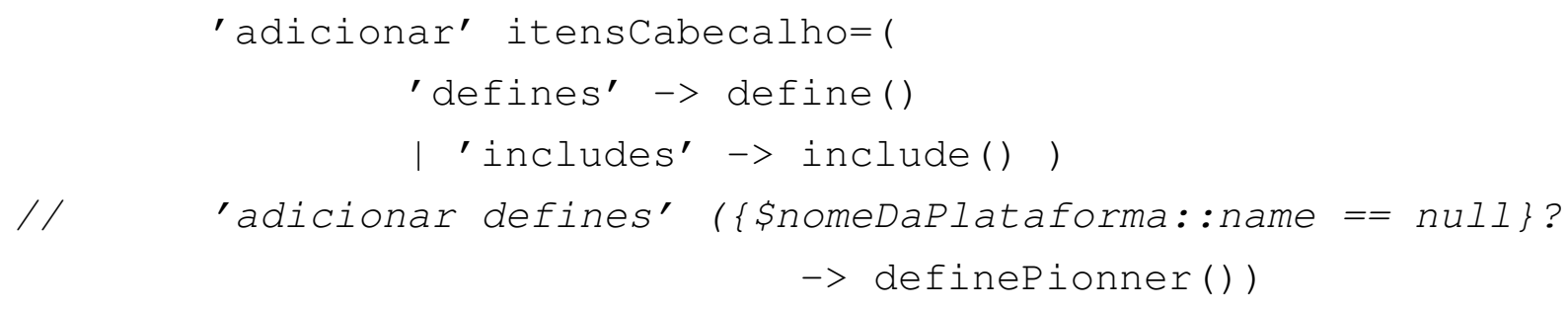




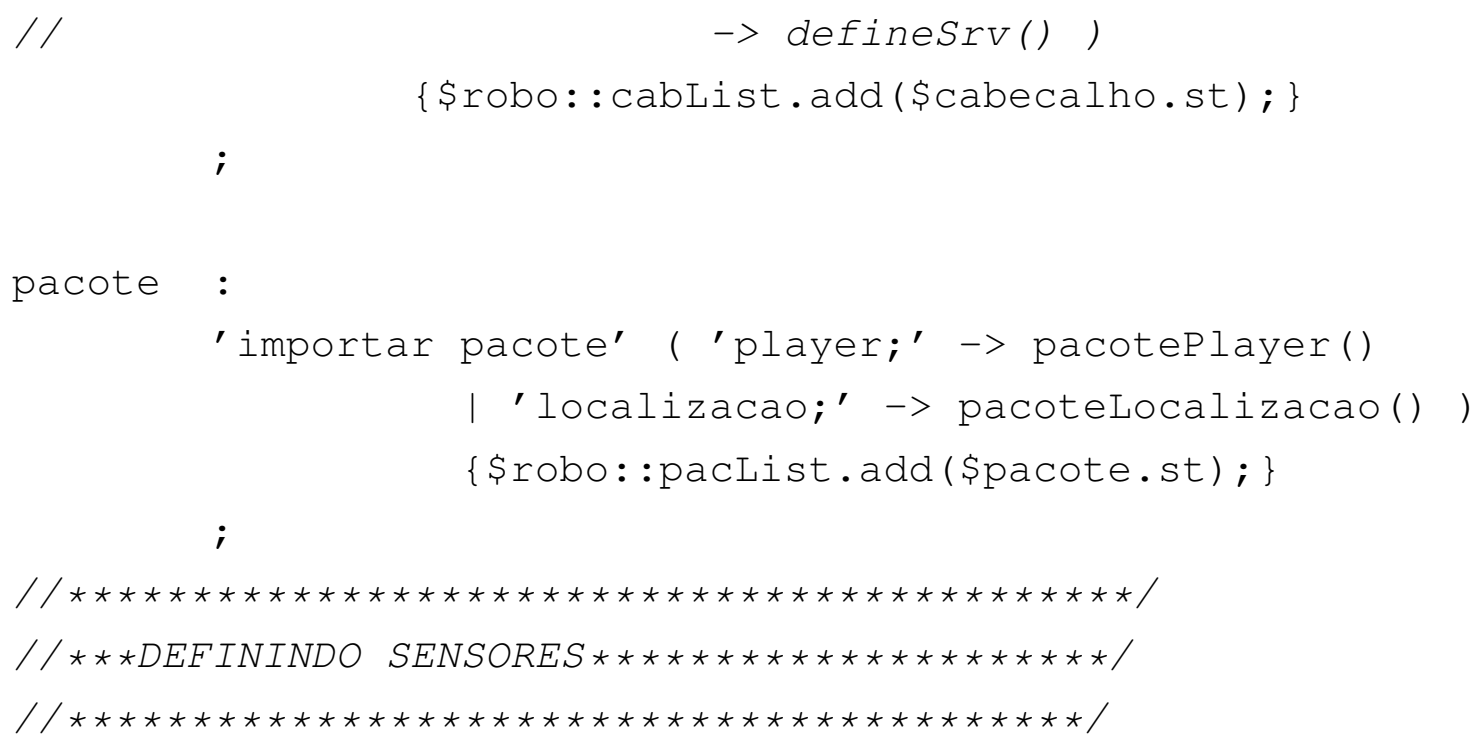

tiposensor

$\begin{array}{ll}: & \text { 'gps' }->\text { gps ( ) } \\ \text { | } & \text { 'bussola' }->\text { bussola ( ) } \\ \text { | } & \text { 'camera' }->\text { camera( ) } \\ \text {; } & \end{array}$

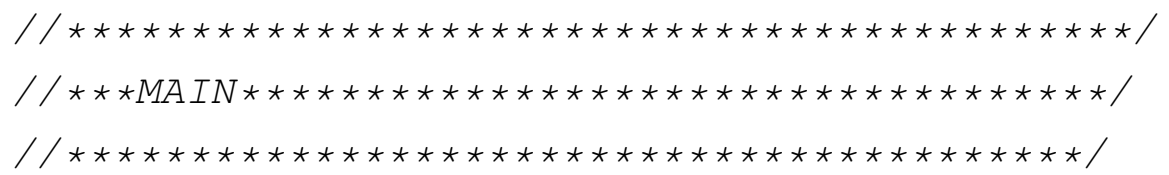

main:

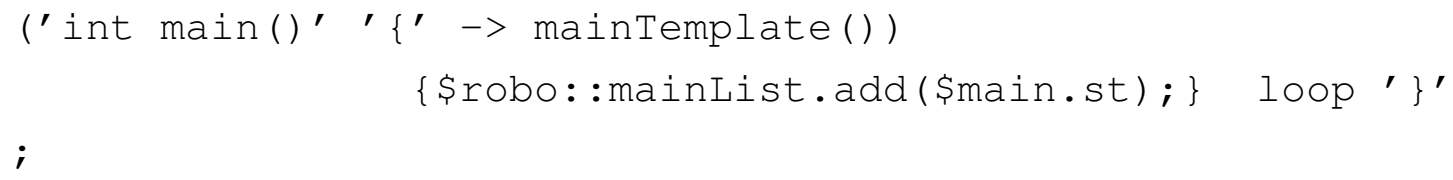

loop :

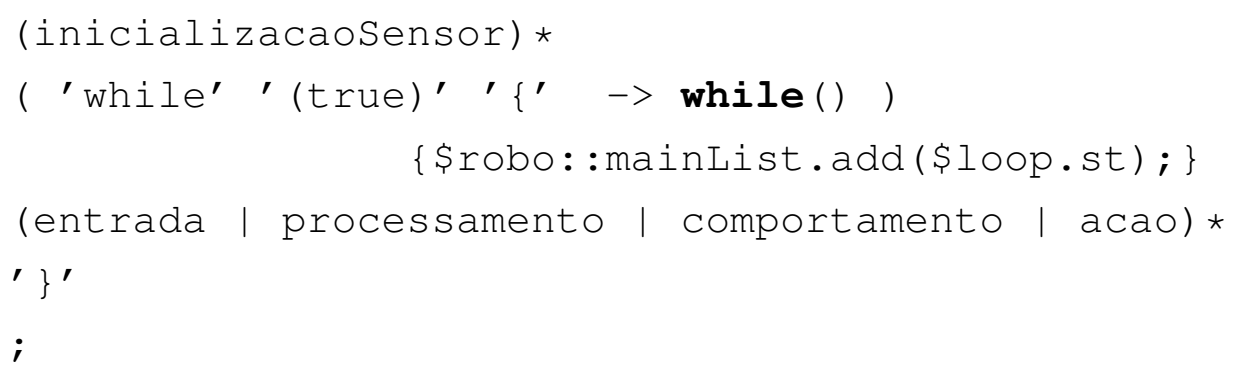




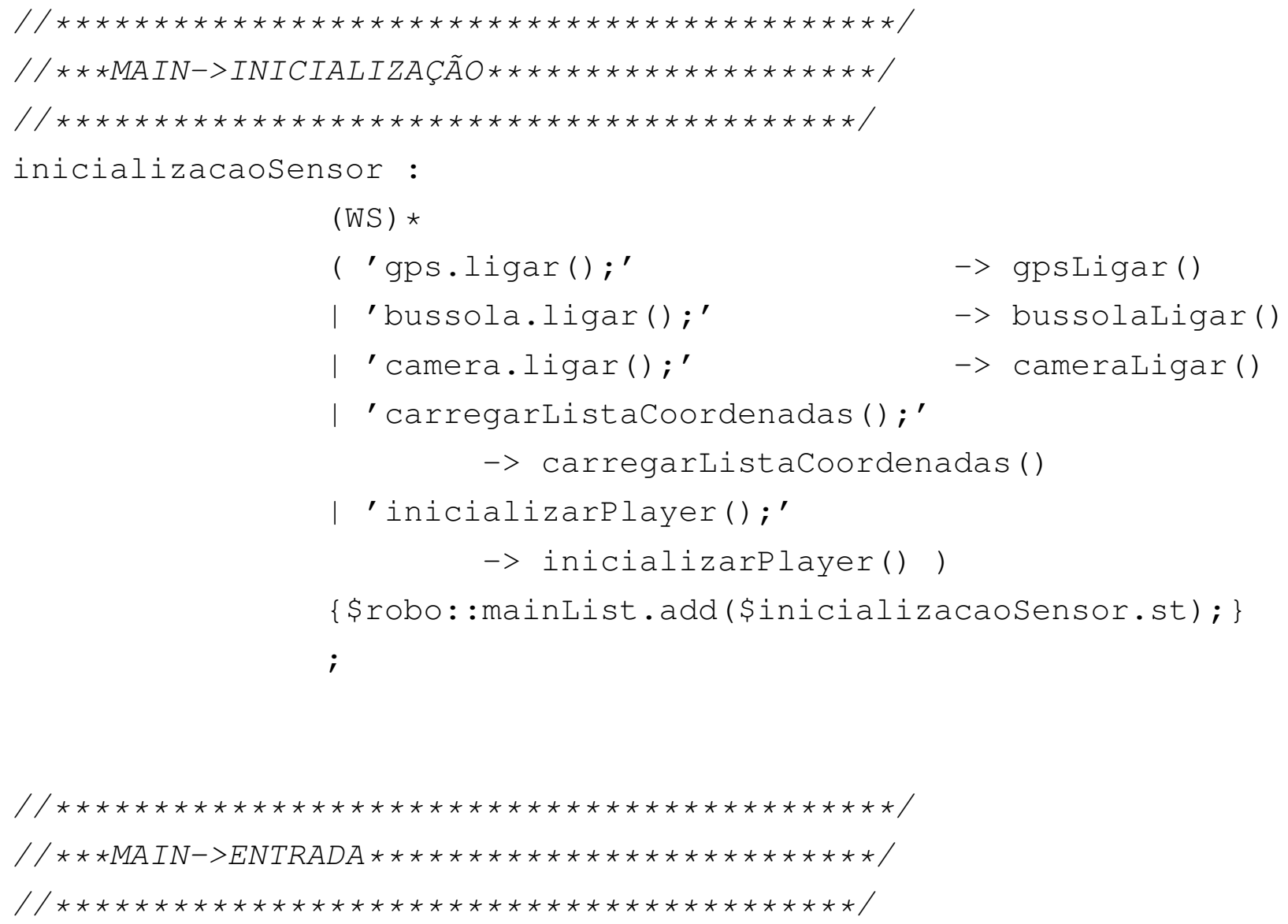




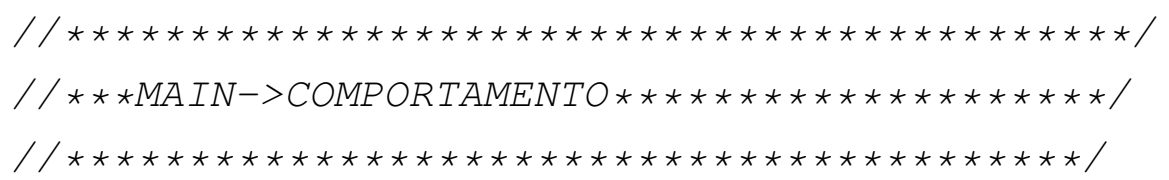



APÊNDICE

\section{$B$}

\section{Textos Apresentados no EC-PG}

Aqui são dispostos os textos apresentados no experimento e referenciados na seção 4

\section{B.1 Texto I: O que é o CoMDD?}

O que é o CoMDD? O CoMDD vem da sigla Colaborative Model Driven Development. É basicamente uma linguagem de programação que funciona em uma wiki

Certo, mas para que serve? Com o CoMDD você pode programar robôs! Isso mesmo! Robôs!

Então eu posso programar qualquer robô com ela? Não. O CoMDD é uma dsl, ou seja, uma Linguagem Específica de Domínio (do inglês Domain Specific Language). O que significa dizer que com ela você não programa qualquer coisa como o $\mathrm{C}, \mathrm{C}++$, Java e etc. Com o CoMDD você programa apenas para um domínio muito específico, o de robôs móveis autônomos. E pelo fato do CoMDD ser um protótipo em desenvolvimento, mesmo para o seu domínio ele é pouco tão versátil.

Tudo bem então, agora que entendi o que é o CoMDD, como posso programar para ele? Muito bem! Estamos felizes que o CoMDD esteja lhe interessando. Para você desenvolver nele conheça melhor ele aqui.

Fonte: http://143.107.183.158:8008/xwiki/bin/view/Main/Tutorial 


\title{
B.2 Texto II: Como programar para o CoMDD
}

\author{
A-Estrutura
}

A estrutura do código deve ser seguida dessa forma:

1-Declarações

2-Includes e Defines

3-Pacotes

4-Adicionando sensores

5-Main

5.1-Inicializações

5.2-Loop

5.3-Funções

Nota:

Atente para as palavras. A linguagem é case sensitive, o que significa que as palavras devem ser escritas exatamente como são mostradas. Caso falte um "s", como por exemplo: adicionar define ao invés de adicionar defines o código gerado estará errado.

1-Declarações

\section{1 - Plataforma}

Você pode desenvolver código para 3 plataformas. São elas pioneer, srv e carrinho de golfe. Veja como escrever:

plataforma [tipo da plataforma]

Ex: plataforma srv

Os tipos são pioneer, srv, golfe

1.2 - Nome do robô

[nome qualquer]

Ex: robo XyZ33

2-Includes e Defines

O CoMDD trás um conjunto de includes e defines. Para usá-los basta escrever:

[includes ou defines]

Ex: adicionar defines

3-Pacotes

Há dois pacotes disponíveis. São eles o player e o localizacao. Para usá-los basta escrever: 
importar pacote [tipo do pacote];

Ex: importar pacote player;

4-Adicionando Sensores

Para usar os 3 tipos de sensores (gps, bussola e camera) você deve adicioná-los antes no código, da seguinte forma:

criarSensor [tipo de sensor]

Ex: criarSensor gps

5-Main

A Main é a função principal do código, todo a lógica do código vai dentro desta função. Para isso você precisa escrever:

int main()

«Inicializações

Loop

Funções

$\gg$

O que está dentro de «» deve ser substituído de acordo com as explicações dos itens 5.1, 5.2, 5.3 .

\section{1 - Inicializações}

Para você usar os sensores criados ou outras funções você deve iniciá-las antes. No caso do sensor:

[tipo do sensor].ligar();

Ex: gps.ligar();

Ainda é possível carregar uma lista de coordenadas e inicializar o player da seguinte forma: carregarListaCoordenadas();

inicializarPlayer();

\section{2 - Loop}

Loop é algo que vai ser executado continuamente. Para usá-lo você deve escrever:

while(true)

«Funções»

Não se esqueça de fechar a chave depois de escrever as funções. 
5.3 - Funções

São possíveis as seguintes funções, a explicação delas está após a seta (->):

gps.ler(); -> O sensor gps lê suas coordenadas

bussola.ler(); -> O sensor bússola obtém a sua orientação

camera.ler(); -> O sensor câmera obtém a sua imagem

carregarListaCoordenadas(); -> O robô carrega uma lista de coordenadas

receberCoordenada(); -> O robô recebe uma coordenada que deve seguir

processaImagem(); -> Processa a imagem recebida pela câmera. Para usá-la você deve antes obter a imagem da câmera.

processaInfo(); -> Processa todas as informações dos sensores.

defineRegraSeguir(); -> Define a regra seguir um outro robô.

defineRegraNaoBater(); -> Define a regra andar pelo ambiente sem bater.

defineRegraSeguirMultiplasCoordenadas(); -> Define a regra percorrer um conjunto de coordenadas dadas.

andar(); -> O robô começa a se locomover no ambiente de acordo com a regra definida.

Para usar uma das funções basta escrever igual ao que está antes da seta

Fonte: http://143.107.183.158:8008/xwiki/bin/view/Main/aqui

\section{B.3 Texto III: Instalação do Eclipse+SVN e importa- ção da DSL}

Texto 1B:

Instalação do Eclipse+SVN e importação da dsl

1. Instalar o Eclipse Modeling Tools versão helios http://www.eclipse.org/downloads/packages/eclipsemodeling-tools-includes-incubating-components/heliossr2

2. A versão helios precisa do java 1.5 (pode-se colar o jre 1.5 direto na pasta do eclipse, assim não precisa alterar o path)

3. Instalar os plugins: xpand e xtext

4. Instalar o svn

5. Configurar o svn no eclipse com o projeto http://code.google.com/p/comdd-eclipse-svn/source/checkout 


\section{Discussão realizada pela equipe B \\ no EC-PG}

\section{C.1 Conversa da Equipe B do Estudo de Caso 2 re- alizada no final do exercício}

Desenvolvedor 1: Eu acho que faz sentido o que temos lá

minha única dúvida é onde deveria ficar aquela função carregarListCoordenadas()

mas acho que ela faz sentido onde ela está

Desenvolvedor 2: eh eu tambem acho q talvez ela fique dentro do loop

Desenvolvedor 1: primeiro eu carrego tudo, defino a regra

e aí passo a receber coordenada por coordenada

Desenvolvedor 2: eu tambem acho

só faria sentido ficar dentro do loop, no caso de poder mudar o tipo de regra

durante a execução

mas isso não está nos requisitos

Desenvolvedor 1: exato

eu vou dar mais uma olhada na wiki 
mas acho que é isso

Desenvolvedor 2: acho que sim

talvez o adicionar includes, adicionar defines, possa ser um comando so

algo como "adicionar dependencias"

ou algo assim

pq todo programa sempre teriam essas duas mesmas linhas

ou talvez ser adicionado automaticamente

mas assim também funciona

Desenvolvedor 1: sim

pra vc estar ciente do fato

Desenvolvedor 2: isso eh

outra coisa seria melhorar a documentação para incluir qual o simbolo que indica comentário, e quando se deve usar ou não ponto e virgula

Desenvolvedor 1: boa 


\section{Questionários Respondidos pelas Equipes A e B do EC - PG}

\section{D.1 Questionário Respondido pela Equipe A}

A seguir são apresentadas as perguntas feitas aos participantes da Equipe A com suas respectivas respostas.

O que vocês acharam da linguagem? Desenvolvedor 1: está legal mas as funções estão muito genéricas, "includes"e "defines"estão confusos (redundante a parte de "adicionar includes"e "importar pacotes").

Desenvolvedor 2: os pacotes já deveriam estar todos inclusos sem a necessidade de importálos.

Vocês mudariam algo na sintaxe? Desenvolvedor 1: a estrutura da linguagem é comum a C ou Java. É melhor deixar tudo em português ou tudo em inglês.

Desenvolvedor 2: a sintaxe está boa para quem sabe programar em $\mathrm{C}$ ou java, aí consegue entender, mas para quem nunca programou "()", ""e ";"não significam nada.

Os comentários que vocês escreveram foram úteis de alguma forma? Desenvolvedor 1: foram interessante. Mas no mundo real um instant messanger é mais útil caso os dois estejam programando na mesma classe. Mas para documentação ou quando os desenvolvedores não estão ao mesmo tempo e na mesma classe, os comentários da página são úteis. 
Desenvolvedor 2: o sistema de comentário do SVN funciona melhor, porque ao dar o commit você é obrigado a comentar e ao dar o check out você é obrigado a ler. Na Wiki fica dissociado do código.

E o histórico das versões de edição, é útil? Desenvolvedor 1: É mais util quando alguém faz alguma besteira.

De uma maneira geral, o que vocês acharam da abordagem? Desenvolvedor 1: não é muito interessante uma vez que tenho que esperar pela pessoa terminar programar para depois programar. No tradicional os dois podem programar juntos e depois fazer o merge, mas se fosse possível fazer edição simultanea estilo o google seria interessante. E se fosse em classes separadas ao mesmo tempo? Aí é interessante. Programar na web também é bom e o histórico também. É bom a flexibilidade de estar em qualquer computador.

Desenvolvedor 2: programar na web é bom porque evita problemas de infraestrutura (a infraestrutura é instantanea, independente do computador).

Então seria interessante uma wiki ou seria melhor um outro site? Desenvolvedor 1: a wiki é um site mais dinâmico, mais fácil de editar, as pessoas já conhecem.

Desenvolvedor 2: poderia ser um site mais especializado.

O que vocês acharam da abordagem CoMDD e da abordagem Eclipse+SVN? Que comparação vocês fazem entre essas duas abordagens? Qual vocês preferem? Desenvolvedor 1: estar na web é mais flexível, configurar uma IDE, SVN e tudo o mais é trabalhoso. Desenvolvedor 2: em geral é melhor programar na wiki do que usar uma IDE, mas fica dependente da conexão. Aí seria interessante ter uma forma de usar a wiki mesmo sem internet.

Vocês usariam o CoMDD no lugar do Eclipse+SVN? Por que não? E se fosse para fazer programas como este, vocês usariam o CoMDD? Desenvolvedor 1: usaria desde que o processo de compilação funcionasse, agora sem compilar e sem executar não. Desenvolvedor 2: concordo.

\section{D.2 Questionário Respondido pela Equipe B}

A empresa de vocês seguia essa abordagem? Desenvolvedor 1 e Desenvolvedor 2 : usam o eclipse e o subversion.

O que vocês acharam da linguagem? Desenvolvedor 1: fácil e simples, poucos comandos. Desenvolvedor 2: curva de aprendizagem rápida, mas faltou prática, não sei se o código funciona. A sintaxe é simples. Outra coisa seria melhorar a documentação para incluir qual o simbolo que indica comentário, e quando se deve usar ou não ";". 
Vocês mudariam algo na sintaxe? Desenvolvedor 2 e Desenvolvedor 1: a parte dos includes poderia ser uma linha só já que sempre vai precisar dela.

Como vocês colaboraram? O que foi mais importante, os comentários? Desenvolvedor 1 e Desenvolvedor 2: usamos apenas os comentários no código para nos comunicarmos. Os comentários do check in não usamos porque o código é pequeno. Desenvolvedor 1: o comentário do SVN é mais quando tem algum problema.

Os comentários que vocês escreveram no SVN foram úteis de alguma forma? Não usaram.

E o histórico, foi útil? Não usaram.

E quais funcoes do SVN vocês acham importantes além das que vocês usaram? Desenvolvedor 1: histórico caso tenha algum problema, merge caso editássemos ao mesmo tempo. Desenvolvedor 2: quando o código é muito extenso é importante comparar as versões de código para ver o que está sendo alterado

Vocês acham que a wiki atenderia à esses propósitos que o Eclipse+SVN atende? Desenvolvedor 1: eu nunca pensei numa wiki para editar código, usaria mais para colaboração na documentação. Desenvolvedor 2: senti falta de algumas coisas como auxílio de sintaxe, auto-complete, import automático, clicar em um arquivo e ir para outro. A parte de comentário, versionar, editar o texto é praticamente a mesma coisa. Mas não sei como me comportaria caso pudesse editasse ao mesmo tempo duas pessoas.

O que vocês acharam da abordagem CoMDD e da abordagem Eclipse+SVN? Que comparação vocês fazem entre essas duas abordagens? Qual vocês preferem? Desenvolvedor 1: to acostumado com o Eclipse+SVN, mas uso tambem o controle de versão integrado com um bugtrack. Desenvolvedor 2: muita coisa já tem pronta pro Eclipse e acho que o costume é a principal barreira, pensando como programador ainda usaria o Eclipse. Mas pensando que usaríamos uma dsl e não Java, talvez o CoMDD fosse melhor.

Mas não seriam muitos programas necessários para, às vezes, resolver um problema simples? Desenvolvedor 1 e Desenvolvedor 2: Para um projeto pontual e pequeno o CoMDD supriria mas para algo maior e complexo acho que não. 

APÊNDICE

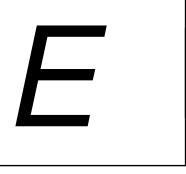

Documentos do EC - IN

\section{E.1 Email solicitando a participação dos desenvol- vedores}

Olá pessoal, estou precisando da ajuda de vocês com um estudo que estou fazendo. Meu estudo é basicamente uma nova forma de desenvolver software colaborativamente, chamada CoMDD.

O CoMDD vem da sigla Collaborative Model Driven Development. É basicamente uma linguagem de programação que funciona em uma wiki. A ideia é que ele possa substituir, dado suas necessidades, uma IDE e um programa de versionamento, tipo o SVN. Então gravei dois screencasts (aqueles vídeos da sua tela de trabalho com áudio): um com o CoMDD e o outro com o Eclipse+SVN.

Nos dois vídeos estou fazendo as mesmas coisas e estou usando uma linguagem específica que criei para robôs, ao invés de C++ ou Java, por exemplo. Isso significa que não é possível usar essa linguagem pra qualquer coisa. Assim você programa, tanto no CoMDD quanto no Eclipse+Svn, em um nível de abstração mais alto (o que chamamos de modelos) do que C++ e depois pode gerar o código-fonte desse modelo, em C++.

Claro que o Eclipse e o SVN são muito mais robustos e com muito mais funcionalidades que o CoMDD, mas com a sua ajuda saberei suas necessidades e poderei melhorar o CoMDD. Espero que você possa ajudar. Cada vídeo tem cerca de 3 minutos e estimo que você leve 
mais 10 minutos respondendo o questionário. Então, em 15 minutos você vai estar contribuindo significativamente para meu trabalho :D

Ok! Agora vamos ao que interessa. Veja primeiro o vídeo do CoMDD: http: / / vimeo. $\mathrm{com} / 36209527$

Agora veja o vídeo do Eclipse com o SVN fazendo a mesma coisa que fiz no CoMDD: http://vimeo.com/36206167

Agora responda o questionário:) https://docs.google.com/spreadsheet/viewform? $\mathrm{pli}=1 \& \mathrm{hl}=\mathrm{en} \_\mathrm{US} \& \mathrm{rm}=\mathrm{ful} \backslash \backslash \&$ formkey=dGlWUmpqZkJlbHZrUk9zMlZkMEJwT1E6MQ\# gid $=0$

Muitíssimo obrigado!

Abraços

\section{E.2 Questionário Apresentado aos Participantes}

Depois de ver os vídeos, por favor, responda o questionário abaixo. Para as perguntas que falam sobre empresa e se você nunca trabalhou numa antes, basta dizer isso. Quanto maior sua participação mais você estará contribuindo para a ciência :)

Você já é formado? Sim/Não

Você faz ou já fez mestrado/doutorado? Sim/Não

Há quanto tempo você programa?

Você já desenvolveu sistemas trabalhando em equipe? Sim/Não

Você trabalha ou já trabalhou numa empresa? Sim/Não

$\mathrm{Na}$ empresa em que você trabalha/trabalhou, vocês usavam algum programa de versionamento associado à uma IDE? Sim/Não/Eu nunca trabalhei numa empresa, mas já usei um programa de versionamento associado à uma $\mathrm{IDE} / \mathrm{Eu}$ nunca trabalhei numa empresa $\mathrm{e}$ NUNCA usei um programa de versionamento associado à uma IDE

Em qual das duas abordagens você acha mais fácil e se sente mais a vontade em colaborar? CoMDD/Abordagem tradicional

E se você já tivesse todos os programas necessários já instalados na sua máquina, em qual deles você se sente mais a vontade para colaborar e acha mais fácil de colaborar? CoMDD/Abordagem tradicional

Que tipo de colaboração você tem/teve na sua empresa ou na sua equipe de desenvolvimento. Ou seja, como vocês colaboram na resolução de problemas?

$\mathrm{Na}$ empresa que você trabalha/trabalhou, como vocês trocam/trocavam informações? 
Você vê como uma barreira ter que instalar programas na sua máquina para programar e configurar seu cliente de SVN? Sim/Não

E para um não desenvolvedor, seria uma barreira instalar uma IDE e uma ferramenta de versionamento? Sim/Não

Quais funcionalidades de uma ferramenta de versionamento você acha mais importante?

Quais funcionalidades de uma ferramenta de versionamento você usa mais?

Você acha que o CoMDD é capaz de suprir suas necessidades em termos de ferramenta de versionamento? Sim/Não

Quais funções de uma IDE você acha mais importante?

Quais funções de uma IDE você usa mais?

Se o CoMDD tivesse syntax highlighting e auto-suggestion/auto-complet, você o usaria? $\mathrm{Sim} / \mathrm{Sim}$, mas as carências em termos de versionamento de modelos me deixariam insatisfeito/Não/Não, pois as carências em termos de versionamento de modelos me deixariam insatisfeito

Levando em consideração que o CoMDD é um protótipo e não uma ferramenta de produção, você acha que o CoMDD atenderia aos propósitos que o Eclipse+SVN trazem em termos de desenvolvimento de software e compartilhamnto? Sim/Não

Você usaria o CoMDD no lugar do Eclipse+SVN? Se não, por quê? Qual sua maior barreira para usar o CoMDD?

Quais funcionalidades você acha que falta no CoMDD? Se sua resposta for a mesma da anterior desconsidere esta pergunta.

E se fosse para fazer programas como o do vídeo, ou seja, usando modelos, você usaria o CoMDD? Sim/Não

E se a linguagem lhe permitisse inserir trechos de código em $\mathrm{C}, \mathrm{C}++$, Java ou afins de modo que esses trechos não sofreriam transformações e estariam na íntegra no código-gerado? Se me permitisse escrever trechos de código eu usaria o CoMDD/Mesmo me permitindo escrever trechos de código eu NÃO usaria o CoMDD

Qual abordagem você acha mais fácil e mai simples? O CoMDD/A abordagem tradicional Levando em consideração que o CoMDD é um protótipo e não uma ferramenta de produção, você acha que o CoMDD traria produtividade no desenvolvimento de sofware de uma equipe? Sim/Não

Fique à vontade pra colocar mais informações ou dar sugestões. 